\title{
Forgetfulness in healthy older adults determinants and interventions
}


Cover picture: $\quad$ C Dries Knapen, www.focusonnature.be

Cover design: Grafisch ontwerpburo Emilio Perez, www.emilioperez.nl

Production: Datawyse BV, Maastricht

ISBN-10: $\quad$ 90-75579-31-4

ISBN-13: $\quad$ 978-90-75579-31-4

(C) M.Mol, Maastricht 2006

Neuropsych Publishers is a non-profit organization, which aims at promoting the science of 'Brain and Behaviour' and improving the application of the products of this science in health care and education. Neuropsych Publishers accomplishes these aims by publishing books, dissertations and other products of scientific activity, by disseminating educational materials and publication of tests, assessment scales and other psychometric instruments in the field of Neuropsychology, Neuropsychiatry and other areas within the domain of 'Brain and Behaviour'.

Neuropsych Publishers

Department of Psychiatry and Neuropsychology

Maastricht University

P.O. Box 616

NL-6200 MD Maastricht

The Netherlands

www.np.unimaas.nl 


\title{
Forgetfulness in healthy older adults determinants and interventions
}

\author{
Proefschrift
}

ter verkrijging van de graad van doctor aan de Universiteit Maastricht, op gezag van Rector Magnificus, Prof. mr. G.P.M.F. Mols, volgens het besluit van het College van Decanen, in het openbaar te verdedigen op vrijdag 19 januari 2007 om 14:00 uur

door

Martine Elisabeth Marcellus Mol 


\section{Promotor}

Prof. dr. J. Jolles

\section{Beoordelingscommissie}

Prof. dr. G. Kok (voorzitter)

Dr. M.P.J. van Boxtel

Prof. dr. L. Fasotti (Radboud Universiteit Nijmegen)

Prof. dr. C. Jonker (VU Medisch Centrum)

Prof. dr. J.F.M. Metsemakers
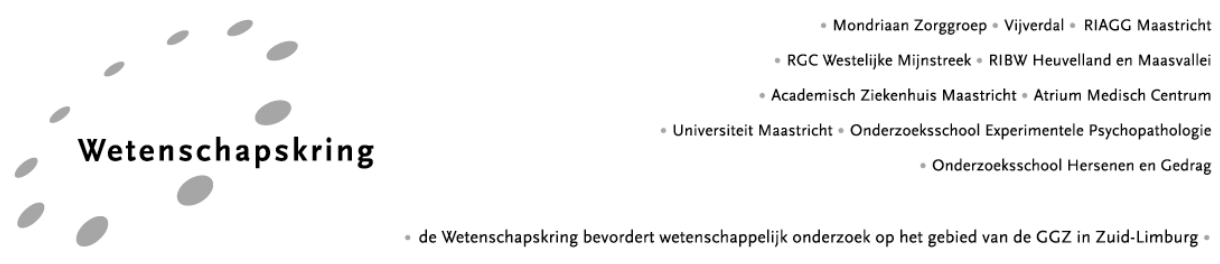

The research described in this thesis was performed in the Maasticht Brain \& Behaviour Institute, and the department of Psychiatry \& Neuropsychology, Maastricht University, the Netherlands.

Financial support for the publication of this thesis has been kindly provided by Alzheimer Nederland, Delta Lloyd Zorgverzekeringen, Eli Lilly Nederland BV, Internationale Stichting Alzheimer Onderzoek, Lundbeck BV, Novartis Pharma $\mathrm{BV}$ and Pfizer BV. 


\section{Contents}



2. Do subjective memory complaints predict cognitive dysfunction over time? A 6-year follow-up of the Maastricht Aging Study

Published in International Journal of Geriatric Psychiatry, 2006; 21: 432-441

3. Quality of life among people with subjective memory complaints: a qualitative review

In press in International Journal of Geriatric Psychiatry

4. Forgetfulness is related to a lower of quality of life: results from a 9-year follow-up of the Maastricht Aging Study

Submitted

5. A study into the psychosocial determinants of forgetfulness: implications for future interventions

Submitted

6. Education about dementia: effectiveness of a public lecture

Published in Dutch in Tijdschrift voor Gerontologie en Geriatrie, 2004; 35: 72-75

7. Public education about memory and aging: objective effects and subjective insights

Published in Educational Gerontology, 2006; 30: 843-858

8. An evaluation of the use of a website and telephonic information service as public education about forgetfulness

In press in Telemedicine and e-health

9. Concluding remarks

10. Summary

11. Samenvatting

Dankwoord 

1

Introduction 
The proportion of individuals aged 50 years and older in our population is growing rapidly (CBS, 2006a). Furthermore, the life expectancy of older individuals has increased. In the last decade the average life expectancy of women in the Netherlands has grown from 80.3 to 81.4 years and that of men from 74.6 to 76.9 years (CBS, 2006b). This prolonged life expectancy is partly caused by improved health care services and more health promotion activities. Because the older population is expected to continue growing for the next decades, health issues that concern older adults will become more prominent in the future. In particular, chronic and neurodegenerative diseases, such as Alzheimer's disease and other forms of dementia, will become more prevalent. The number of individuals with Alzheimer's disease, for example, is expected to increase by $21 \%$ between the year 2000 and the year 2010 (PBOO, 2004).

It is commonly known that patients with Alzheimer's disease are characterized by profound degeneration of the brain, by cognitive and affective symptoms and by behavioural dysfunction. Individuals in preclinical phases of the disease have more subtle symptoms, such as memory complaints. However, scientific research has shown that memory complaints, or forgetfulness, is not necessarily a precursor of Alzheimer's disease or other forms of dementia. Memory failures can also be part of the normal aging process. Yet, many older individuals with memory complaints are afraid of becoming demented (Ponds, Commissaris, \& Jolles, 1997) and there are indications that they might experience a poor quality of life. Therefore, it is to be expected that interventions targeted at informing individuals about memory and cognitive aging might be helpful in diminishing worries about developing dementia, and possibly improve the quality of life. In recent years it has been suggested that psycho-education or public health interventions might be useful in this respect (e.g. Commissaris, Ponds, \& Jolles, 1998; Commissaris, Verhey, Ponds, Jolles, $\&$ Kok, 1994). The information presented in such interventions may enable individuals to evaluate their cognitive functioning and subsequently decrease their worries about developing dementia, or make it easier for them to visit their general practitioner or a specialized health care facility when memory complaints have a more serious character.

The focus of the present thesis is to gain insight into the characteristics of older individuals who perceive themselves as forgetful, with the intention to provide implications for current and future interventions on forgetfulness. In the remaining sections of this chapter, background information will be provided on forgetfulness and its relation with objective cognitive performance. In addition, an introduction will be given on the quality of life experienced by individuals who report subjective memory complaints and on the possibilities of interventions for those individuals. This chapter is concluded with a brief overview of the aims and outline of the present thesis. Note, that the terms 'forgetfulness', 'memory problems' and 'subjective memory complaints' are synonymous for perceived memory failures, and are used interchangeably throughout this thesis. 


\section{Forgetfulness and objective cognitive performance}

Many middle-aged and older individuals complain about forgetfulness (Ponds et al., 1997). In a large-scale population-based study (the Maastricht Aging Study) the prevalence of forgetfulness was as high as $41 \%$ in the 55 to 65 age group, and even $52 \%$ in the 70 to 85 age group (Ponds et al., 1997). In other community-based samples of older people the prevalence of memory complaints was also substantial, varying from approximately $22 \%$ (Jonker, Launer, Hooijer, \& Lindeboom, 1996) to over 50\% (Blazer, Hays, Fillenbaum, $\&$ Gold, 1997). It is an ongoing debate in the cognitive aging literature, whether or not complaints about forgetfulness are caused by an abnormal decrease in objective performance. Previous research on this topic was inconclusive. In some papers a relationship between memory complaints and objective cognitive decline has been reported (e.g. Jonker, Geerlings, \& Schmand, 2000), whereas other authors failed to observe such a relationship (e.g. Ponds, Van Boxtel, \& Jolles, 2000). It is possible that memory complaints are not exclusively determined by actual memory functioning but also by psychosocial and psychiatric variables, such as memory self-efficacy, and/or symptoms of depression and anxiety, because these variables are also known to be related to forgetfulness (Comijs, Deeg, Dik, Twisk, \& Jonker, 2002; Commissaris et al., 1998). More insight into the psychosocial and psychiatric determinants of forgetfulness, and identification of the most important ones, might be helpful in providing future interventions with relevant target variables to reduce forgetfulness.

\section{Forgetfulness and quality of life}

The quality of life experienced by individuals with forgetfulness might be diminished. A possible reason may be the burden of forgetfulness in daily life. For instance, repeatedly searching the house in order to find one's keys, frequently forgetting appointments or avoiding situations in which one would be required to remember names of people may have a negative impact on someone's wellbeing. Another possible reason for the reduction in someone's quality of life might be the fear of dementia that is induced by forgetfulness. Many individuals fear that their subjective memory complaints are a sign of dementia (Commissaris et al., 1994). This fear of dementia is likely to affect an individual's perception of wellbeing and quality of life.

Only a few studies have investigated the relationship between forgetfulness and quality of life. Commissaris et al. (1998) found that forgetful participants aged between 25 and 85 years were less satisfied with life, as measured with the Satisfaction with Life Scale. The study of Derouesné et al. (1999) reported a significantly negative correlation between memory complaints and scores on the Well-being Questionnaire. However, these findings were solely based on cross-sectional data. Unfortunately, no information is available on the long-term effects of memory complaints on the quality of life someone 
experiences. Furthermore, the studies described above did not differentiate between separate age groups within the older population, but considered the older population as one entity. This is rather unfortunate, as it might very well be the case that forgetfulness is appreciated differently by older old individuals compared with younger old individuals. A more thorough investigation of the relationship between memory complaints and quality of life is needed in order to reveal a more evident impact of forgetfulness on older individuals' quality of life. This would imply the importance of appropriate interventions aimed at diminishing perceived forgetfulness.

\section{Interventions for older people who perceive themselves as forgetful}

Interventions for older individuals which are targeted at forgetfulness often consist of psycho-educational and neuropsychological interventions (examples are: Ball et al., 2002; Valentijn et al., 2005; Woolverton, Scogin, Shackelford, \& Black, 2001). Although these interventions may be effective, they often consist of intensive training programmes, which are time-consuming and only suitable for small groups. Other types of interventions, such as educational interventions that can reach a large group of individuals, might be useful because a large proportion of the population perceives themselves as forgetful. Educational interventions usually consist of low-cost and low-profile activities that can reach a large group of people, such as lectures and symposia or magazines and brochures. In recent years educational interventions and activities have been used to educate older individuals. These activities elaborate on the cause of subjective memory complaints and the differences between normal forgetfulness and dementia. Although these educational activities are thought to be useful, it is not clear whether they are in fact suitable for older individuals with forgetfulness.

In addition, interventions that rely on modern media as a means of health care delivery have received increased attention in recent years (Mair \& Whitten, 2000). The term telehealth is used in that respect and refers to public health services and health promotion activities via electronic means of communication. People who do not necessarily have a medical condition, but who wish to be informed on how to remain well and independent, might benefit from telehealth (Craig \& Patterson, 2005). There are several advantages in informing the public at a distance, such as reduced time and costs associated with traveling and immediate access to information that is available at any time (Bashshur, 2002; Bos, Visser, Tempert, \& Schaalma, 2004). Individuals with subjective memory complaints might benefit from this. However, it is as yet unknown whether telehealth is suitable for informing the older population about forgetfulness. 


\section{Aims of this thesis}

The main objective of this thesis is to gain more insight into the possibilities of educational interventions on forgetfulness for healthy older adults. In order to achieve this, the first aim is to increase knowledge about forgetfulness by studying determinants of individuals who regard themselves as forgetful. Determinants of interest are objective cognitive performance, experienced quality of life and psychosocial factors. The second aim is to evaluate specific educational interventions and investigate whether these interventions can contribute in providing information to the older population. This information might change the subjective evaluation of memory complaints in older adults, and possibly improve their quality of life.

\section{Outline of this thesis}

The first part of this thesis (Chapters 2 to 5) addresses the study of determinants of forgetfulness. Chapters 2 and 4 are based on data from the Maastricht Aging Study (MAAS), which is a large longitudinal study on normal cognitive aging (Jolles, Houx, Van Boxtel, \& Ponds, 1995; Van Boxtel et al., 1998). MAAS data are suitable for investigating various psychological and psychosocial determinants of cognitive aging. Chapter 3 is a qualitative review of the previous literature and Chapter 5 is based on newly acquired data. The second part of the thesis addresses various educational interventions. Two forms of educational interventions, namely a lecture and a symposium, are evaluated in Chapters 6 and 7, respectively. A newly developed telehealth intervention about forgetfulness is evaluated and discussed in Chapter 8 .

In Chapter 2, insight is provided into the relationship between subjective memory complaints and objective cognitive performance. A longitudinal design with a 6-year follow-up measurement was used to investigate whether subjective memory complaints among 557 MAAS participants are a possible predictor of decreased performance on cognitive tasks. Furthermore, the possible beneficial effect of trying to keep mentally active on memory performance was investigated among participants reporting subjective memory complaints.

Chapter 3 presents a systematic review of previous literature on the relation between forgetfulness (in the absence of objective memory deficit) and quality of life in older individuals. A literature search resulted in 682 scientific papers, of which five studies met the inclusion criteria and investigated the relationship between subjective memory complaints and quality of life. These papers are methodologically analyzed and discussed.

In Chapter 4, a study is reported in which 412 healthy older adults participating in the Maastricht Aging Study were assessed to determine whether forgetfulness is related to quality of life in various age groups, and whether forgetfulness predicts a change in quality of life. Analyses were performed using Linear Mixed Models in a longitudinal design with data obtained at 
baseline, and after 3, 6 and 9 years. Four aspects of quality of life were selected to serve as outcome measures (i.e. satisfaction with life, mental wellbeing and symptoms of anxiety and depression).

Many healthy individuals who perceive themselves as forgetful are interested in educational interventions to decrease their worries and improve their memory performance. Educational interventions can be more effective when the determinants that are known to predict forgetfulness are targeted. In Chapter 5, a broad range of determinants is cross-sectionally investigated in a large sample of 300 healthy participants older than 54 years. The most prominent predictors of forgetfulness are identified and discussed.

Memory and dementia are often the subject of educational activities. Yet only limited information is available on the effectiveness of these activities. In Chapter 6, the effectiveness of a specific lecture, as part of a series of lectures on dementia, is evaluated. Participants were health care professionals as well as non-professionals, aged between 22 and 83 years. The increase in knowledge after the lecture and the participants' satisfaction with the information presented are investigated and discussed.

In Chapter 7, the effectiveness of public education about memory is evaluated using an intervention trial with a parallel group design and a pre- and post-measurement. Participants who attended a dedicated one-day symposium and received a magazine, both covering memory-related topics $(n=273)$, are compared with participants who received only the magazine $(n=141)$. Outcome measures are knowledge about memory, measured with the Knowledge of Memory and Aging Questionnaire, and subjective experience.

In Chapter 8, two types of newly developed information services using telehealth (i.e. the Memory Website and the Memory Phone) are compared and evaluated. Using the advantages of telehealth, a large group of older individuals with subjective memory complaints might be reached. It is not yet known whether telehealth is suitable for informing the older population about forgetfulness. We therefore aimed to identify the characteristics of those individuals who use telehealth, to investigate what kind of information they request, and to evaluate their satisfaction with the information presented.

Finally, in Chapter 9 the findings reported in this thesis are combined and are discussed with respect to practical implications that are relevant for interventions on forgetfulness. Also, the implications for future research are addressed. 


\section{References}

Ball, K., Berch, D. B., Helmers, K. F., Jobe, J. B., Leveck, M. D., \& Marsiske, M. (2002). Effects of cognitive training interventions with older adults. Journal of the American Medical Association, 288(18), 2271-2281.

Bashshur, R. L. (2002). Telemedicine/telehealth: an international perspective. Telemedicine and health care. Telemedicine Journal and e-Health, 8(1), 5-12.

Blazer, D. G., Hays, J. C., Fillenbaum, G. G., \& Gold, D. T. (1997). Memory complaint as a predictor of cognitive decline: a comparison of African American and White elders. Journal of Aging and Health, 9(2), 171-184.

Bos, A. E., Visser, G. C., Tempert, B. F., \& Schaalma, H. P. (2004). Evaluation of the Dutch AIDS information helpline: an investigation of information needs and satisfaction of callers. Patient Education and Counseling, 54(2), 201-206.

CBS. (2006a). Statline database: Population: Key figures. Retrieved 28 July 2006, from http://statline.cbs.nl.

CBS. (2006b). Statline database: Population history: Life expectancy. Retrieved 28 July 2006, from http://statline.cbs.nl.

Comijs, H. C., Deeg, D. J. H., Dik, M. G., Twisk, J. W. R., \& Jonker, C. (2002). Memory complaints: the association with psycho-affective and health problems and the role of personality characteristics. A 6-year follow-up study. Journal of Affective Disorders, 72, 157-165.

Commissaris, C. J. A. M., Ponds, R. W. H. M., \& Jolles, J. (1998). Subjective forgetfulness in a normal Dutch population: possibilities for health education and other interventions. Patient Education and Counseling, 34, 25-32.

Commissaris, C. J. A. M., Verhey, F. R. J., Ponds, R. W. H. M., Jolles, J., \& Kok, G. (1994). Patient education about normal forgetfulness and dementia: importance and effects. Patient Education and Counseling, 25, 163-167.

Craig, J., \& Patterson, V. (2005). Introduction to the practice of telemedicine. Journal of Telemedicine and Telecare, 11(1), 3-9.

Derouesné, C., Lacomblez, L., Thibault, S., \& LePoncin, M. (1999). Memory complaints in young and elderly subjects. International Journal of Geriatric Psychiatry, 14(4), 291301.

Jolles, J., Houx, P. J., Van Boxtel, M. P. J., \& Ponds, R. W. H. M. (1995). Maastricht Aging Study: determinants of cognitive aging. Maastricht: Neuropsych Publishers.

Jonker, C., Geerlings, M. I., \& Schmand, B. (2000). Are memory complains predictive for dementia? A review of clinical and population-based studies. International Journal of Geriatric Psychiatry, 15, 983-991.

Jonker, C., Launer, L. J., Hooijer, C., \& Lindeboom, J. (1996). Memory complaints and memory impairment in older individuals. Journal of the American Geriatrics Society, 44(1), 4449.

Mair, F., \& Whitten, P. (2000). Systematic review of studies of patient satisfaction with telemedicine. British Medical Journal, 320(7248), 1517-1520.

PBOO. (2004). De zilveren eeuw [The silver century]. Retrieved 20 August 2006 from www.limburg.nl/upload/pdf/PBOO_DeZilverenEeuw.pdf.

Ponds, R. W., Commissaris, K. J., \& Jolles, J. (1997). Prevalence and covariates of subjective forgetfulness in a normal population in The Netherlands. International Journal of Aging and Human Development, 45(3), 207-221.

Ponds, R. W. H. M., Van Boxtel, M. P. J., \& Jolles, J. (2000). Age-related changes in subjective cognitive functioning. Educational Gerontology, 26(1), 67-81.

Valentijn, S. A., van Hooren, S. A., Bosma, H., Touw, D. M., Jolles, J., Van Boxtel, M. P., et al. (2005). The effect of two types of memory training on subjective and objective memory 
performance in healthy individuals aged 55 years and older: a randomized controlled trial. Patient Education and Counseling, 57(1), 106-114.

Van Boxtel, M. P., Buntinx, F., Houx, P. J., Metsemakers, J. F., Knottnerus, A., \& Jolles, J. (1998). The relation between morbidity and cognitive performance in a normal aging population. Journals of Gerontology Series B: Psychological Sciences and Social Sciences, 53(2), M147-154.

Woolverton, M., Scogin, F., Shackelford, J., \& Black, S. (2001). Problem-targeted memory training for older adults. Aging Neuropsycholoy and Cognition, 8(4), 241-255. 


\section{Do subjective memory complaints predict cognitive dysfunction over time? \\ A 6-year follow-up of the Maastricht Aging Study}

Martine E.M. Mol, Martin P.J. van Boxtel, Dick Willems \& Jelle Jolles 


\section{Abstract}

\section{Background}

Middle-aged and older people often worry that their perceived Objectives diminishing memory function may indicate incipient dementia.

The present study addresses questions regarding subjective memory complaints as a predictor of lower performance on cognitive tasks. Also, in participants with subjective memory complaints it was investigated, whether trying to keep mentally active improved memory function. Characteristics of the participants who were and were not interested in an intervention to decrease worries and to improve memory function in daily life were determined.

\section{Methods}

Data were obtained from a large longitudinal study: the Maastricht Aging Study, involving 557 participants aged 55 to 85 years. Follow-up measurement was performed after six years. Outcome variables were simple, complex and general information processing speed and immediate and delayed recall.

\section{Results}

At baseline, forgetfulness was associated with a slower general information processing and delayed recall. At the 6-year follow-up, being forgetful was not associated with a significant change in cognitive performance. Taking steps to remain cognitively active was not a predictor of better performance on cognitive tasks at baseline or at the 6-year follow-up.

\section{Conclusion}

Being forgetful might be an indicator of slower general information processing speed and delayed recall at baseline but does not predict cognitive change over six years in older adults. However, the effects are rather small and cannot directly be generalized to applications in clinical settings. Other factors, such as depression and anxiety might also underlie the cause of the forgetfulness. 


\section{Introduction}

Memory complaints are common among middle-aged and older people (Ponds, Commissaris, \& Jolles, 1997). In the Maasticht Aging Study, the prevalence of forgetfulness among 1,971 volunteers aged between 25 and 85 years was $41 \%$ in the age group 55 to 65 years and 52\% in the age group 70 to 85 years (Ponds et al., 1997). In other community-based samples of older people, the prevalence of memory complaints varied considerably, from approximately $22 \%$ in a population of 65- to 84-year-old individuals (Jonker, Launer, Hooijer, \& Lindeboom, 1996) to over 50\% in a population aged 65 years and older (Blazer, Hays, Fillenbaum, \& Gold, 1997), depending on sample selection and how memory complaints were assessed (Jonker, Geerlings, \& Schmand, 2000). The causes of these memory complaints are very diverse. In severe cases, the underlying problem may be an objective cognitive disorder, such as mild cognitive impairment (MCI) or dementia. Several studies have shown an association between subjective memory complaints and poor cognitive performance (Jorm, Christensen, Korsten, Jacomb, \& Henderson, 2001; Wang et al., 2000) or even dementia (Geerlings, Jonker, Bouter, Ader, \& Schmand, 1999; Schmand, Jonker, Geerlings, \& Lindeboom, 1997; St John \& Montgomery, 2002). Other studies have not been able to establish an association between subjective cognitive complaints and poor cognitive performance (Bolla, Lindgren, Bonaccorsy, \& Bleecker, 1991; Derouesné, Lacomblez, Thibault, \& LePoncin, 1999) or cognitive decline (Blazer et al., 1997; Jorm et al., 1997). These studies show a variety of methodological differences, such as the population studied, the measurement of memory complaints and cognitive functioning and how potential confounding variables are controlled for, such as age and symptoms of depression. Due to these differences in methodology, the results of these studies remain inconclusive.

It is possible that memory complaints or perceived decline in cognitive functions in old age is not solely determined by actual memory ability but also by other variables, such as personality traits, memory self-efficacy, personal and psychological wellbeing, and subjective health (Commissaris, Ponds, \& Jolles, 1998; Niederehe, 1998; Pearman \& Storandt, 2004). Memory complaints may also arise because of a diminished function of memory-related cognitive domains, such as attention, working memory, and information processing speed (Kausler, 1994). It has been amply documented that slower information processing due to aging can cause slower rehearsal and impoverishment of information, resulting in a poorer memory performance (Salthouse, 1980; 1992; 1996). Not only healthy aging adults display deficits in multiple cognitive domains, including working memory and executive functions (Balota, Dolan, \& Duchek, 2000; Braver \& Barch, 2002; Craik, Morris, \& Gick, 1990), also individuals with sub-clinical cerebral white matter lesions have been associated with cognitive dysfunction, especially the speed of cognitive processes (De 
Groot et al., 2000). To our knowledge, only one study has evaluated the relation between forgetfulness and speed of information processing as well as memory, in a longitudinal perspective (Taylor, Miller, \& Tinklenberg, 1992). We report here the results of large-scale study with a 6-year follow-up in healthy participants, where we investigated the performance of forgetful participants on information processing speed as well as on memory tasks. To minimize the effect of confounding variables in the present study, we corrected for age, education, sex, and feelings of anxiety and depression. With the design of this study we accounted for several of the methodological drawbacks in previous studies.

Data were obtained from the Maastricht Aging Study (MAAS), a longitudinal study of normal aging in a large sample of 2,043 Dutch adults across the life span (Jolles, Houx, Van Boxtel, \& Ponds, 1995). The first aim of the study was to investigate whether subjective memory complaints were associated with a slower speed of information processing and with poorer objective memory performance at baseline. In addition, the predictive value of subjective forgetfulness on cognitive performance after six years of follow-up was investigated. We expected information processing speed as well as memory to change over time in participants with subjective memory complaints. To this end, a comparison was made between participants who perceived no forgetfulness versus forgetful participants who were characterized by little or much worries about and hindrance from their memory problems. Participants who regarded themselves as forgetful but were not worried or hindered by their forgetfulness were excluded. This distinction was made because many older people are forgetful but do not consider that their forgetfulness interferes with daily life activities, as was found earlier by Ponds (1997) in the Maastricht Aging Study. In that study, about $30 \%$ of forgetful participants aged between 55 and 85 years experienced hardly any hindrance from their forgetfulness and about $40 \%$ were not or hardly worried about their forgetfulness.

The second aim was to investigate whether taking effort to remain cognitively active was associated with the cognitive performance of forgetful participants. For this purpose, we compared the performance on cognitive tasks of forgetful participants who did and did not attempt to remedy their memory problems. According to Commissaris et al. (1998), a small proportion of forgetful people are interested in cognitive training and other activities as a possible way to decrease their worries or to improve the functioning of their memory in daily life. Various training programmes have been developed to help older adults improve their memory performance (Rasmusson, Rebok, Bylsma, $\&$ Brandt, 1999; Troyer, 2001), and these programmes appear to be effective in improving performance on objective measures of memory. A study by Ball et al. (2002) demonstrated in a sample of 2,832 volunteers aged 65 to 94 years that several group interventions with cognitive exercises (such as memory, reasoning and speed of processing) improved the targeted cognitive abilities. 
Therefore, the second aim was to investigate whether staying cognitively active can improve cognitive performance.

The final aim of the study was to determine the characteristics of forgetful participants with or without inclination to undertake action regarding the memory complaint, in order to design future interventions and to improve existing interventions.

\section{Methods}

\section{Sample and procedure}

This study was conducted as part of an ongoing longitudinal study into the determinants of cognitive aging, the Maastricht Aging Study (MAAS) (Jolles et al., 1995; Van Boxtel et al., 1998). The 1,823 participants who were enrolled in the MAAS were randomly recruited from a general practitioner's register in the south of the Netherlands and were aged between 24 and 81 years (Metsemakers, Hoppener, Knottnerus, Kocken, \& Limonard, 1992). The participants had no medical condition that could interfere with normal cognitive functioning. Exclusion criteria were dementia, overt cerebrovascular disease, chronic neurological pathology, mental retardation, and major psychiatric disorders. All participants were screened by means of a semi-structured interview to update the exclusion criteria from the general practitioner's register by a dedicated MAAS staff member. Participants were stratified for three demographic variables that are known to be related to cognitive outcome measures, namely age (12 discontinuous age classes, ranging from $25 \pm 1,30 \pm 1$, up to $80 \pm 1$ year), sex, and general ability (two levels, based on the achievement in professional life). In the present study, analyses were based on a subset of 557 individuals aged 55 years and older and who had a score of 24 or more on the Mini-Mental State Examination (MMSE: (Folstein, Folstein, \& McHugh, 1975)) and for whom complete data were available. The participants filled in a questionnaire and completed a battery of cognitive tests at baseline and after six years. Drop-outs were approached by telephone by a MAAS staff member to ask them about their reason to step out of the study. In total 391 participants were retested at six years $(70 \%) ; 166$ participants were lost to follow-up due to death $(n=57)$, medical conditions incompatible with testing $(n=27)$, personal circumstances, e.g. no further interest or experienced burden $(n=52)$, incomplete or unreliable test results $(n=16)$ or other reasons $(n=14)$.

\section{Measurements}

\section{Subjective memory}

The terms forgetfulness, memory problems and subjective memory complaints are used interchangeably in this paper. Subjective memory complaints were measured with a single question, because this has appeared to be sufficient to 
demonstrate a correlation between memory complaints and test performance in several other large scale studies (Bassett \& Folstein, 1993; Geerlings et al., 1999; Schofield et al., 1997). At baseline and at follow-up, the following question was used: 'Do you consider yourself to be forgetful?' Participants at baseline who replied affirmatively also rated the degree of hindrance and worry about this forgetfulness on a 5-point scale, ranging from 'no hindrance at all' or 'not worried at all' to 'very much hindrance' or 'very much worried'. Two groups of individuals were identified - those who did not consider themselves forgetful and those who considered themselves forgetful but who were also, to some extent, hindered and/or worried about their complaints (a rating of 3 or more on a 5-point scale was required). In order to make the two groups as distinct as possible, participants who regarded themselves as forgetful but who were not worried and/or hindered by their forgetfulness $(n=78)$ were excluded (rating 1 and 2 on a 5-point scale). Participants who were forgetful and were worried and/or hindered by their forgetfulness are referred to as forgetful participants. They were asked if they had undertaken any action to remedy their memory problems, with the question: 'Have you undertaken any action to remedy your memory problem, apart from possible medication?' Response options were: no, nothing; searched for information about memory and forgetfulness; participated in memory-training activities; visited a doctor who practices alternative medicine; other. Activities mentioned here included courses on staying mentally active, reading, doing crossword puzzles, and using internal and external memory strategies. Because some participants were engaged in more than one activity, the outcome was dichotomized as 'no activity undertaken' and 'at least one activity undertaken'.

Educational level was measured by a Dutch scoring system (De Bie, 1987) which consists of an 8-point scale, ranging from primary to university education.

\section{Cognitive function}

The primary dependent variables were general information processing speed, as measured with the Letter-Digit-Substitution Test, simple and complex speed, as measured with the Stroop Color-Word test, and immediate and delayed recall, as measured with the Verbal Learning Test.

The Letter-Digit-Substitution Test (LDST) is conceptually identical to the Symbol-Digit Modalities Test developed by Smith (1968). This test was used to measure general speed of information processing. At the top of a sheet of paper, a box was presented with nine numbers coupled to nine letters in a random order. On the remainder of the page, an array of boxes was presented with only letters. Participants were asked to fill in as many corresponding numbers as possible within one minute. The total number of correctly copied digits, was used as the dependent variable.

The Stroop Color-Word test was used to assess information processing speed (Klein, Ponds, Houx, \& Jolles, 1997; Stroop, 1935). The test involves 
three cards displaying a hundred stimuli each: colour names printed in black (subtask I), coloured patches (subtask II) and colour names printed in incongruously coloured ink (subtask III). For subtask I, participants had to read the printed items, while for subtask II they had to name the coloured patches and for subtask III they had to name the colour of the ink the words were printed in. The extra time needed to discard irrelevant but very salient information (reading) in favour of a less obvious aspect (colour naming) was recorded. The average speed on subtasks I and II was used as a measure of general information processing speed (simple speed). Subtask III minus the average speed on subtasks I and II was used to measure complex speed.

To assess memory capacity and delayed recall from long-term memory, the participants completed the visual Verbal Learning Test (VLT: (Brand \& Jolles, 1985)). This test is an adapted version of the test originally devised by Rey (1964). Fifteen words were presented on a computer screen, one after the other at two-second intervals. The participants were then asked to recall as many words as possible, in random order. This procedure was repeated five times. After 20 minutes, delayed recall was measured. Dependent variables were the total recall over the first three trials (VLT immediate recall) and the delayed recall after 20 minutes (VLT delayed recall).

\section{Depressive and anxiety symptoms}

Feelings of depression and anxiety were measured with subscales of the Symptom Checklist (SCL-90: (Derogatis, 1977) Dutch version (Arrindell \& Ettema, 1986)). The SCL-90 is a multidimensional self-report inventory of psychopathology. Symptoms of depression and anxiety were used in further analyses to adjust for the effects of mood on subjective memory complaints.

\section{Statistical analyses}

Unpaired $t$-tests were used to determine whether age, education, depression, and anxiety were different between the participants with and without memory complaints and between the participants who did and did not actively train their memory to alleviate their memory complaints. Differences in male-female ratio between the groups were tested with the Chi-square test. Unpaired $t$-tests and Chi-square tests were used to determine the differences between the characteristics of volunteers who did or did not participate in the 6-year followup. Logistic regression analysis, corrected for sex, education, and age, was used to determine whether the participants who were lost to follow-up were more likely to be forgetful than volunteers who participated at the second measurement. To investigate whether forgetfulness was a predictor of a poorer cognitive performance of participants with memory complaints versus 


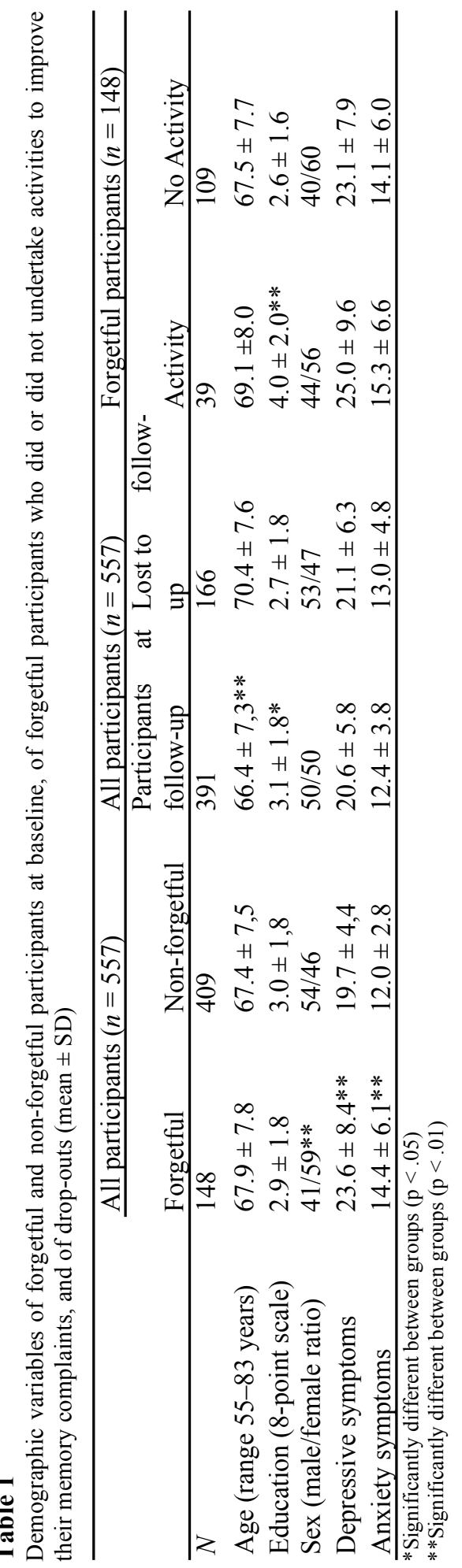


participants without memory complaints, linear regression analysis was used, with correction for age, education, sex, depressive, and anxiety symptoms in the cross-sectional analyses, and additionally baseline performance in the longitudinal analyses. Baseline analyses were performed in individuals participating at baseline as well as in individuals who participated at baseline and at follow-up. Furthermore, linear regression analysis was used to investigate whether the activities undertaken to modify memory complaints were a predictor of a better cognitive performance among participants who did or did not try to improve their memory, corrected for age, education, and sex in crosssectional analyses and also for baseline scores in longitudinal analyses. The significance level was set at $p<.05$.

\section{Results}

\section{Participant characteristics}

The demographic characteristics of the 557 volunteers are shown in Table 1. At baseline, nearly $27 \%$ of the participants considered themselves forgetful. Significantly more women than men had memory complaints $\left(\chi^{2}(1, N=557)=\right.$ $7.41, p<.01)$. Furthermore, forgetful participants had more depressive $(t(555)=$ $-7.24, p<.01)$ and anxiety-related symptoms $(t(555)=-6.42, p<.01)$ than did individuals who did not complain of forgetfulness. This pattern of results was the same in the 391 participants at follow-up: more women were forgetful $\left(\chi^{2}(1\right.$, $n=391)=13.70, p<.01)$, and forgetful participants had more depressive symptoms $(t(389)=-6.80, p<.01)$ and more anxiety-related symptoms $(t(389)$ $=-5.28, p<.01)$.

After six years, 166 participants (30\%) were lost to follow-up, of whom $55(33 \%)$ initially reported being forgetful. Four participants $(2.4 \%)$ who were lost to follow-up were diagnosed with dementia, three of whom had considered themselves forgetful at baseline. Participants who were lost to follow-up had a significantly lower educational level $(t(555)=2.41, p=.016)$, were older $(t(555)=-6.12, p<.01)$, and performed worse on all outcome variables at baseline than did the participants who attended the 6-year follow-up $(p<.01)$. In a logistic regression analysis, being forgetful was predictive of attrition (OR $=1.6, \mathrm{~W}=4.5, p=.04)$, as were older age $(\mathrm{OR}=2.0 \mathrm{~W}=28.9, p<.01)$ and lower education $(\mathrm{OR}=0.7, \mathrm{~W}=4.7, p=.03)$.

\section{Subjective memory complaints}

Table 2 shows the mean raw test performances of general information processing speed, simple and complex information processing speed, and immediate recall and delayed recall for participants with and without memory complaints at baseline. Data are separately shown for participants at baseline, participants at follow-up and participants who were lost to follow up. When all 


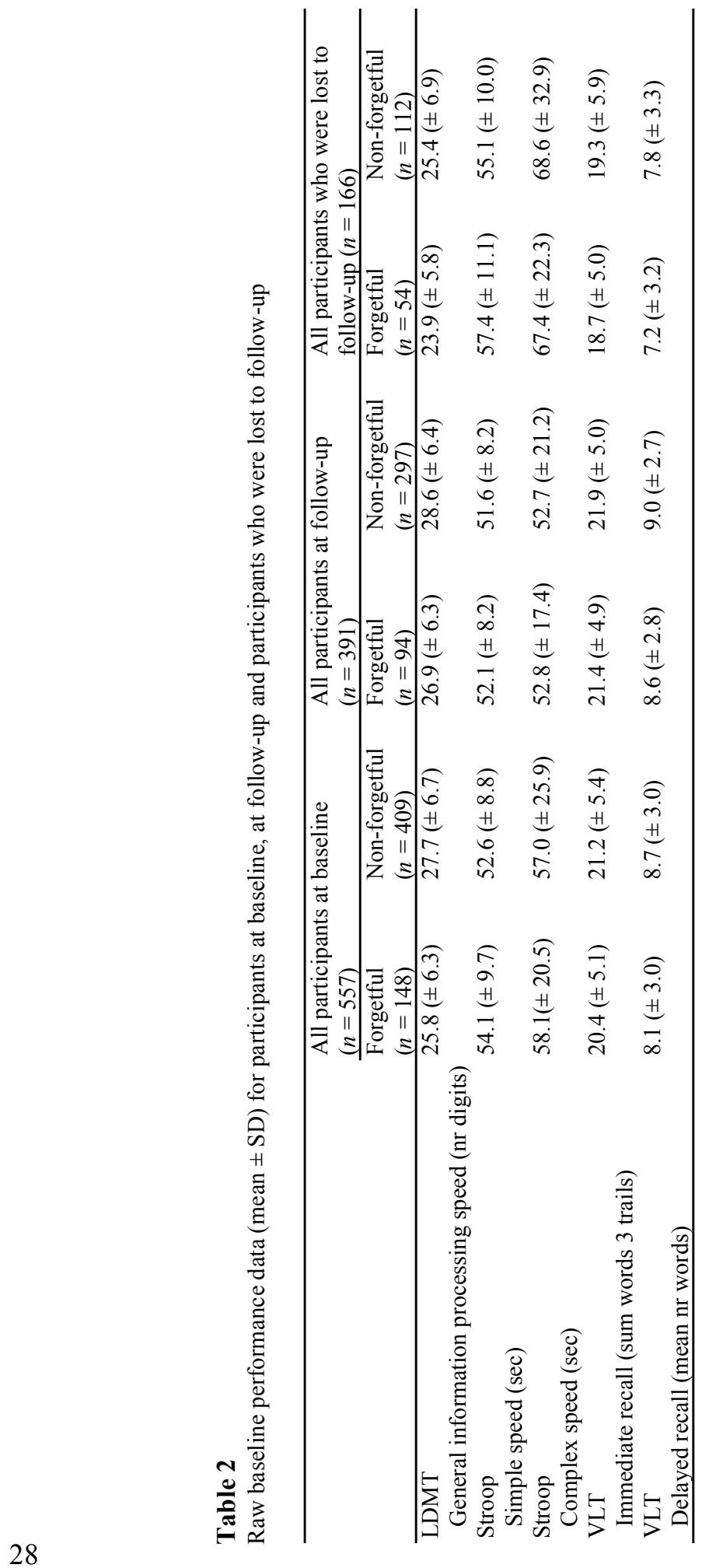


participants were analysed $(N=557)$, the non-forgetful participants performed significantly better than forgetful participants on tasks of general information processing speed $\left(\beta=0.087, t(549)=-2.30, p<0.05, \eta^{2}=0.01\right)$ and delayed recall $\left(\beta=0.091, t(549)=-2.25, p<0.05, \eta^{2}=0.01\right)$ after correcting for age, education, sex, and symptoms of depression and anxiety. The correlation between symptoms of depression and being forgetful was $0.29(p<.01)$, and the correlation between symptoms of anxiety and being forgetful was $0.26(p<$ $.01)$. When only participants were analysed who participated twice in the study $(n=391)$, no significant differences in cognitive measures were found between the forgetful and non-forgetful participants. In this group, the correlation between symptoms of depression at baseline and being forgetful was $0.33(p<$ .01 ), and the correlation between symptoms of anxiety at baseline and being forgetful was $0.26(p<.01)$.

Table 3 shows the mean raw performance data of general information processing speed, simple and complex information processing speed, and immediate recall and delayed recall for participants with and without memory complaints at follow-up. 'Being forgetful' at follow-up and the mean MMSEscores are also presented in this table. Being forgetful at baseline did not predict an individual's change in performance on the general information processing speed task, the simple and complex information processing speed tasks, and the immediate and delayed memory tasks six years later.

Table 3

Raw performance data (mean \pm SD) and MMSE scores at follow-up of participants at follow-up

\begin{tabular}{lll}
\hline & \multicolumn{2}{l}{ All participants at follow-up $(n=391)$} \\
\cline { 2 - 3 } & Forgetful $(n=94)$ & Non-forgetful $(n=297)$ \\
\hline $\begin{array}{l}\text { LDMT } \\
\text { General information processing speed (nr digits) }\end{array}$ & $27.6( \pm 7.4)$ & $28.6( \pm 7.7)$ \\
$\begin{array}{l}\text { Stroop } \\
\quad \text { Simple speed (sec) }\end{array}$ & $55.7( \pm 9.7)$ & $55.0( \pm 9.4)$ \\
$\begin{array}{l}\text { Stroop } \\
\quad \text { Complex speed (sec) }\end{array}$ & $63.9( \pm 41.6)$ & $59.8( \pm 31.9)$ \\
$\quad$ VLT & $22.1( \pm 6.3)$ & $23.2( \pm 5.6)$ \\
$\quad$ Immediate recall (sum words 3 trails) & $8.7( \pm 3.9)$ & $9.4( \pm 3.3)$ \\
VLT & & $70(25 \%)$ \\
$\quad$ Delayed recall (mean nr words) & $65(71 \%)$ & $28.3( \pm 1.6)$ \\
$\quad$ Number of participants being forgetful at follow-up $(\%)$ & 3 \\
$\quad$ MMSE Score & $28.1( \pm 2.0)$ & \\
$\quad$ Number participants $<24$ & 3 &
\end{tabular}

\section{Effect of self-initiated intervention}

Of the 148 participants who had memory complaints at baseline, 39 (26\%) reported having undertaken some activity to remedy their memory problems. There was a significant difference in educational level between the forgetful participants who did and did not take action: active participants were more 
highly educated $(p<.01)$. The two groups did not differ in age, sex, and depressive and anxiety symptoms (Table 1). Of the 94 forgetful participants at follow-up, 26 (28\%) participants engaged in memory activities at baseline and 68 did not engage in an activity to remedy their memory complaints.

Linear regression analysis, corrected for age, sex, and education, showed that undertaking activities to remedy memory problems was not a significant predictor of a better performance on tasks of general information processing speed, simple and complex information processing speed, and immediate recall or delayed recall at baseline or at the 6-year follow-up.

\section{Discussion}

In this study, we investigated the cross-sectional and longitudinal relationship between forgetfulness and cognitive task performance in a healthy population. Forgetful individuals who were worried about their memory problems and who felt hampered by them performed worse at baseline on a general information processing speed task and on a delayed recall task than did participants who were not forgetful. However, when only participants were analysed who participated at follow-up, forgetful participant did not perform worse on the cognitive tasks, than non-forgetful participants. Furthermore, forgetfulness at baseline was not a predictor of the change in performance on any cognitive task by forgetful or non-forgetful participants six years later. In addition, forgetfulness was strongly correlated with symptoms of anxiety and depression. In the remainder of this text, we will discuss these results and compare them with previous studies. In addition, this discussion will focus on the relationship between undertaking action to remedy the memory problems and cognition.

One other study has investigated the relationship between subjective forgetfulness and information processing speed. Taylor, Miller and Tinklenberg (1992) observed no decline on a test of mental speed, as measured by the Wechsler Adult Intelligence Scale, in a 4-year longitudinal study involving 30 healthy older adults (mean age 67.5 years) with subjective memory complaints. Our results, performed in a large population, are inconsistent with these findings, showing that subjective memory complaints co-exist with a slower speed of information processing.

In addition to the poorer performance on the general information processing speed task, the forgetful participants also performed worse on the delayed recall task at baseline. In a cross-sectional study, Basset \& Folstein (1993) found that participants older than 65 years who complained of memory difficulties were twice as likely to have a poor memory performance as those who did not have such complaints. Furthermore, Jonker et al. (1996) found in a cross-sectional study that individuals aged between 65 and 85 years with memory complaints performed worse on tests of memory and memory-related functions than similarly aged individuals without such memory complaints. Several longitudinal studies have found subjective memory complaints to be 
predictive of a poorer memory performance. For example, Jorm (2001) performed a longitudinal study over eight years involving 331 volunteers older than 70 and found that memory complaints predicted future memory performance, and Schmand (1997) found that memory complaints at baseline were predictive of future dementia in a four year longitudinal study of 2,114 participants older than 65 years. However, other longitudinal studies have not confirmed the positive association between memory complaints and cognitive decline. For example, Blazer \& Hayes (1997), who performed a 3-year followup study of 3,079 participants with a mean age of 72.7 years, found that memory complaints did not predict cognitive decline, as measured with the Short Portable Mental Status Questionnaire. Flicker, Ferris \& Reisberg (1993) reported similar findings in a 3.5-year follow-up study of 59 participants with a mean age of 68.7 years. Possible explanations for the inconsistent findings are the age of the selected samples, how variables (such as depression) were treated in the analysis, and the use of different cognitive tests (Jonker et al., 2000).

Overall, in the present study, forgetfulness was an indicator of cognitive dysfunction at baseline on two out of five measures, when all participants were analysed. We found an effect on delayed recall, but not on immediate recall. This differentiation can be explained by the fact that delayed recall implies a defect in memory storage and/ or in the use of an effective retrieval strategy. This is also found in clinical settings in patients with memory disorders. Furthermore, we found an effect on a general measure of information processing speed, but not on the more specific measures of information processing, which may be related to the fact that the cognitive aspects measured by the Stroop tasks, are probably not affected by being forgetful, but other aspects of information processing speed might be affected. In addition, the two significant effects found in the present study were rather small, as was shown by their small effect sizes. This suggests that the findings cannot directly be generalized to applications in clinical populations or individual participants. The relevance of the data is that they attract notice to information processing speed as being a potential mediator of cognitive complaints. The present study found such a relation in healthy subjects who do not present themselves with cognitive complaints to their doctor. Further research should be performed in clinical populations, where it can be expected that the effects found in the present study are more substantial.

After controlling for baseline scores, forgetfulness did not predict a poorer cognitive performance at follow-up. It seems therefore that memory complaints and diminished memory performance might co-occur in a specific group including the participants who dropped out, but, at least in our study, complaints do not seem to precede a decline in memory function over a longer period of time, i.e. six years. Moreover, memory problems in otherwise healthy individuals may be temporary. Visser et al. (2000) found that memory impairment appeared to be reversible over a five-year period in $42 \%$ of the participants recruited from an outpatient memory clinic. These authors found 
that in almost $50 \%$ of the participants with reversible memory impairment, the improvement in cognitive functioning may have resulted from improvement of depressed mood. In other participants, the improvement may have been due to improvement of subsyndromal depression or stress that was caused, for example, by bereavement, co-morbid disorders, or pain (Visser et al., 2000). However, Visser et al. did not include a control group, whereas we did (participants who did not considered themselves forgetful). We found that about $29 \%$ of the participants who considered themselves forgetful at baseline no longer did so six years later. Conversely, about $25 \%$ of the non-forgetful participants at baseline regarded themselves as forgetful at follow-up, indicating that the overall proportion of forgetful individuals remained constant. Also, after six years of follow-up, only 3 forgetful and 3 non-forgetful participants had an MMSE score below 24. Furthermore, the correlation between being forgetful and symptoms of depression and anxiety was fairly high in the present study. It is possible that these symptoms are underlying the memory complaints, rather than a cognitive deficit. Another possible explanation for the different relation between complaints and objective performance at baseline and at follow-up could be that the subjective memory complaints are not only determined by actual performance, but also by personality traits, such as neuroticism or low self-esteem (Pearman \& Storandt, 2004) or symptoms of depression (Ponds et al., 1997) or anxiety (Comijs, Deeg, Dik, Twisk, \& Jonker, 2002). Another reason for not finding a longitudinal change in cognitive function can be that subjective memory complaints may differ in severity. In addition, the population was relatively young ( $\mathrm{M}=67.7$ years), so only a few cases of incident dementia or memory impairment would be expected on $a$ priori basis.

Taking effort to remain cognitively active (such as searching for information about memory and forgetfulness, visiting a doctor who practices alternative medicine, participating in a memory course or another course to stay mentally active, reading, doing crossword puzzles, and using internal and external memory strategies) did not appear to influence the performance on memory and speed of information processing tasks of forgetful subjects in the present study. Other research has shown that participating in an activity one day a week (for example, playing board games or reading) is associated with a small decrease in the risk of developing dementia in 469 healthy participants, older than 75 years of age (Verghese et al., 2003). Bosma (2002), who studied 830 participants in the Maastricht Aging Study, found that participating in mental, social, and physical activities partially protected against age-related cognitive deterioration. Not finding an improvement in cognitive functioning in the forgetful participants who stayed cognitively active in the present study might be caused by the high variety in the activities that the participants undertook. Future studies should look more in depth into subgroups of participants who share particular characteristics. Moreover, the intensity of such activities may depend on the severity of the memory complaints, which in turn might explain 
the great variability in the types of activities undertaken, because individuals with more severe complaints probably undertake more intensive activities.

In order to improve the quality and efficacy of future interventions and health educational activities, demographic characteristics were gathered from forgetful participants who did or did not attempt to stay cognitively active. Participants of the present study who tried to improve their memory function were significantly more highly educated than participants who did not. Therefore it is important to target specifically participants with lower educational levels in future interventions. Furthermore, the finding that more women experienced memory problems, and that forgetful participants experienced more depressive and anxiety symptoms than non-forgetful participants, should also be taken into account when designing new interventions. For example, by focusing the intervention on female participants and by addressing feelings of depression and anxiety as part of the intervention.

A limitation of the current study involves the considerable attrition $(30 \%)$, which can be a reason for not finding a change in performance after six years. It is a general finding of longitudinal studies that drop-outs tend to differ from participants and perform more poorly on neuropsychological tests at baseline (Cooney, Schaie, \& Willis, 1988). Van Beijsterveldt (2002) investigated the predictors of attrition after three years of follow-up in the Maastricht Aging Study population and found that drop-outs who refused to participate in the follow-up had lower scores on cognitive tests at baseline. In the present study, the participants who dropped out performed worse on the outcome variables, were forgetful, were older, and had a lower education. Thus, only a select group of participants attended the follow-up investigation, which means that results might be biased. To account for this, we performed separate analyses at baseline, for all participants and participants who participated twice in the study. This makes it possible to compare the same group at baseline as at follow-up. No significant differences that were present at baseline were found when participants at follow-up were analysed, which emphasises that the effect is only present in a select group, participants including drop-outs. Selective attrition of individuals with memory difficulties may have occurred. Another methodological issue of the current study concerns the different activities that were undertaken by the forgetful participants, which made it difficult to create a homogenous group. This may be a reason why we did not find a difference in cognitive performance between the groups.

In conclusion, the results at baseline indicate that forgetfulness in all individuals older than 55 years might be an indicator of slower general information processing and delayed recall, but no indicator of simple and complex information processing speed and immediate recall. However, the effects were rather small and cannot directly be applied to clinical settings. Other factors, such as depression and anxiety may also underlie the forgetfulness. Furthermore, forgetfulness does not predict a change in cognitive performance after six years. Therefore, it seems that forgetfulness and a poor 
cognitive function might co-occur but, at least in our study, subjective memory complaints do not precede cognitive decline over a period of six years. This finding is important because forgetfulness is highly prevalent in the normal population. Furthermore, being cognitively active was not a predictor of better performance on cognitive tasks, indicating that more extensive activities than only staying cognitively active may be needed to improve cognitive functioning. 


\section{References}

Arrindell, W. A., \& Ettema, J. H. M. (1986). SCL-90. Manual for a multidimensional indicator of psychopathology [Handleiding bij een multidimensionele psychopathologie-indicator]. Lisse, the Netherlands: Swets \& Zeitlinger B.V.

Ball, K., Berch, D. B., Helmers, K. F., Jobe, J. B., Leveck, M. D., \& Marsiske, M. (2002). Effects of cognitive training interventions with older adults. Journal of the American Medical Association, 288(18), 2271-2281.

Balota, D. A., Dolan, P. O., \& Duchek, J. M. (2000). Memory changes in healthy older adults. In E. Tulving \& F. Craik (Eds.), The Oxford handbook of memory (pp. 395-409). New York: Oxford University Press.

Bassett, S. S., \& Folstein, M. F. (1993). Memory complaint, memory performance, and psychiatric diagnosis: a community study. Journal of Geriatric Psychiatry and Neurology, 6(2), 105-111.

Blazer, D. G., Hays, J. C., Fillenbaum, G. G., \& Gold, D. T. (1997). Memory complaint as a predictor of cognitive decline: a comparison of African American and White elders. Journal of Aging and Health, 9(2), 171-184.

Bolla, K. I., Lindgren, K. N., Bonaccorsy, C., \& Bleecker, M. L. (1991). Memory complaints in older adults. Fact or fiction? Archives of Neurology, 48(1), 61-64.

Bosma, H., Van Boxtel, M. P., Ponds, R. W., Jelicic, M., Houx, P., Metsemakers, J., et al. (2002). Engaged lifestyle and cognitive function in middle and old-aged, non-demented persons: a reciprocal association? Zeitschrift für Gerontologie und Geriatrie, 35(6), 575581.

Brand, N., \& Jolles, J. (1985). Learning and retrieval rate of words presented auditory and visually. The Journal of General Psychology, 112(2), 201-210.

Braver, T. S., \& Barch, D. M. (2002). A theory of cognitive control, aging cognition, and neuromodulation. Neuroscience and Biobehavioral Reviews, 26(7), 809-817.

Comijs, H. C., Deeg, D. J. H., Dik, M. G., Twisk, J. W. R., \& Jonker, C. (2002). Memory complaints: the association with psycho-affective and health problems and the role of personality characteristics. A 6-year follow-up study. Journal of Affective Disorders, 72, 157-165.

Commissaris, C. J. A. M., Ponds, R. W. H. M., \& Jolles, J. (1998). Subjective forgetfulness in a normal Dutch population: possibilities for health education and other interventions. Patient Education and Counseling, 34, 25-32.

Cooney, T. M., Schaie, K. W., \& Willis, S. L. (1988). The relationship between prior functioning on cognitive and personality dimensions and subject attrition in longitudinal research. Journal of Gerontology, 43(1), P12-17.

Craik, F. I. M., Morris, R., \& Gick, M. (1990). Adult age differences in working memory. In G. Vallar \& T. Shallice (Eds.), Neuropsychological impairment in short-term memory (pp. 247-267). Cambridge, England: University Press.

De Bie, S. E. (1987). Standaardvragen 1987: voorstellen voor uniformering van vraagstellingen naar achtergrondkenmerken en interviews [Standard questions 1987: proposal for uniformisation of questions regarding background variables and interview]. (2nd ed.). Leiden, The Netherlands: Leiden University Press.

De Groot, J. C., De Leeuw, F. E., Oudkerk, M., Hofman, A., Jolles, J., \& Breteler, M. M. (2000). Cerebral white matter lesions and depressive symptoms in elderly adults. Archives of General Psychiatry, 57(11), 1071-1076.

Derogatis, L. R. (1977). SCL-90: administration, scoring and procedures manual-I for the R(evised) version. Baltimore: John Hopkins School of Medicine, Clinical Psychometrics Research unit. 
Derouesné, C., Lacomblez, L., Thibault, S., \& LePoncin, M. (1999). Memory complaints in young and elderly subjects. International Journal of Geriatric Psychiatry, 14(4), 291301.

Flicker, C., Ferris, S. H., \& Reisberg, B. (1993). A longitudinal study of cognitive function in elderly persons with subjective memory complaints. Journal of the American Geriatrics Society, 41(10), 1029-1032.

Folstein, M. F., Folstein, S. E., \& McHugh, P. R. (1975). "Mini-mental state". A practical method for grading the cognitive state of patients for the clinician. Journal of Psychiatric Research, 12(3), 189-198.

Geerlings, M. I., Jonker, C., Bouter, L. M., Ader, H. J., \& Schmand, B. (1999). Association between memory complaints and incident Alzheimer's disease in elderly people with normal baseline cognition. The American Journal of Psychiatry, 156(4), 531-537.

Jolles, J., Houx, P. J., Van Boxtel, M. P. J., \& Ponds, R. W. H. M. (1995). Maastricht Aging Study: determinants of cognitive aging. Maastricht: Neuropsych Publishers.

Jonker, C., Geerlings, M. I., \& Schmand, B. (2000). Are memory complains predictive for dementia? A review of clinical and population-based studies. International Journal of Geriatric Psychiatry, 15, 983-991.

Jonker, C., Launer, L. J., Hooijer, C., \& Lindeboom, J. (1996). Memory complaints and memory impairment in older individuals. Journal of the American Geriatrics Society, 44(1), 4449.

Jorm, A. F., Christensen, H., Korsten, A. E., Jacomb, P. A., \& Henderson, A. S. (2001). Memory complaints as a precursor of memory impairment in older people: a longitudinal analysis over 7-8 years. Psychological Medicine, 31, 441-449.

Jorm, A. F., Christensen, H., Korten, A. E., Henderson, A. S., Jacomb, P. A., \& Mackinnon, A. (1997). Do cognitive complaints either predict future cognitive decline or reflect past cognitive decline? A longitudinal study of an elderly community sample. Psychological Medicine, 27, 91-98.

Kausler, D. H. (1994). Learning and Memory in Normal Aging (1st ed). San Diego: Academic Press.

Klein, M., Ponds, R. W., Houx, P. J., \& Jolles, J. (1997). Effect of test duration on age-related differences in Stroop interference. Journal of Clinical and Experimental Neuropsychology, 19(1), 77-82.

Metsemakers, J. F., Hoppener, P., Knottnerus, J. A., Kocken, R. J., \& Limonard, C. B. (1992). Computerized health information in The Netherlands: a registration network of family practices. British Journal of General Practice, 42(356), 102-106.

Niederehe, G. (1998). The significance of memory complaints in later life: methodological and theoretical considerations. In J. Lomranz (Ed.), Handbook of aging and mental health: an integrative approach (pp. 417-434). New York: Plenum Press.

Pearman, A., \& Storandt, M. (2004). Predictors of subjective memory in older adults. Journals of Gerontology Series B: Psychological Sciences and Social Sciences, 59B(1), p4-6.

Ponds, R. W., Commissaris, K. J., \& Jolles, J. (1997). Prevalence and covariates of subjective forgetfulness in a normal population in The Netherlands. International Journal of Aging and Human Development, 45(3), 207-221.

Rasmusson, X., Rebok, G. W., Bylsma, F. W., \& Brandt, J. (1999). Effects of three types of memory training in normal elderly. Aging Neuropsychology and Cognition, 6(1), 56-66.

Rey, A. (1964). L'examen psychologique dans les cas d'encephalopathie traumatique [psychological assessment in cases of traumatic brain injury]. Paris: Presses Universitaires de France.

Salthouse, T. A. (1980). Age and memory: strategies for localizing the loss. In Poon L W, J. L. Fozard, L. S. Cermak, D. Arenberg \& L. W. Thompson (Eds.), New directions in memory and aging: proceedings of the George A. Talland Memorial Conference. Hillsdale, NJ: Erlbaum.

Salthouse, T. A. (1992). Mechanisms of age-cognition relations in adulthood. Hillsdale, NJ: Lawrence Erlbaum Associates. 
Salthouse, T. A. (1996). The processing-speed theory of adult age differences in cognition. Psychological Review, 103(3), 403-428.

Schmand, B., Jonker, C., Geerlings, M. I., \& Lindeboom, J. (1997). Subjective memory complaints in the elderly: depressive symptoms and future dementia. The British Journal of Psychiatry, 171, 373-376.

Schofield, P. W., Marder, K., Dooneief, G., Jacobs, D. M., Sano, M., \& Stern, Y. (1997). Association of subjective memory complaints with subsequent cognitive decline in community-dwelling elderly individuals with baseline cognitive impairment. The American Journal of Psychiatry, 154(5), 609-615.

Smith, A. (1968). The Symbol Digit Modalities Test: a neuropsychologic test for economic screening of learning and other cerebral disorders. Learning Disorders, 3, 83-91.

St John, P., \& Montgomery, P. (2002). Are cognitively intact seniors with subjective memory loss more likely to develop dementia? International Journal of Geriatric Psychiatry, 17(9), 814-820.

Stroop, J. (1935). Studies of interference in serial verbal reaction. Journal of Experimental Psychology, 18, 643-662.

Taylor, J. L., Miller, T. P., \& Tinklenberg, J. R. (1992). Correlates of memory decline: a 4-year longitudinal study of older adults with memory complaints. Psychology and Aging, $7(2), 185-193$.

Troyer, A. (2001). Improving memory knowledge, satisfaction and functioning via an education and intervention program for older adults. Aging, Neuropsychology and Cognition, 8(4), 256-268.

Van Beijsterveldt, C. E. M., Van Boxtel, M. P. J., Bosma, H., Houx, P. J., Buntinx, F., \& Jolles, J. (2002). Predictors of attrition in a longitudinal cognitive aging study: the Maastricht Aging Study (MAAS). Journal of Clinical Epidemiology, 55, 216-223.

Van Boxtel, M. P., Buntinx, F., Houx, P. J., Metsemakers, J. F., Knottnerus, A., \& Jolles, J. (1998). The relation between morbidity and cognitive performance in a normal aging population. Journals of Gerontology Series B: Psychological Sciences and Social Sciences, 53(2), M147-154.

Verghese, J., Lipton, R. B., Katz, M. J., Hall, C. B., Derby, C. A., Kuslansky, G., et al. (2003). Leisure activities and the risk of dementia in the elderly. The New England Journal of Medicine, 348(25), 2508-2516.

Visser, P. J., Verhey, F. R., Ponds, R. W., Cruts, M., Van Broeckhoven, C. L., \& Jolles, J. (2000). Course of objective memory impairment in non-demented subjects attending a memory clinic and predictors of outcome. International Journal of Geriatric Psychiatry, 15(4), 363-372.

Wang, P. N., Wang, S. J., Fuh, J. L., Teng, E. L., Liu, C. Y., Lin, C. H., et al. (2000). Subjective memory complaint in relation to cognitive performance and depression: a longitudinal study of a rural Chinese population. Journal of the American Geriatrics Society, 48(3), 295-299. 


\section{The effect of perceived forgetfulness on quality of life in older adults: a qualitative review}

Martine E.M. Mol, Margot Carpay, Inez H.G.B. Ramakers, Nico Rozendaal, Frans R.J. Verhey \& Jelle Jolles 


\section{Abstract}

\section{Background}

Approximately $50 \%$ of older individuals perceive themselves as being forgetful.

\section{Objective}

The objective of this review is to get an overview of previous research on the relation between perceived forgetfulness (in the absence of objective memory deficit) and quality of life in older individuals. Findings in previous research might be a starting point for further research and possible future interventions.

\section{Methods}

Scientific papers that investigated the relation between subjective memory complaints and quality of life were searched. Two independent raters scored the articles on their methodology. The methodological quality was taken into account when conclusions were drawn.

\section{Results}

The literature search resulted in 682 articles, of which five studies met the inclusion criteria. Although the five studies differed in their methodology, the findings of the methodologically adequate studies showed a relation between memory complaints and a diminished quality of life in the elderly.

\section{Conclusions}

The negative impact that subjective memory complaints can have on quality of life makes it important to acknowledge forgetfulness as a serious issue in the life of older individuals. However, more research is needed to explore the relationship between subjective memory complaints and quality of life, also with regard to the influence of depression and objective memory performance. 


\section{Introduction}

Complaints about forgetfulness and diminishing memory function are very common among older people (Blazer, Hays, Fillenbaum, \& Gold, 1997; Ponds, Commissaris, \& Jolles, 1997). The prevalence of memory complaints in community-based samples of older people varies from approximately $25 \%$ to over 50\% (Jonker, Geerlings, \& Schmand, 2000). In the Maastricht Aging Study the prevalence of forgetfulness in the 55 to 65 age group was $41 \%$, and in the 70 to 85 age group the prevalence was 52\% (Ponds et al., 1997). Approximately $60 \%$ of the middle-aged individuals perceive much hindrance from their forgetfulness, and approximately $70 \%$ are very worried about it (Commissaris, Ponds, \& Jolles, 1998). However, not much attention is given to the impact that memory complaints, even when only subjective, can have on someone's quality of life, although complaints about forgetfulness and diminishing memory function are very common among older people. An overview of previous research is needed to get insight into the relation between perceived forgetfulness and a person's quality of life. Findings in previous research might be a starting point for further research and possible future interventions.

In order to get an overview of the results of previous studies on the relation between being forgetful and quality of life in older people, we performed a search in the relevant literature. The identified studies were scored on their methodological quality, which was taken into account when conclusions were drawn. Forgetfulness and subjective memory complaints were used interchangeably in this review. Being forgetful in this paper was regarded as having subjective memory complaints in the absence of an objective deficit. Furthermore, the focus of quality of life in this review was to look at a broad span of quality of life, including life satisfaction and wellbeing. Symptoms of depression and anxiety were included when it was part of the quality of life or wellbeing scale.

\section{Methods}

\section{Literature search}

The publications involved in this study were retrieved by computerized searches of PubMed (1966 to February 2006), PsycINFO (1966 to February 2006) and Embase (1986 to February 2006). The following search strategy and key words were used: ['age' or 'elderly' or 'aging'] and ['quality of life' or 'wellbeing'] and ['memory' or 'subjective memory complaints' or 'memory complaints' or 'forgetfulness']. The databases were also searched with different spelling forms of these words. After obtaining all relevant papers, the references of these studies were hand searched to find additional potentially relevant papers. 
To be selected for this review, studies had to meet all of the following criteria: (a) the participants examined in the study were healthy older people with subjective memory complaints, but with no objective cognitive disorder such as dementia; (b) the study measured the relation between subjective memory complaints and the participants' quality of life or wellbeing; (c) the study was not an intervention study, to prevent that the intervention would confound the relation between subjective memory complaints and quality of life. However, articles that examined a cross-sectional relation on baseline-date were included; (d) the article was a full report of the study; (e) the paper was published in English. The studies that were expected to meet all the inclusion criteria on the basis of the title or, if available, the abstract, were obtained.

\section{Quality assessment of selected studies}

The methodological quality was assessed according to standardized methodological criteria (De Vet, De Bie, Verhagen, Sijpkes, \& Knipschild, 1997). A list of 13 criteria divided into 4 methodological items of an observational study was constructed, including research population and study design, measurement instruments, and data analyses and presentation (appendix 1). Maximum scores were determined beforehand, with more important criteria receiving relatively higher scores. A maximum score of 43 could be obtained per study.

Two raters, who were not involved in the development of the methodological criteria list, independently applied the criteria to all selected articles. The raters received a brief instruction to prevent misinterpretation of the criteria. Such an instruction increases the consistency between the raters, which might increase the reliability of this qualitative review (Lipsey \& Wilson, 2001). To prevent bias, all reviewed articles had the author(s), journal, year of publishing, name and location of institute, and acknowledgements removed. Inconsistencies in the assessments of both raters were identified and discussed during a consensus meeting. The final scores for the papers were then summed. The studies were ranked according to these total scores, resulting in a hierarchical list in which a higher score means a higher considered methodological quality of the study. Methodological ratings were based solely on material presented in the article. Some studies may therefore have been under-rated if authors failed to mention important details of the study.

\section{Results}

\section{Literature search}

The search resulted in 682 articles (292 in Pubmed, 188 in PsychINFO, and 202 in Embase). These 682 articles were searched to establish whether they met the inclusion criteria on the basis of their title and abstract. This resulted in the 
identification of fifteen articles (Bazargan \& Bazargan, 1997; Bryan \& Calvaresi, 2004; Capsi \& Elder, 1986; Commissaris et al., 1998; Deeg et al., 1992; Derouesné et al., 1989; Derouesné, Lacomblez, Thibault, \& LePoncin, 1999; Kim \& Mueller, 1997; McDougall, 1994; McDougall et al., 2003; Neri, Andermarcher, Pradelli, \& Salvioli, 1995; Starr, Deary, \& Macintyre, 2003; Steen, Hagberg, Johnson, \& Steen, 1987; Verhaeghen, Geraerts, \& Marcoen, 2000; Wolters, Bemelmans, Spinhoven, Theunissen, \& Van der Does, 1996). Subsequently, these 15 articles were obtained and 9 of these 15 articles were found not to meet our inclusion criteria. Three articles did not assess the impact of subjective memory complaints on the participants' quality of life (Bryan \& Calvaresi, 2004; Neri et al., 1995; Wolters et al., 1996). Four articles measured objective memory, but did not measure subjective memory complaints (Capsi \& Elder, 1986; Deeg et al., 1992; Starr et al., 2003; Steen et al., 1987). Two articles did not measure quality of life (McDougall, 1994; McDougall et al., 2003).

Six articles met the inclusion criteria. One of these studies (Kim \& Mueller, 1997) was a case report. Four cases were selected from a sample of 107 Korean American older adults, with the specific intent of providing a more comprehensive understanding of the relationship between memory self-efficacy and wellbeing. Each case showed a unique pattern of interplay of these cognitive and affective variables. Two cases support the relationship between memory complaints and quality of life, while the other two contradicted the relationship. However, the number of cases studied is too small and the selection method is too prejudiced to generalize the findings of this study. We therefore chose to exclude the article from this review. Ultimately, five articles were included in this review (Bazargan \& Bazargan, 1997; Commissaris et al., 1998; Derouesné et al., 1989; Derouesné et al., 1999; Kim \& Mueller, 1997; Verhaeghen et al., 2000) (see also Table 1).

\section{Methodological quality}

The raters' scores were similar on 35 of the 65 aspects (13 aspects and 5 articles; 54\%). The results of the methodological assessment can be found in Table 2. All five papers presented here scored above 60\%; (Bazargan \& Bazargan, 1997; Commissaris et al., 1998; Derouesné et al., 1989; Derouesné et al., 1999; Verhaeghen et al., 2000). The mean methodological quality score was $31(72 \%$ of the total score of 43$)$. The scores ranged between $26(60 \%)$ and 34 (79\%), showing that the studies were of moderate to high methodological quality. The most common shortcomings were the description of the study population and design. Descriptions of the instruments used to measure subjective memory and quality of life were adequate, as were the descriptions of the statistical analysis and the presentation of the data. 
Table 1

Characteristics of included studies

\begin{tabular}{|c|c|c|c|c|c|}
\hline$\overline{\text { Study }}$ & Sample & $\begin{array}{l}\text { Instruments } \\
\text { measuring } \\
\text { memory } \\
\text { complaints }\end{array}$ & $\begin{array}{l}\text { Instruments } \\
\text { measuring } \\
\text { quality of life }\end{array}$ & Outcome & Relation \\
\hline $\begin{array}{l}\text { 1. Derouesné } \\
\text { et al., } 1999\end{array}$ & $\begin{array}{l}N=260 \\
\text { Age range: } 20-49 \\
\text { and } 49-85 \\
\text { Self-referrals } \\
\text { EC: GCS } \leq 90\end{array}$ & SMS & WBQ & $\begin{array}{l}\text { In the oldest age group, a } \\
\text { significant negative } \\
\text { correlation was found } \\
\text { between subjective } \\
\text { memory complaints and } \\
\text { WBQ (Pearson correlation } \\
=-.28, p<.01) \text {. Wellbeing } \\
\text { as well as anxiety were } \\
\text { related to subjective } \\
\text { memory complaints }\left(\mathrm{F}_{2,180}\right. \\
=14.7 \text { and } \mathrm{F}_{1,181}=22.6 \\
\text { respectively) }\end{array}$ & + \\
\hline $\begin{array}{l}\text { 2. Commissaris } \\
\text { et al., } 1998\end{array}$ & $\begin{array}{l}N=1,971 \\
\text { Age range: } 25-85 \\
\text { Community } \\
\text { based EC: } \\
\text { dementia, overt } \\
\text { cerebro- } \\
\text { vascular disease }\end{array}$ & $\begin{array}{l}\text { Single-item } \\
\text { question }\end{array}$ & SWLS & $\begin{array}{l}\text { Participants who were } \\
\text { forgetful were less satisfied } \\
\text { with life }(t=5.5 ; p<.01)\end{array}$ & + \\
\hline $\begin{array}{l}\text { 3. Derouesné } \\
\text { et al., } 1989\end{array}$ & $\begin{array}{l}N=367 \\
\text { Age range: } 50-80 \\
\text { Self-referrals } \\
\text { EC: organic } \\
\text { cerebral disorder }\end{array}$ & SMS & WBQ & $\begin{array}{l}\text { Severity of memory } \\
\text { complaints was strongly } \\
\text { related to low scores in the } \\
\text { WBQ. However, } \\
\text { depression and not well- } \\
\text { being was the unique } \\
\text { variable related to severity } \\
\text { of memory complaints }\end{array}$ & + \\
\hline $\begin{array}{l}\text { 4. Bazargan and } \\
\text { Bazargan, } 1997\end{array}$ & $\begin{array}{l}N=998 \\
\text { Age range: } 62-99 \\
\text { Community } \\
\text { based }\end{array}$ & MFQ & $\begin{array}{l}\text { PGC } \\
\text { Morale Scale }\end{array}$ & $\begin{array}{l}\text { Memory functioning is } \\
\text { significantly related to } \\
\text { psychological wellbeing ( } r \\
=.43, p<.001) \text {. Memory } \\
\text { functioning was the best } \\
\text { predictor of psychological } \\
\text { wellbeing ( }(B=.25, p< \\
.001)\end{array}$ & + \\
\hline $\begin{array}{l}\text { 5. Verhaeghen } \\
\text { et al., } 2000\end{array}$ & $\begin{array}{l}N=179 \\
\text { Age range: } 49-97 \\
\text { Community } \\
\text { based }\end{array}$ & MIA & $\begin{array}{l}\text { Combination of } \\
\text { LSI and CES-D }\end{array}$ & $\begin{array}{l}\text { Coping with memory } \\
\text { complaints and } \\
\text { experiencing low } \\
\text { frequency of complaints } \\
\text { (high memory capacity) is } \\
\text { related to a better well- } \\
\text { being (relation in model } \\
.20 \text { and } .18 \text { respectively) }\end{array}$ & + \\
\hline
\end{tabular}

$\mathrm{EC}=$ Exclusion Criteria; GCS $=$ Global Cognitive Score; LSI $=$ Life Satisfaction Index; CES-D = Center for Epidemiologic Studies-Depression-Scale; MCI = Memory Controllability Inventory; MFQ $=$ Memory Functioning Questionnaire; MIA = Meta-memory in Adulthood; PGC = Philadelphia Geriatric Centre; SMS = Subjective Memory Scale; SWLS $=$ Satisfaction with Life Scale; WBQ $=$ Well-being Questionnaire; + = Relation found between forgetfulness and memory complaints 
Table 2

Methodological quality of the five included studies

\begin{tabular}{|c|c|c|c|c|c|c|c|c|c|c|c|c|c|c|c|}
\hline Criterion & $\mathrm{A} 1$ & $\mathrm{~A} 2$ & A3 & A4 & $\mathrm{A} 5$ & $\mathrm{~B} 1$ & B2 & $\mathrm{C} 1$ & $\mathrm{C} 2$ & D1 & D2 & D3 & D4 & \multicolumn{2}{|c|}{ Total $\%$} \\
\hline Max score & 6 & 6 & 2 & 6 & 2 & 3 & 2 & 3 & 2 & 3 & 2 & 2 & 4 & 43 & 100 \\
\hline \multicolumn{16}{|l|}{ Incl. studies: } \\
\hline $\begin{array}{l}\text { 1. Derouesné } \\
\text { et al., } 1999\end{array}$ & 6 & 3 & 1 & 4 & 0 & 3 & 2 & 3 & 2 & 3 & 2 & 1 & 4 & 34 & $79 \%$ \\
\hline $\begin{array}{l}\text { 2. Commissaris } \\
\text { et al., } 1998\end{array}$ & 6 & 2 & 1 & 6 & 0 & 2 & 2 & 3 & 2 & 3 & 0 & 2 & 4 & 33 & $77 \%$ \\
\hline $\begin{array}{l}\text { 3. Derouesné } \\
\text { et al.,1989 }\end{array}$ & 6 & 3 & 2 & 4 & 0 & 3 & 2 & 0 & 2 & 3 & 1 & 2 & 4 & 32 & $74 \%$ \\
\hline $\begin{array}{l}\text { 4. Bazargan and } \\
\text { Bazargan, } 1997\end{array}$ & 1 & 3 & 2 & 6 & 0 & 3 & 2 & 3 & 2 & 3 & 0 & 1 & 4 & 30 & $70 \%$ \\
\hline $\begin{array}{l}\text { 5. Verhaeghen } \\
\text { et al., } 2000\end{array}$ & 1 & 3 & 0 & 4 & 2 & 3 & 2 & 3 & 0 & 3 & 0 & 1 & 4 & 26 & $60 \%$ \\
\hline Mean & 4 & 2.8 & 1.2 & 4.8 & 0.4 & 2.8 & 2 & 2.4 & 1.6 & 3 & 0.6 & 1.4 & 4 & 31 & $72 \%$ \\
\hline$\%$ of max. score & $67 \%$ & $47 \%$ & $60 \%$ & $80 \%$ & $20 \%$ & $93 \%$ & $100 \%$ & $80 \%$ & $80 \%$ & $100 \%$ & $30 \%$ & $70 \%$ & $100 \%$ & $72 \%$ & \\
\hline
\end{tabular}

\section{Relation between subjective memory and quality of life}

Table 1 presents the study characteristics of the five included studies. There was a wide variety in study design and instruments used to measure the participants' subjective memory complaints and wellbeing. One study used life satisfaction scales to measure quality of life (Commissaris et al., 1998), three studies used wellbeing questionnaires (Bazargan \& Bazargan, 1997; Derouesné et al., 1989; Derouesné et al., 1999) and one study used a life satisfaction scale in combination with a depression scale as a measure of wellbeing (Verhaeghen et al., 2000). Subjective memory function was measured with subjective memory scales (Derouesné et al., 1989; Derouesné et al., 1999), memory functioning questionnaires (Bazargan \& Bazargan, 1997), meta-memory scales (Verhaeghen et al., 2000) and a single item question (Commissaris et al., 1998).

All five identified studies reported a relation between subjective memory problems and lower quality of life in older adults (Bazargan \& Bazargan, 1997; Commissaris et al., 1998; Derouesné et al., 1989; Derouesné et al., 1999; Verhaeghen et al., 2000). The first study (Derouesné et al., 1999) found a correlation of $r=-.33(p<.001)$ in the young $(20-49$ years) and $r=-.28$ $(p<.001)$ in the older (49-85 years) age group between subjective memory complaints and wellbeing. They conducted a multivariate stepwise regression and found that wellbeing $\left(\mathrm{F}_{2,180}=14.7\right)$ together with anxiety $\left(\mathrm{F}_{1,181}=22.6\right)$ 
were related to subjective memory complaints $(p<.001)$. The second study (Commissaris et al., 1998) compared participants who considered themselves forgetful with participants who had no complaints about their memory. The average score of the forgetful participants on the questionnaire to measure satisfaction with life was 38.9 and that of the non-forgetful participants was 40.4 (range 15-45). After performing a $t$-test, it appeared that participants who were forgetful were less satisfied with life $(t=5.5, p<.001)$. In the third study, an earlier study from Derouesné et al. (1989), they also found that memory complaints were strongly related with low scores in the wellbeing questionnaire. However, depression and not wellbeing was the unique variable related to severity of memory complaints. The mean score of participants with minor memory complaints on the questionnaire to measure wellbeing was $74.5( \pm 13.4)$ and of participants with major memory complaints was $68.8( \pm 16.2)$ (range 0$110)$. No values of the analysis were reported in the paper. The fourth study (Bazargan \& Bazargan, 1997) found a correlation of $r=.43(p<.001)$ between self-reported memory functioning and wellbeing. They also analyzed the predictive value of subjective memory complaints on measures of wellbeing and found that self-reported memory function was the strongest predictor of psychological wellbeing $(\beta=.25, p<.001)$ after conducting multiple regression analysis. Finally, the fifth study (Verhaeghen et al., 2000) reported a path analysis performed with LISREL 8 . In the final model, wellbeing received a total effect of .20 of the coping variable, .14 of the locus of control variable, .12 of the capacity variable, .10 of the change variable, .06 of the seriousness variable and .03 of the anxiety variable. The total effect of each of these variables on wellbeing is the sum of all direct and indirect effects from the variable to wellbeing through all possible paths linking the two.

In summary, all studies reported a relation between subjective memory complaints and lower quality of life. In addition, one study reported that depression and not wellbeing was the unique variable related with severity of memory complaints.

\section{Discussion}

Five papers on the relation between subjective memory complaints and quality of life fulfilled the inclusion criteria (Bazargan \& Bazargan, 1997; Commissaris et al., 1998; Derouesné et al., 1989; Derouesné et al., 1999; Verhaeghen et al., 2000). The methodological quality of the studies was moderate to high, considering the mean of 31 out of 43 points (72\%). All identified studies confirmed the existence of a relation between forgetfulness and a lower level of wellbeing (Bazargan \& Bazargan, 1997; Commissaris et al., 1998; Derouesné et al., 1989; Derouesné et al., 1999; Verhaeghen et al., 2000).

One of the five studies confirmed that memory complaints were strongly related to low wellbeing, but found that symptoms of depression, and not wellbeing, was the unique variable related to severity of memory complaints 
(Derouesné et al., 1989). Additionally, Derouesné et al. (1999) found that symptoms of anxiety together with wellbeing was related to subjective memory complaints. The finding that depression and anxiety are related to subjective memory complaints is a plausible finding, because negative affect and mood are often seen as a part of wellbeing (Diener \& Suh, 1998; Felce \& Perry, 1995). Furthermore, previous research has shown that subjective memory complaints are associated with symptoms of depression (Ponds et al., 1997) and anxiety (Comijs, Deeg, Dik, Twisk, \& Jonker, 2002). Thus, symptoms of depression seem to be related to both perceived forgetfulness and quality of life. The relation between forgetfulness and quality of life might therefore be mediated by symptoms of depression.

Another way to explain the relation between subjective memory complaints and diminished wellbeing might be the fear of dementia that is induced by individuals with perceived forgetfulness. Many individuals are afraid that their subjective memory complaints are a sign of early dementia (Commissaris, Verhey, Ponds, Jolles, \& Kok, 1994). However, there is no conclusive support that subjective memory complaints are strong predictors of incipient dementia. Whereas several studies failed to find a relationship between subjective memory complaints and objective performances (Bolla, Lindgren, Bonaccorsy, \& Bleecker, 1991; Jorm et al., 1997), others did report an association between subjective memory complaints and diminished cognitive performance (Jonker et al., 2000; Jorm, Christensen, Korten, Jacomb, \& Henderson, 2001). Therefore, it cannot be precluded that the relation between perceived forgetfulness and low wellbeing is actually resulting from an incipient neurodegenerative disorder such as Alzheimer's disease. Another explanation for the relation between forgetfulness and quality of life might be that a diminished quality of life is causing forgetfulness, and not that forgetfulness is causing the diminished quality of life. However, more research is needed to determine the causal relation between these two factors.

Overall, all five studies are in line with a possible relationship between memory complaints and a low quality of life. These findings appear to be robust because the five studies are characterized by a wide variety of instruments. One study used life satisfaction scales to measure participants' quality of life (Commissaris et al., 1998), three other studies used wellbeing questionnaires (Bazargan \& Bazargan, 1997; Derouesné et al., 1989; Derouesné et al., 1999) and one study used a life satisfaction scale in combination with a depression scale as a measure of wellbeing (Verhaeghen et al., 2000). Variation was also found in the measurement of subjective memory function, which was measured with subjective memory scales (Derouesné et al., 1989; Derouesné et al., 1999), memory functioning questionnaires (Bazargan \& Bazargan, 1997), and metamemory scales (Verhaeghen et al., 2000).

Considering the methodological issue of this review, there seems to be a lack of longitudinal studies on the effect of self-reported memory function on the wellbeing of older individuals. Future research should consist of properly 
designed studies that focus on the longitudinal effects of memory complaints on wellbeing. This might give more insight in the causal relation between memory complaints and quality of life. It might be that the memory complaints are not influencing someone's wellbeing but that poor wellbeing is causing the subjective complaints. Furthermore, the effect sizes of the results were not profoundly discussed in the studies. More research is needed to give insight into the clinical significance and importance of the relationship between quality of life and subjective memory complaints. Another topic of interest for further research could also be the different impact of a more serious cognitive impairment, such as MCI and dementia, on someone's quality of life. Previous research has shown that an objective cognitive disorder is not always associated with a diminished quality of life, as is reported in several studies (Comijs, Dik, Aartsen, Deeg, \& Jonker, 2005; Katsuno, 2005; Ready, Ott, \& Grace, 2004; Selwood, Thorgrimsen, \& Orrell, 2005). This is contradictory to the expectations of healthy individuals without a cognitive dysfunction (Patrick, Starks, Cain, Uhlmann, \& Pearlman, 1994). The fear of developing dementia, which is often underlying the subjective memory complaints, might have a major impact on quality of life. However, more research is needed before conclusions can be drawn. The findings of the present study emphasize the impact that perceived forgetfulness can have on quality of life. Apparently, individuals with perceived forgetfulness are a population at risk to low wellbeing. It might therefore be important to design health educational activities and psycho-educational interventions for individuals with subjective memory complaints to reduce the memory complaints and improve quality of life.

It should be noted that this review included a relatively small number of articles because few studies were available on the relation between subjective memory function and wellbeing. However, to our knowledge all published articles on the relation between subjective memory complaints and quality of life were included. We are reasonably confident that we did not miss relevant articles because we searched Pubmed, PsychINFO as well as Embase, made use of a combination of search terms covering a wide range of the field, and the selected articles were hand searched to find additional relevant papers. Because no other literature was available, this review provides a complete overview of the studies concerning forgetfulness and wellbeing. It should also be noted that two studies did not explicitly state that individuals with objective cognitive dysfunction were excluded from the study population (Bazargan \& Bazargan, 1997; Verhaeghen et al., 2000). However, it is not probable that participants with dementia or other cognitive dysfunction were present in these studies, because only healthy individuals were investigated in the studies.

In summary, the findings of the five methodologically adequate studies suggest a relation between memory complaints and a lower quality of life of older individuals, even though there is a substantial heterogeneity in the methodology of the studies. This finding emphasizes that memory complaints are related to a negative quality of life. It is therefore important to acknowledge 
subjective memory complaints as a serious issue. However, more research is needed to explore the relationship between subjective memory complaints and quality of life, especially with regard to the influence of depression and objective memory performance. In addition, further research should be conducted to investigate the longitudinal effect of memory complaints on someone's quality of life in more detail.

\section{Acknowledgements}

We thank Dick Willems for his methodological and statistical advice. 


\section{References}

Bazargan, M., \& Bazargan, S. (1997). Self-reported memory function and psychological wellbeing among elderly African American persons. Journal of Black Psychology, 23(2), 103-119.

Blazer, D. G., Hays, J. C., Fillenbaum, G. G., \& Gold, D. T. (1997). Memory complaint as a predictor of cognitive decline: a comparison of African American and White elders. Journal of Aging and Health, 9(2), 171-184.

Bolla, K. I., Lindgren, K. N., Bonaccorsy, C., \& Bleecker, M. L. (1991). Memory complaints in older adults. Fact or fiction? Archives of Neurology, 48(1), 61-64.

Bryan, J., \& Calvaresi, E. (2004). Associations between dietary intake of folate and vitamins B-12 and B-6 and self-reported cognitive function and psychological well-being in Australian men and women in midlife. The Journal of Nutrition, Health and Aging, 8(4), 226-232.

Capsi, A., \& Elder, G. H., Jr. (1986). Life satisfaction in old age: linking social psychology and history. Psychology and Aging, 1(1), 18-26.

Comijs, H. C., Deeg, D. J. H., Dik, M. G., Twisk, J. W. R., \& Jonker, C. (2002). Memory complaints: the association with psycho-affective and health problems and the role of personality characteristics. A 6-year follow-up study. Journal of Affective Disorders, 72, 157-165.

Comijs, H. C., Dik, M. G., Aartsen, M. J., Deeg, D. J., \& Jonker, C. (2005). The impact of change in cognitive functioning and cognitive decline on disability, well-being, and the use of healthcare services in older persons. Results of Longitudinal Aging Study Amsterdam. Dementia and Geriatric Cognitive Disorders, 19(5-6), 316-323.

Commissaris, C. J. A. M., Ponds, R. W. H. M., \& Jolles, J. (1998). Subjective forgetfulness in a normal Dutch population: possibilities for health education and other interventions. Patient Education and Counseling, 34, 25-32.

Commissaris, C. J. A. M., Verhey, F. R. J., Ponds, R. W. H. M., Jolles, J., \& Kok, G. (1994). Patient education about normal forgetfulness and dementia: importance and effects. Patient Education and Counseling, 25, 163-167.

De Vet, H. C. W., De Bie, S. E., Verhagen, A., Sijpkes, P., \& Knipschild, P. (1997). Systematic reviews on the basis of methodological criteria. Physiotherapy, 83(6), 284-289.

Deeg, D. J., Haga, H., Yasumura, S., Suzuki, T., Shichita, K., \& Shibata, H. (1992). Predictors of 10 -year change in physical, cognitive and social function in Japanese elderly. Archives of Gerontology and Geriatrics, 15(2), 163-179.

Derouesné, C., Alperovitch, A., Arvay, N., Migeon, P., Moulin, F., Vollant, M., et al. (1989). Memory complaints in the elderly: a study of 367 community-dwelling individuals from 50 to 80 years old. Archives of Gerontology and Geriatrics. Supplement, 1, 151-163.

Derouesné, C., Lacomblez, L., Thibault, S., \& LePoncin, M. (1999). Memory complaints in young and elderly subjects. International Journal of Geriatric Psychiatry, 14(4), 291301.

Diener, E., \& Suh, E. M. (1998). Subjective well-being and age: an international analysis. Annual Review of Gerontology and Geriatrics, 17, 304-324.

Felce, D., \& Perry, J. (1995). Quality of life: its definition and measurement. Research in Developmental Disabilities, 16(1), 51-74.

Jonker, C., Geerlings, M. I., \& Schmand, B. (2000). Are memory complains predictive for dementia? A review of clinical and population-based studies. International Journal of Geriatric Psychiatry, 15, 983-991.

Jorm, A. F., Christensen, H., Korten, A. E., Henderson, A. S., Jacomb, P. A., \& Mackinnon, A. (1997). Do cognitive complaints either predict future cognitive decline or reflect past cognitive decline? A longitudinal study of an elderly community sample. Psychological Medicine, 27, 91-98. 
Jorm, A. F., Christensen, H., Korten, A. E., Jacomb, P. A., \& Henderson, A. S. (2001). Memory complaints as a precursor of memory impairment in older people: a longitudinal analysis over 7-8 years. Psychological Medicine, 31(3), 441-449.

Katsuno, T. (2005). Dementia from the inside: how people with early-stage dementia evaluate their quality of life. Ageing and Society, 25, 197-214.

Kim, K. A., \& Mueller, D. J. (1997). Memory, self-efficacy, and adaptability in korean american older adults: a collective study of four cases. Educational Gerontology, 23, 407-423.

Lipsey, M., \& Wilson, D. (2001). Practical meta-analyses. California: Thousand Oaks Sage Publications.

McDougall, G. J. (1994). Predictors of metamemory in older adults. Nursing Research, 43(4), 212-218.

McDougall, G. J., Montgomery, K. S., Eddy, N., Jackson, E., Nelson, E., Stark, T., et al. (2003). Aging memory self-efficacy: elders share their thoughts and experience. Geriatric Nursing, 24(3), 162-168.

Neri, M., Andermarcher, E., Pradelli, J. M., \& Salvioli, G. (1995). Influence of a double blind pharmacological trial on two domains of well-being in subjects with age associated memory impairment. Archives of Gerontology Geriatrics, 21(3), 241-252.

Patrick, D. L., Starks, H. E., Cain, K. C., Uhlmann, R. F., \& Pearlman, R. A. (1994). Measuring preferences for health states worse than death. Medical Decision Making, 14(1), 9-18.

Ponds, R. W., Commissaris, K. J., \& Jolles, J. (1997). Prevalence and covariates of subjective forgetfulness in a normal population in The Netherlands. International Journal of Aging and Human Development, 45(3), 207-221.

Ready, R. E., Ott, B. R., \& Grace, J. (2004). Patient versus informant perspectives of Quality of Life in Mild Cognitive Impairment and Alzheimer's disease. International Journal of Geriatric Psychiatry, 19(3), 256-265.

Selwood, A., Thorgrimsen, L., \& Orrell, M. (2005). Quality of life in dementia--a one-year follow-up study. International Journal of Geriatric Psychiatry, 20(3), 232-237.

Starr, J. M., Deary, I. J., \& Macintyre, S. (2003). Associations with successful ageing in the "Healthy Old People in Edinburgh" cohort: being well, fit and healthy. Aging Clinical and Experimental Research, 15(4), 336-342.

Steen, G., Hagberg, B., Johnson, G., \& Steen, B. (1987). Cognitive function, cognitive style and life satisfaction in a 68-year-old male population. Comprehensive Gerontology [B], $1(2), 54-61$.

Verhaeghen, P., Geraerts, N., \& Marcoen, A. (2000). Memory complaints, coping, and well-being in old age: a systemic approach. Gerontologist, 40(5), 540-548.

Wolters, G., Bemelmans, K. J., Spinhoven, P., Theunissen, I., \& Van der Does, A. J. W. (1996). Immediate and intermediate-term effectiveness of a memory training program for the elderly. The Journal of Cognitive Rehabilitation, 16-22. 


\section{Appendix 1}

List of criteria for the methodological assessment of observational research

\begin{tabular}{|c|c|}
\hline Criteria & Obtainable points \\
\hline A Research population and design & 22 \\
\hline $\begin{array}{l}\text { 1. Have the research population and the applied inclusion } \\
\text { and exclusion criteria been described? }\end{array}$ & 6 \\
\hline $\begin{array}{l}\text { 2. Have the differences and similarities between cases } \\
\text { and controls been described? For example education, age, } \\
\text { sex, social-economic background, self-referral / Are the } \\
\text { differences between the groups described? }\end{array}$ & $\begin{array}{l}\text { Only cases in the study } \\
\text { (well described): } 3 \\
\text { Cases and controls } \\
\text { (well described): } 6\end{array}$ \\
\hline $\begin{array}{l}\text { 3. What is the participation rate of the study? / How many } \\
\text { summoned people actually participate in the research? / } \\
\text { Have measures to prevent selection bias been taken? }\end{array}$ & $\begin{array}{l}\text { Participation rate } 50-80 \%: 1 \\
\text { Participation rate }>80 \%: 2\end{array}$ \\
\hline 4. Is the study size of the research sufficient? & $\begin{array}{l}N>56: 2 \\
N>128: 4 \\
N>788: 6 \\
\text { Power analysis performed: } 6\end{array}$ \\
\hline 5. Have measures to prevent reactivity been taken? & 2 \\
\hline B Measurement of memory complaints & 5 \\
\hline $\begin{array}{l}\text { 1. Has the validity and reliability of the measurement } \\
\text { instruments been determined (in an earlier or in the same } \\
\text { article)? }\end{array}$ & 3 \\
\hline 2. Are several aspects of memory complaints measured? & 2 \\
\hline $\mathrm{C}$ Measurement of quality of life & 5 \\
\hline $\begin{array}{l}\text { 1. Has the validity and reliability of the measurement } \\
\text { instruments been determined (in an earlier or in the same } \\
\text { article)? }\end{array}$ & 3 \\
\hline 2. Are several aspects of quality of life measured? & 2 \\
\hline D Analysis and data presentation & 11 \\
\hline 1. Are the data clearly and fully presented? & 3 \\
\hline $\begin{array}{l}\text { 2. Has the analysis been corrected for relevant } \\
\text { confounders? }\end{array}$ & 2 \\
\hline $\begin{array}{l}\text { 3. Has, besides the statistical significance, the clinical } \\
\text { significance/effect size also been described? }\end{array}$ & 2 \\
\hline $\begin{array}{l}\text { 4. Have statistical methods been used in an appropriate } \\
\text { manner? }\end{array}$ & 4 \\
\hline Total number of obtained points & 43 \\
\hline
\end{tabular}




\section{Forgetfulness is associated with lower quality of life: a 9-year follow-up in older participants from the Maastricht Aging Study}




\section{Abstract}

A large group of healthy older adults $(\mathrm{N}=412,54-91$ years $)$ from the Maastricht Aging Study was studied to determine whether forgetfulness was related to quality of life (QOL) and if forgetfulness predicted a change in QOL over time. Data obtained at baseline, 3, 6, and 9-year follow-up measurements were analyzed with Linear Mixed Models. Four domains of QOL were used as outcome measures, such as satisfaction with life, mental well-being, and symptoms of anxiety and depression. Forgetfulness was associated with an overall reduced QOL. The relation between forgetfulness and low satisfaction with life was significant in younger (54-69 years), but not in older participants (70-91 years). Furthermore, there was a significant increase in symptoms of anxiety per year in forgetful individuals when compared with non-forgetful individuals. Overall, these findings emphasize the impact of forgetfulness on a person's life. 


\section{Introduction}

Many people perceive themselves as being forgetful. The prevalence of forgetfulness in 1,971 volunteers aged between 25 and 85 in the Maastricht Aging Study was $40 \%$ (Ponds, Commissaris, \& Jolles, 1997). This prevalence increased with age, varying from $41 \%$ in the 55 to 65 age group and $52 \%$ in the 70 to 85 age group. Much hindrance and worries were experienced as a result of this forgetfulness in daily life. Approximately $60 \%$ of forgetful middle-aged individuals perceived much hindrance from their forgetfulness in daily life, and approximately $70 \%$ of these individuals indicated they were very worried about their forgetfulness (Commissaris, Ponds, \& Jolles, 1998). In addition, many individuals with forgetfulness are interested in an intervention to improve their memory. For example, approximately $25 \%$ of 414 participants were interested in an intervention targeted at memory function (Mol, de Groot, Willems, \& Jolles, in press). Also, many individuals were interested in a memory training programme, while others were more interested in studying a dedicated book or a brochure about memory and forgetfulness (Valentijn et al., 2005). Apparently, individuals with forgetfulness are uncomfortable with their memory complaints and tend to seek more information about memory, forgetfulness and the cognitive changes which accompany the aging process, or sometimes consult their general practitioner about their memory complaints (Commissaris et al., 1996). However, up to $16 \%$ of persons who were referred to a memory clinic for cognitive complaints had no objective deficits in cognitive testing, but nevertheless seek help (Verhey et al., 1993). It therefore seems plausible that forgetfulness may interfere with daily activities and affect a person's wellbeing and quality of life.

There is only a small number of studies which have looked into the relation between subjective memory complaints and quality of life in older people (for example; Bazargan \& Bazargan, 1997; Commissaris et al., 1998; Derouesné et al., 1989; Derouesné, Lacomblez, Thibault, \& LePoncin, 1999; Verhaeghen, Geraerts, \& Marcoen, 2000). All of these studies did find a relation between forgetfulness and a lower quality of life. The studies of Derouesné et al. $(1989 ;$, 1999) showed a significant negative correlation between memory complaints and scores on the Wellbeing Questionnaire. Commissaris et al. (1998) found that forgetful participants aged between 25 and 85 were less satisfied with life, as measured with the Satisfaction with Life Scale. Furthermore, Bazargan \& Bazargan (1997) found in 998 participants aged between 62 and 99 that subjective memory functioning was the best predictor of psychological wellbeing. However, these previous studies presented only crosssectional data. No information is available on the question whether long-term forgetfulness indeed might reduce quality of life over time. Also, these studies did not look at differential age groups in the older population but considered the older population as one entity. This is unfortunate, as it could very well be that 
forgetfulness in the older old individuals is appreciated differently than in younger old individuals.

It was hypothesized that in individuals above approximately 70 years forgetfulness might be more loosely associated with quality of life than in the younger age group (below 70). Older individuals are probably not active in a job anymore, are not experiencing workload, and might therefore perceive less hindrance from their forgetfulness in daily life. Forgetfulness in older individuals may be appreciated differently and forgetfulness might be more accepted in this age range than in individuals who are confronted with agerelated forgetfulness at an earlier stage in life. Global differences between age groups were previously studied by Derouesné et al. (1999), who showed that subjective memory complaints in individuals under 50 were specifically related to depression, while the subjective memory complaints in individuals above 50 were related to depression as well as wellbeing. In the present study we set out to make a more detailed differentiation of the age groups in order to gain insight in the relation between forgetfulness and wellbeing in more distinct age groups.

The aim of the present study was to determine whether forgetfulness in healthy older adults is related to a lower quality of life and if forgetfulness can be predictive of a change in quality of life over time. We also investigated these aims in two age groups, younger (54-69 years) and older participants (70-91 years). For this purpose, we studied a large group of participants from the longitudinal Maastricht Aging Study (MAAS). Data for this study were collected at baseline, and after 3, 6 and 9 years of follow-up (Jolles, Houx, Van Boxtel, \& Ponds, 1995). The terms forgetfulness, memory problems and subjective memory complaints indicate perceived memory failures, and are used interchangeably.

Quality of life in the present paper was defined as a multidimensional concept, because it is in itself a broad and elusive construct (Diener \& Suh, 1998; Felce \& Perry, 1995). Several reviews have tried to summarize the different perspectives and definitions of the notion of quality of life (Berlim \& Fleck, 2003; Diener \& Suh, 1998; Diener, Suh, Lucas, \& Smith, 1999; Felce \& Perry, 1995). However, no singular and unequivocal definition can be given. Definitions of quality of life often consist of components such as life satisfaction (Diener \& Suh, 1998), wellbeing (Mount \& Cohen, 1995), pleasant affect, and mood (Diener \& Suh, 1998; Felce \& Perry, 1995). Thus, with the four outcome measures chosen in the present study, i.e. satisfaction with life, mental wellbeing and symptoms of depression and anxiety, we tried to cover the different components that are commonly used in definitions of quality of life. 


\section{Methods}

\section{Sample and procedure}

This study was conducted as part of an ongoing longitudinal study into the determinants of cognitive aging, the Maastricht Aging Study (MAAS) (Jolles et al., 1995; Van Boxtel et al., 1998). The 1,823 participants who were enrolled in the MAAS programme were randomly recruited from a general practitioner's register in the south of the Netherlands and were aged between 24 and 81 at baseline (Metsemakers, Hoppener, Knottnerus, Kocken, \& Limonard, 1992). The participants had no medical condition that could interfere with normal cognitive functioning. Exclusion criteria were dementia, overt cerebrovascular disease, chronic neurological pathology, mental retardation and major psychiatric disorders. Participants were stratified for three demographic variables that are known to be related to cognitive outcome measures: age (12 discontinuous age classes of 5 years, ranging from $25 \pm 1,30 \pm 1$, up to $80 \pm 1$ year), sex, and general ability (two levels, based on achievement in professional life). All participants filled in a questionnaire at baseline and after 3, 6 and 9 years.

For this study, we selected participants who were aged 54 years or older at baseline assessment and who had a score of 24 or more on the Mini-Mental State Examination (MMSE: (Folstein, Folstein, \& McHugh, 1975)). This resulted in a subset of 412 individuals. The drop-out rate after 3, 6 and 9 years was 20,26 and $34 \%$, respectively (see Table 1). In total 263 participants were reassessed at nine years $(64 \%) ; 149$ participants were lost to follow-up due to death $(n=54)$, personal circumstances, e.g. no further interest in participation or experienced burden $(n=79)$, or incomplete or unreliable data $(n=16)$. Participants who dropped out of the study after 3,6 or 9 years were significantly older $(68.4$ vs $63.9 ; t(410)=-6.36, p<.01)$ and had a lower score on the MMSE $(27.6$ vs $28.2 ; t(410)=-3.22, p<.01)$ than non-drop-outs at baseline.

\section{Measurements}

Educational level was measured on an 8-point scale, according to a Dutch scoring system, ranging from primary to university education (De Bie, 1987). Perceived forgetfulness was measured with the question 'Do you consider yourself to be forgetful?' (yes/no). This single question has previously been successfully used to determine subjective memory complaints (Bassett \& Folstein, 1993; Commissaris et al., 1998; Mol, Van Boxtel, Willems, \& Jolles, 2006).

\section{Outcome measures}

The Satisfaction With Life Scale (SWLS: (Diener, Emmons, Larsen, \& Griffin, 1985)) was used to measure general life satisfaction. Participants were asked to 
rate five statements in terms of satisfaction with their personal situation on a 7point Likert scale. The range of the scale is 5-35, a higher score indicating greater satisfaction with life.

To measure mental wellbeing, the mental component of the Short Form36 (SF-36), a 36-item questionnaire on general health and the quality of life, was used (Ware, Snow, Kosinski, \& Gandek, 1993). The range of the score on the mental wellbeing component of the SF-36 is 17-63, with a higher score indicating a higher level of wellbeing. Although available, the physical component of the SF-36 was not investigated in this study, because no prior hypothesis was present on the effects of forgetfulness on physical wellbeing.

Feelings of depression or anxiety were measured with two subscales of the Symptom Checklist (SCL-90: (Derogatis, 1977), Dutch version (Arrindell \& Ettema, 1986)). The SCL-90 is a multidimensional self-report inventory of psychopathology. Scores for the anxiety subscale range from 0-50, with a higher score indicating more symptoms of anxiety. Scores for the depression subscale range from $0-80$, with a higher score indicating more depressive symptoms. At the third measurement (after six years), no data were collected on the SCL-depression and SCL-anxiety scores.

\section{Statistical analyses}

Linear Mixed Models (LMM) were used to test our hypotheses. LMM offers several advantages in the analysis of longitudinal data compared with more conventional approaches, such as General Linear Model (GLM). Most importantly, missing observations do not result in exclusion of all data of an individual case from the analysis. Furthermore, explanatory variables in the model may be varying over time, in this case 'forgetfulness' (Hox, 2002). The statistical package used for the analyses was the SPSS version 11 programme series for Apple Macintosh.

LMM were used to test whether forgetfulness is related to a lower quality of life and if forgetfulness is a predictor of a change in quality of life over time. Besides forgetfulness and the forgetfulness by age interaction term, the model included the variables age, education, sex and the intercept as fixed factors and intercept and age as random factors. The coefficient of age indicated the individual linear deterioration in the outcome variables per year. Initially, the covariance structure of the random effects was set at unstructured (no restrictions), but when the model did not converge the covariance of the random effects was set at 0 (diagonal).

LMM was also used to determine whether forgetfulness is related to a lower quality of life and if forgetfulness is a predictor of a change in quality of life over time in younger (54-69 years) and in older participants (70-91 years). To achieve this, the participants were split into a younger $(<70)$ and an older $(\geq 70)$ group. The model described above was fitted twice, once with participants aged between 54 and 69 as the reference group, and once with participants aged 
between 70 and 91 as the reference group. With this approach, one model is used to analyse both age-groups and estimates of forgetfulness and the forgetfulness by age interaction term for each age group are yielded without losing power. Meanwhile, it was possible to compare the parameters of both age groups, because all other variables were controlled for. The significance level was set at $\alpha=.05$.

\section{Results}

\section{Participants' characteristics}

Participants' characteristics are shown in Table 1. The percentage of forgetfulness increased slightly from $36 \%$ at baseline, to $41 \%$ at the 9 -year follow-up.

\section{Table 1}

Participants' characteristics and participants' mean scores $( \pm$ SD) on all outcome measures at baseline, 3, 6, and 9-year follow-up $(N=412)$.

\begin{tabular}{|c|c|c|c|c|}
\hline & $\begin{array}{l}\text { Baseline } \\
(n=412)\end{array}$ & $\begin{array}{l}\text { 3-year } \\
(n=330)\end{array}$ & $\begin{array}{l}\text { 6-year } \\
(n=305)\end{array}$ & $\begin{array}{l}9 \text { 9-year } \\
(n=263)\end{array}$ \\
\hline Education (8-point scale) & 3.1 & & & \\
\hline Sex (male/female ratio) & $50 / 50$ & $53 / 47$ & $51 / 49$ & $51 / 49$ \\
\hline Age (average years) & $65.8( \pm 7.4)$ & $68.5( \pm 7.2)$ & $71.1( \pm 7.3)$ & $72.9( \pm 6.9)$ \\
\hline MMSE-score & $27.9( \pm 1.6)$ & $28.1( \pm 1.7)$ & $28.2( \pm 1.7)$ & - \\
\hline$\%$ Forgetfulness & $36 \%$ & $36 \%$ & $40 \%$ & $41 \%$ \\
\hline $\begin{array}{l}\text { Satisfaction with Life (SWLS) } \\
\text { (range 5-35) }\end{array}$ & $25.5( \pm 5.5)$ & $25.9( \pm 5.6)$ & $24.3( \pm 5.9)$ & $24.9( \pm 5.2)$ \\
\hline $\begin{array}{l}\text { Mental well-being (SF-36) } \\
\text { (range 17-63) }\end{array}$ & $53.5( \pm 7.7)$ & $53.0( \pm 8.9)$ & $52.1( \pm 8.9)$ & $51.5( \pm 8.9)$ \\
\hline $\begin{array}{l}\text { Symptoms of depression (SCL-90) } \\
\text { (range 0-80) }\end{array}$ & $21.1( \pm 6.2)$ & $22.2( \pm 6.9)$ & - & $23.4( \pm 7.6)$ \\
\hline $\begin{array}{l}\text { Symptoms of anxiety (SCL-90) } \\
\text { (range } 0-50 \text { ) }\end{array}$ & $12.9( \pm 4.4)$ & $13.2( \pm 4.8)$ & - & $13.4( \pm 4.6)$ \\
\hline
\end{tabular}

\section{Relation between forgetfulness and quality of life}

Table 2 presents the data on the effects of forgetfulness and the interaction term forgetfulness by age on the four outcome measures, using the non-forgetful individuals as a reference group. As regards the main effect of forgetfulness, the estimate represents the mean difference in score for forgetful individuals compared with non-forgetful individuals at baseline. Regarding the interaction term forgetfulness by age, the estimate represents the increase or decrease with age in mean difference for forgetful individuals compared with non-forgetful individuals. 
The results show that forgetfulness was significantly related to lower satisfaction with life, lower mental wellbeing, and to more symptoms of depression and anxiety. Furthermore, the forgetfulness by age interaction term was not significant for satisfaction with life, mental wellbeing and symptoms of depression. This indicates that the difference between forgetful and nonforgetful individuals on the outcome measures was not age dependent.

For symptoms of anxiety, the estimate of forgetfulness was $1.46(p<$ $.01)$ and for the interaction term $0.1(p<.01)$. This indicates that forgetful individuals score 1.46 points higher on the SCL-90 than non-forgetful individuals at baseline, and for forgetful individuals this difference increases by 0.1 points on the SCL-90 per year, compared with non-forgetful individuals.

\section{Table 2}

Main and interaction effects of forgetfulness on the measures of quality of life in the whole age range, using Linear Mixed Model analysis

\begin{tabular}{lllll}
\hline & Estimate & $F$ & $\mathrm{dF}$ & $p$ \\
\hline Satisfaction with life (SWLS) & & & & \\
$\quad$ Forgetfulness & -0.64 & 3.82 & 566.8 & $.05^{*}$ \\
$\quad$ Forgetfulness by age & 0.04 & 1.07 & 301.2 & .3 \\
$\quad$ Mental wellbeing (SF-36) & & & & \\
$\quad$ Forgetfulness & -2.57 & 23.9 & 679.4 & $.00^{* *}$ \\
$\quad$ Forgetfulness by age & 0.03 & 2.02 & 727.4 & .16 \\
Symptoms of depression (SCL-90) & & & & \\
$\quad$ Forgetfulness & 2.68 & 36.84 & 375.8 & $.00^{* *}$ \\
$\quad$ Forgetfulness by age & 0.08 & 2.09 & 218.8 & .15 \\
Symptoms of anxiety (SCL-90) & & & & \\
$\quad$ Forgetfulness & 1.46 & 27.69 & 437.2 & $.00^{* *}$ \\
$\quad$ Forgetfulness by age & 0.10 & 9.25 & 239.6 & $.00^{* *}$ \\
\hline
\end{tabular}

SWLS = Satisfaction with Life Scale; SF-36 = Short Form-36; SCL-90 = Symptom Checklist-90 $* p<.05 ; * * p<.01$

\section{Relation between forgetfulness and quality of life in two different age groups (54-69 years and 70-91 years)}

Table 3 presents the results of LMM analysis for both age groups separately. Looking at satisfaction with life, a main effect of forgetfulness was found in individuals younger than 69. However, no main effect was present in individuals older than 70 . Next, regarding mental wellbeing and symptoms of depression, a main effect of forgetfulness was found in both age groups, but no interaction was found between age and forgetfulness.

As for symptoms of anxiety, a main effect of forgetfulness and a significant interaction term age by forgetfulness was found in both age groups. This indicates that in both age groups forgetful individuals showed more symptoms of anxiety than non-forgetful individuals and forgetful individuals 
increased more per year in the number of reported symptoms of anxiety when compared with non-forgetful individuals.

Overall, only the variable satisfaction with life showed a specific differentiated age effect; forgetfulness was related to (reduced) quality of life in the younger age group (ages 54-69), but not in the older age group (ages 70-91).

\section{Table 3}

Main and interaction effects in Linear Mixed Model analysis in measures of quality of life by forgetfulness, for the age range from 54 to 69 and 70 to 91 separately

\begin{tabular}{|c|c|c|c|c|}
\hline & Estimate & $F$ & $\mathrm{dF}$ & $p$ \\
\hline \multicolumn{5}{|c|}{ Satisfaction with life (SWLS) } \\
\hline \multicolumn{5}{|l|}{ Age 54-69 } \\
\hline Forgetfulness & -0.86 & 4.3 & 797.5 & $.038 *$ \\
\hline Forgetfulness by age & 0.52 & 0.79 & 405.3 & .37 \\
\hline \multicolumn{5}{|l|}{ Age $70-91$} \\
\hline Forgetfulness & -0.37 & 0.67 & 777.9 & .41 \\
\hline Forgetfulness by age & -0.45 & 0.61 & 442.9 & .44 \\
\hline \multicolumn{5}{|l|}{ Mental wellbeing (SF-36) } \\
\hline \multicolumn{5}{|l|}{ Age 54-69 } \\
\hline Forgetfulness & -2.22 & 10.88 & 941.8 & $.00 * *$ \\
\hline Forgetfulness by age & -0.88 & 0.82 & 692.2 & .37 \\
\hline \multicolumn{5}{|l|}{ Age $70-91$} \\
\hline Forgetfulness & -3.10 & 16.74 & 856.0 & $.00 * *$ \\
\hline Forgetfulness by age & 0.88 & 0.82 & 719.0 & .37 \\
\hline \multicolumn{5}{|c|}{ Symptoms of depression (SCL-90) } \\
\hline \multicolumn{5}{|l|}{ Age 54-69 } \\
\hline Forgetfulness & 2.47 & 19.31 & 492.7 & $.00 * *$ \\
\hline Forgetfulness by age & 0.63 & 0.59 & 511.8 & .44 \\
\hline \multicolumn{5}{|l|}{ Age $70-91$} \\
\hline Forgetfulness & 3.09 & 23.04 & 486.7 & $.00 * *$ \\
\hline Forgetfulness by age & -0.63 & 0.59 & 511.8 & .44 \\
\hline \multicolumn{5}{|c|}{ Symptoms of anxiety (SCL-90) } \\
\hline \multicolumn{5}{|l|}{ Age 54-69 } \\
\hline Forgetfulness & 1.03 & 8.84 & 617 & $.00 * *$ \\
\hline Forgetfulness by age & 0.97 & 3.77 & 611.1 & $.05^{*}$ \\
\hline \multicolumn{5}{|l|}{ Age 70-91 } \\
\hline Forgetfulness & 2.00 & 24.87 & 617.2 & $.00 * *$ \\
\hline Forgetfulness by age & -0.97 & 3.77 & 611.1 & $.05 *$ \\
\hline
\end{tabular}

SWLS = Satisfaction with Life Scale; SF-36 = Short Form-36; SCL-90 = Symptom Checklist-90 $* p<.05 ; * * p<.01$ 


\section{Discussion}

Results of the present study show that in participants aged above 54, forgetfulness was related to a lower quality of life, as measured with the SWLS, the SF-36 mental scale, and the SCL-90 depression and anxiety symptom scales. The mean difference of satisfaction with life, mental wellbeing and symptoms of depression between forgetful individuals and non-forgetful individuals was not affected by age. However, as regards symptoms of anxiety, there was a significant increase in symptoms per year in forgetful individuals compared with non-forgetful individuals. Furthermore, when analyses were performed in two distinct age groups, it appeared that, with regard to satisfaction with life, the forgetful participants aged between 54 and 69 had a lower satisfaction with life than non-forgetful participants. In individuals over 70 , being forgetful was not related to a lower satisfaction with life.

The lower quality of life in individuals with subjective memory complaints might be caused by an increase in perceived cognitive effort associated with cognitive task performance. Since the speed and efficiency of information processing declines with advancing age (e.g., Madden, 2001; Salthouse, 1996), middle-aged adults need to invest more cognitive effort to achieve a specific performance level than younger individuals. The investment of more cognitive effort may lead to more tiredness, which will adversely affect quality of life. More research is needed to unravel the mechanisms proposed in this line of reasoning. The finding that forgetfulness is related to a lower quality of life, might also be caused by the fact that forgetfulness has been associated with variables such as neuroticism and conscientiousness (Pearman \& Storandt, 2004), poor subjective health (Comijs, Deeg, Dik, Twisk, \& Jonker, 2002), a poor social network, negative stereotypes of aging (Derouesné et al., 1989) and stressful life events (Bazargan \& Barbre, 1994). As these variables might also influence a person's quality of life, they may also cause individuals with forgetfulness to have a lower quality of life than individuals without forgetfulness. The relation between forgetfulness and quality of life could therefore be mediated by variables as described above.

Another explanation for the possible mechanism underlying the relation between subjective memory complaints and reduced wellbeing may be the fear of dementia that is experienced in quite some older individuals with forgetfulness (Commissaris et al., 1996). Many older individuals are afraid that their forgetfulness is a sign of incipient dementia. Still, there is no conclusive support that forgetfulness is a risk factor or determinant for the development of early dementia. Several studies have found that there is no direct association between memory complaints and objective performance (Bolla, Lindgren, Bonaccorsy, \& Bleecker, 1991; Jorm et al., 1997). However, other studies did find an association between subjective memory complaints and diminished cognitive performance (Jonker, Geerlings, \& Schmand, 2000; Jorm, 
Christensen, Korten, Jacomb, \& Henderson, 2001). These indecisive findings suggest the possibility that the relation between forgetfulness and low wellbeing could actually also result from incipient dementia. Further research using a different longitudinal design should be undertaken to evaluate this possibility.

The results of the present study show that the relation between forgetfulness and satisfaction with life was apparent in younger individuals, but not in older individuals. Apparently forgetfulness is appreciated differently at different ages. It has been previously shown that younger people tend to ascribe their forgetfulness to tension and emotional problems, lack of interest and poor concentration (Commissaris et al., 1998; Ponds et al., 1997). Older people, on the other hand, believe that their forgetfulness is attributed to less manageable and to more or less irreversible memory-intrinsic causes, such as 'aging' and 'always had a poor memory' (Commissaris et al., 1998; Ponds et al., 1997). In addition, older individuals may accept forgetfulness as being part of the aging process as opposed to younger individuals who are just confronted with agerelated forgetfulness (aged between 54 and 70). It is possible that these younger individuals may still be active in professional activities, experiencing workload, and may therefore perceive more direct hindrance from their forgetfulness in daily life. This emphasizes the need for health educational activities and psycho-educational interventions tailored to this specific age group, because it has been shown that educational activities achieve the best effect when they are tailored to the needs of the individual (Kreuter, Strecher, \& Glassman, 1999).

Furthermore, due to the longitudinal nature of this study we were able to find evidence for an increase in symptoms of anxiety in forgetful individuals with increasing age. The forgetfulness might reduce a person's functioning, which has a continuing impact on a person's daily life. When this forgetfulness persists over the years, it can increase the feelings of anxiety. So, anxiety is an important associated factor in forgetfulness that becomes more prominent when people grow older. Although our data do not warrant a causal interpretation, the present analysis does support the notion that forgetfulness in older individuals may be clinically relevant. It may cause symptoms of anxiety to increase and thus be relevant for the mental health of older individuals.

A possible limitation of the current study involves the non-random drop-out of participants. Older participants and participants with a lower score on the MMSE were more likely to drop out at some point in the study. This might have resulted in a select group of participants. However, drop-outs did not differ from participants with regard to the outcome variables at baseline. And although we accounted for missing data by using LMM, where missing observations do not result in exclusion of all data of an individual case, the results of the LMM can still be an underestimate of the effect.

In summary, the present study in a large longitudinal population-based sample, using data from four measurements over nine years, showed a relation between forgetfulness and four different aspects of quality of life. In addition, the relation between forgetfulness and satisfaction with life was stronger in 
younger individuals than in older individuals. Furthermore, when forgetfulness continues over time, symptoms of anxiety increase. Our findings underscore the impact of forgetfulness on a person's daily life, especially in younger old individuals. Tailored intervention strategies aimed at reducing forgetfulness, particularly in younger old individuals, may provide the benefit of an improved quality of life. 


\section{References}

Arrindell, W. A., \& Ettema, J. H. M. (1986). SCL-90. Manual for a multidimensional indicator of psychopathology [Handleiding bij een multidimensionele psychopathologie-indicator]. Lisse, the Netherlands: Swets \& Zeitlinger B.V.

Bassett, S. S., \& Folstein, M. F. (1993). Memory complaint, memory performance, and psychiatric diagnosis: a community study. Journal of Geriatric Psychiatry and Neurology, 6(2), 105-111.

Bazargan, M., \& Barbre, A. (1994). The effects of depression, health status, and stressful lifeevents on self-reported memory problems among aged blacks. International Journal of Aging and Human Development, 38, 351-362.

Bazargan, M., \& Bazargan, S. (1997). Self-reported memory function and psychological wellbeing among elderly African American persons. Journal of Black Psychology, 23(2), 103-119.

Berlim, M. T., \& Fleck, M. P. (2003). "Quality of life": a brand new concept for research and practice in psychiatry. Revista Brasileira de Psiquiatria, 25(4), 249-252.

Bolla, K. I., Lindgren, K. N., Bonaccorsy, C., \& Bleecker, M. L. (1991). Memory complaints in older adults. Fact or fiction? Archives of Neurology, 48(1), 61-64.

Comijs, H. C., Deeg, D. J. H., Dik, M. G., Twisk, J. W. R., \& Jonker, C. (2002). Memory complaints: the association with psycho-affective and health problems and the role of personality characteristics. A 6-year follow-up study. Journal of Affective Disorders, 72, 157-165.

Commissaris, C. J. A. M., Jolles, J., Verhey, F. R. J., Ponds, R. W. H. M., Damoiseaux, V., \& Kok, G. (1996). Forgetfulness or dementia? Who is worried and why? European Journal of Public Health, 6, 297-299.

Commissaris, C. J. A. M., Ponds, R. W. H. M., \& Jolles, J. (1998). Subjective forgetfulness in a normal Dutch population: possibilities for health education and other interventions. Patient Education and Counseling, 34, 25-32.

De Bie, S. E. (1987). Standaardvragen 1987: voorstellen voor uniformering van vraagstellingen naar achtergrondkenmerken en interviews [Standard questions 1987: proposal for uniformisation of questions regarding background variables and interview]. (2nd ed.). Leiden, The Netherlands: Leiden University Press.

Derogatis, L. R. (1977). SCL-90: administration, scoring and procedures manual-I for the R(evised) version. Baltimore: John Hopkins School of Medicine, Clinical Psychometrics Research unit.

Derouesné, C., Alperovitch, A., Arvay, N., Migeon, P., Moulin, F., Vollant, M., et al. (1989). Memory complaints in the elderly: a study of 367 community-dwelling individuals from 50 to 80 years old. Archives of Gerontology and Geriatrics. Supplement, 1, 151-163.

Derouesné, C., Lacomblez, L., Thibault, S., \& LePoncin, M. (1999). Memory complaints in young and elderly subjects. International Journal of Geriatric Psychiatry, 14(4), 291301.

Diener, E., Emmons, R., Larsen, J., \& Griffin, S. (1985). The satisfaction with life scale J Personality Assessment, 49(1), 71-75.

Diener, E., \& Suh, E. M. (1998). Subjective well-being and age: an international analysis. Annual Review of Gerontology and Geriatrics, 17, 304-324.

Diener, E., Suh, E. M., Lucas, R. E., \& Smith, H. L. (1999). Subjective well-being: three decades of progress. Psychological Bulletin, 125(2), 276-302.

Felce, D., \& Perry, J. (1995). Quality of life: its definition and measurement. Research in Developmental Disabilities, 16(1), 51-74.

Folstein, M. F., Folstein, S. E., \& McHugh, P. R. (1975). "Mini-mental state". A practical method for grading the cognitive state of patients for the clinician. Journal of Psychiatric Research, 12(3), 189-198. 
Hox, J. J. (2002). Multilevel analysis. Techniques and applications. New Jersey: Lauwrence Erlbaum Associates.

Jolles, J., Houx, P. J., Van Boxtel, M. P. J., \& Ponds, R. W. H. M. (1995). Maastricht Aging Study: determinants of cognitive aging. Maastricht: Neuropsych Publishers.

Jonker, C., Geerlings, M. I., \& Schmand, B. (2000). Are memory complains predictive for dementia? A review of clinical and population-based studies. International Journal of Geriatric Psychiatry, 15, 983-991.

Jorm, A. F., Christensen, H., Korten, A. E., Henderson, A. S., Jacomb, P. A., \& Mackinnon, A. (1997). Do cognitive complaints either predict future cognitive decline or reflect past cognitive decline? A longitudinal study of an elderly community sample. Psychological Medicine, 27, 91-98.

Jorm, A. F., Christensen, H., Korten, A. E., Jacomb, P. A., \& Henderson, A. S. (2001). Memory complaints as a precursor of memory impairment in older people: a longitudinal analysis over 7-8 years. Psychological Medicine, 31(3), 441-449.

Kreuter, M. W., Strecher, V. J., \& Glassman, B. (1999). One size does not fit all: the case for tailoring print materials. Annals of Behavioral Medicine, 21(4), 276-283.

Madden, D. J. (2001). Speed and timing of behavioral processes. In J. E. Birren \& K. W. Schaie (Eds.), Handbook of the psychology of aging (5th ed., pp. 288-312): Academic Press.

Metsemakers, J. F., Hoppener, P., Knottnerus, J. A., Kocken, R. J., \& Limonard, C. B. (1992). Computerized health information in The Netherlands: a registration network of family practices. British Journal of General Practice, 42(356), 102-106.

Mol, M. E. M., de Groot, R. H. M., Willems, D., \& Jolles, J. (in press). Public Education about Memory and Aging; Objective Findings and Subjective Insights. Educational Gerontology.

Mol, M. E. M., Van Boxtel, M. P. J., Willems, D., \& Jolles, J. (2006). Do subjective memory complaints predict cognitive dysfunction over time? A 6-year follow-up of the Maastricht Aging Study. International Journal of Geriatric Psychiatry, 21(5), 432-441.

Mount, B., \& Cohen, S. (1995). Quality of life in the face of life-threatening illness: what should we be measuring? Current Oncology, 2, 121-125.

Pearman, A., \& Storandt, M. (2004). Predictors of subjective memory in older adults. Journals of Gerontology Series B: Psychological Sciences and Social Sciences, 59B(1), p4-6.

Ponds, R. W., Commissaris, K. J., \& Jolles, J. (1997). Prevalence and covariates of subjective forgetfulness in a normal population in The Netherlands. International Journal of Aging and Human Development, 45(3), 207-221.

Salthouse, T. A. (1996). The processing-speed theory of adult age differences in cognition. Psychological Review, 103, 403-428.

Valentijn, S. A., van Hooren, S. A., Bosma, H., Touw, D. M., Jolles, J., Van Boxtel, M. P., et al. (2005). The effect of two types of memory training on subjective and objective memory performance in healthy individuals aged 55 years and older: a randomized controlled trial. Patient Education and Counseling, 57(1), 106-114.

Van Boxtel, M. P., Buntinx, F., Houx, P. J., Metsemakers, J. F., Knottnerus, A., \& Jolles, J. (1998). The relation between morbidity and cognitive performance in a normal aging population. Journals of Gerontology Series B: Psychological Sciences and Social Sciences, 53(2), M147-154.

Verhaeghen, P., Geraerts, N., \& Marcoen, A. (2000). Memory complaints, coping, and well-being in old age: a systemic approach. Gerontologist, 40(5), 540-548.

Verhey, F. R., Jolles, J., Ponds, R. W., Rozendaal, N., Plugge, L. A., de Vet, R. C., et al. (1993). Diagnosing dementia: a comparison between a monodisciplinary and a multidisciplinary approach. Journal of Neuropsychiatry and Clinical Neuroscience, $5(1), 78-85$.

Ware, J. J. E., Snow, K. K., Kosinski, M., \& Gandek, B. (1993). Sf-36 health survey manual and interpretation guide. Boston, MA: New England Medical Center, The health institute. 
5

\section{A study into the psychosocial determinants of forgetfulness: implications for future interventions}

Martine E.M. Mol, Robert A.C. Ruiter, Frans, R.J. Verhey, Jeanette B. Dijkstra \& Jelle Jolles 


\begin{abstract}
Many healthy individuals perceive themselves as forgetful and are interested in interventions to decrease their worries and increase their memory functioning. Educational interventions can be more effective when determinants are targeted that are known to predict forgetfulness. In the present study, first, a broad range of determinants was selected from the literature and from experiences in clinical settings. Second, the most important determinants among the selected ones were identified with multivariate regression analyses. The study had a cross-sectional design. A sample of 300 healthy participants above 54 years filled in a selfreport questionnaire. Findings indicated that low memory self-efficacy, high memory-related anxiety, negative attitude, and high subjective norm (e.g. anticipating negative evaluations by important others) were the most important correlates of forgetfulness. It is argued that future interventions should focus on the specified determinants to improve programme effectiveness in reducing subjective memory complaints.
\end{abstract}




\section{Introduction}

Memory complaints are common among older adults (Jonker, Geerlings, \& Schmand, 2000; Ponds, Commissaris, \& Jolles, 1997). In the Maastricht Aging Study, the prevalence of forgetfulness was approximately $41 \%$ among individuals aged between 55 to 65 years and 52\% among individuals aged between 79 to 85 years (Ponds et al., 1997). In another sample with individuals aged 65 years and older, the percentage of forgetful people was more than $50 \%$ (Blazer, Hays, Fillenbaum, \& Gold, 1997). Even though several studies suggested that subjective memory complaints are not directly associated with cognitive decline (Blazer et al., 1997; Jorm et al., 1997; Mol, Van Boxtel, Willems, \& Jolles, 2006), many individuals experience hindrance and worries from this forgetfulness in daily life (Commissaris, Ponds, \& Jolles, 1998).

A small proportion of people who perceive themselves forgetful is interested in memory training or other educational activities to decrease their worries and increase memory functioning (Commissaris et al., 1998). Most of these programmes aim to improve objective memory functioning, for example by training verbal episodic memory, information processing speed (Ball et al., 2002) or by remembering names (Schmidt, Dijkstra, Berg, \& Deelman, 1999). However, these programmes are not always effective in reducing subjective memory complaints. A study by Rasmusson, Rebok, Bylsma, and Brandt (1999) found that older adults who received a memory training showed no change in self-reports on memory functioning. Floyd and Scogin (1997) concluded in their meta-analysis that memory training led only to minimal reductions in subjective memory complaints.

To improve health issues, such as forgetfulness, it is important to get more insight in the health problem that is experienced by the individual. A possible way to understand and influence health problems is by gaining insight in the factors, or determinants, that influence health problems and by identifying the ones that significantly enforce or hinder health issues. Such a determinant analysis is an important step in designing health interventions according to systematic health promotion planning models, such as Intervention Mapping (Bartholomew, Parcel, Kok, \& Gottlieb, 2006) and the PRECEDE-PROCEED planning model (Green \& Kreuter, 2005). These models describe the development process of health promotion interventions development in a series of steps. Studying determinants of the health problem is a designated part within the first step of conducting a needs assessment. Overall, by aiming interventions at determinants that are known to be correlated to the identified health problem, educational interventions can be more effective (Bartholomew et al., 2006; Green \& Kreuter, 2005).

Yet, an overview of important psychosocial, psychiatric and behavioural determinants related to forgetfulness is lacking and no research has been done to determine the most essential correlates of forgetfulness. The 
present study therefore aimed to provide future interventions with relevant target variables by performing a determinant analysis of forgetfulness. We first selected from the literature and from experiences in clinical settings those determinants that were related to forgetfulness. We then tested by means of multivariate regression the relative importance of these determinants in the prediction of forgetfulness.

First, the databases of Pubmed and PsychInfo were searched for relevant literature to identify the most important psychological and psychiatric variables that are associated with forgetfulness. The following determinants were identified and used in the present study. A study by Hultsch, Hertzog, Dixon, and Davidson (1988) identified four dimensions of meta-memory that are related to forgetfulness. These dimensions encompass different aspects of subjective memory; that is, memory knowledge (i.e., factual knowledge about memory tasks), memory monitoring (i.e., self-knowledge about one's capacity), memory self-efficacy (i.e., beliefs about memory abilities and strengths), and memory-related anxiety (i.e., affective state generated by memory-demanding situations). The fear of dementia is also found to be an important factor associated with subjective forgetfulness (Commissaris et al., 1996), as well as symptoms of depression (Comijs, Deeg, Dik, Twisk, \& Jonker, 2002; Commissaris et al., 1998; Jonker et al., 2000), and therefore also included in the study.

Second, experiences in clinical settings suggest that two types of behaviour are related to forgetfulness. These are, on the one hand, performing $a$ high level of effort in using one's memory and, on the other hand, performing $a$ low level of effort in using one's memory. When someone puts high levels of effort in using his memory, for example by continuously learning large groceries lists by heart or by trying to remember all topics of the eight o'clock news, worrisome thoughts about failing the task might interfere with the attention needed for such a difficult task. This reduces the cognitive resources available for task-processing activities (Eysenck \& Calvo, 1992), and diminishes the ultimate performance on the task. As a consequence, forgetfulness can be experienced. On the other hand, when only little effort is put into remembering things, for example by avoiding a party where someone would have to remember the names of the guests, it will lead to inaction of using one's memory. This reduced memory use results in lesser recall and recognition, which can also cause forgetfulness. So, performing either much effort or little effort in the use of one's memory might generate forgetfulness. Both types of behaviour are therefore included as determinants in the present study.

Behaviour is thus believed to be an important determinant of forgetfulness, at least in clinical settings. Because educational interventions typically target behaviour indirectly by influencing psychosocial determinants of behaviour (Bartholomew et al., 2006), several of these determinants of behaviour are also included in the present study. These determinants are derived 
from the Theory of Planned Behaviour (Ajzen, 1991) which is the most influential explanatory model of behaviour. This model assumes that behaviour is mainly explained by the motivation to perform the behaviour (intention), which in turn is determined by three determinants: attitude, subjective norm and perceived behavioural control (Ajzen, 1991; Norman \& Conner, 2005). Attitude represents a person's overall evaluation of the proposed behaviour. In the context of the present study, attitude refers to a person's evaluation of his or her memory functioning. Subjective norm reflects beliefs about whether significant others approve of behaviour. In the present study, subjective norms reflect subjective beliefs about how significant others will approve or disapprove of subjective memory complaints. Perceived behaviour control indexes the degree to which people think they can control whether or not they are able to undertake a specific behaviour (Ajzen, 1991). Perceived behaviour control is considered as a similar construct as self-efficacy (Ajzen, 1998; Bandura, 1998). Because memory self-efficacy was already included as a determinant in the study, no extra variable of perceived behaviour control was composed. Furthermore, based on previous literature about the importance of social influence on health behaviour (De Vries, Backbier, Kok, \& Dijkstra, 1995) we included two additional social influence components in the present study. These are, perceived social support, which represents beliefs about how the individual perceives social support to improve subjective memory complaints, and societal beliefs, referring to beliefs about how the society reflects on forgetfulness.

In sum, interventions to reduce forgetfulness can be improved when they target determinants that are highly correlated to subjective feelings of forgetfulness. Therefore, the present study aims to establish the relation between the selected determinants and forgetfulness and to identify the determinant(s) with the most predictive value. The following determinants were found to be related to forgetfulness and therefore included in the present study: memory knowledge, memory monitoring, memory self-efficacy, memory-related anxiety, fear of dementia, symptoms of depression, behaviour leading to forgetfulness (much effort and little effort), attitude, social norm, social support and societal beliefs. To control for demographic characteristics, the factors age, sex and education were also included in the study.

Finally, we explored age-differences in the determinants. It might be possible that younger and older adults perceive their forgetfulness differently. Older individuals are usually not active in a job anymore, are not experiencing workload, and might perceive less hindrance from their forgetfulness in daily life. Forgetfulness might therefore be more accepted in older individuals than in individuals who are confronted with age-related forgetfulness at an earlier stage in life. Because individuals tend to acquire more information when the intervention is adjusted to the needs of the individuals (Brug \& De Vries, 1999), we studied whether younger (aged 53-72) and older individuals (aged 73-94) differed on determinants related to forgetfulness. 


\section{Methods}

\section{Participants and procedure}

The study population consisted of individuals who were member of the catholic society for older people (Katholieke Bond voor Ouderen; KBO). This is a widely supported society in the Netherlands consisting of more than 282,000 community citizens above 50 years. A priori power analyses (Buchner, Faul, \& Erdfelder, 1992) using a medium effect size of 0.15 (Cohen, 1988), an alfa level of .05 and a power of 0.99 indicated a required sample size of 257 participants. We anticipated non-response and incomplete questionnaires, and therefore invited 1,000 participants living in the south of the Netherlands for participation in the study. A letter and questionnaire was sent to them by regular mail to invite them to participate in the study. Participants could indicate their willingness to participate in the study by completing the questionnaire and returning it in a prepaid envelope. In total, 360 participants returned the questionnaire. Disease history was asked in the questionnaire. Two individuals who reported cerebrovascular disease were excluded from the study. In addition, 58 participants were excluded because they returned incomplete questionnaires (more than $20 \%$ missing items per scale). This resulted in a total study sample of 300 participants with a mean age of 72 years $(\mathrm{SD}=7.5$, range $53-94)$ and $59 \%$ being female. The mean level of education was $3.8(\mathrm{SD}=1.8)$, measured on a 8-point scale, ranging from (1) primary education (2) lower vocational education, (3) intermediate secondary education, (4) intermediate vocational education, (5) higher secondary education, (6) higher vocational education, (7) higher professional education, and (8) university education (De Bie, 1987).

\section{Measures}

Each determinant was measured with a scale consisting of several items. Five variables (behaviour leading to forgetfulness, attitude, social norm, social support, societal beliefs) were measured with newly developed scales. We based the structure of these scales on previous research where similar constructs were measured (Dreezens, Martijn, Tenbult, Kok, \& de Vries, 2005; Lemmens et al., 2005). The internal consistency (reliability) of the constructed scales was determined with Cronbach's alfa $(\alpha)$ or in case of scales with only two items with Pearson's correlations $(r)$. The respondent's mean scale score replaced missing values when participants had less than $20 \%$ missing items on a scale. Scales were calculated by averaging the scores on the related items. The scores were coded so that higher scores indicate a higher value of the determinant. 


\section{Forgetfulness}

Forgetfulness was rated with the question "Do you consider yourself to be forgetful?". Response options were yes or no. This single question has previously been successfully used to determine subjective memory complaints (Bassett \& Folstein, 1993; Commissaris et al., 1998; Mol et al., 2006).

\section{Behaviour leading to forgetfulness}

Behaviour was divided into two behavioural determinants, each measured with two items. The first determinant was performing little effort to use one's memory ('little effort'; i.e., "Did you ever avoid someone, because you didn't remember his or her name?", "Have you ever performed less effort to remember something?", on a scale from $1=$ never to $5=$ always; $r=.42$ ). The other determinant was performing much effort in using one's memory ('much effort'; "Did you ever excessively focus on your memory?" "Have you ever performed too much effort in using your memory", on a scale from $1=$ never to $5=$ always; $r=.21)$.

\section{Fear of dementia}

Fear of dementia was measured by two items (i.e., "Are you worried to become demented?", "Are you afraid of becoming demented?", on a scale from $1=n o t$ at all to $5=$ very much; $r=.69$ ).

\section{Symptoms of depression}

Symptoms of depression were measured by a subscale of the Symptom Checklist (SCL-90: (Derogatis, 1977) Dutch version (Arrindell \& Ettema, 1986)). The SCL-90 is a multidimensional self-report inventory of psychopathology, measured with 16 statements. Examples are "To what degree were you troubled by feeling low in energy", "To what degree were you troubled by feeling lonely" $(1=$ not at all, $5=$ very badly; $\alpha=.92)$.

\section{Memory related-anxiety}

Memory-related anxiety was measured by the subscale Anxiety of the Abridged Dutch Metamemory in Adulthood Questionnaire (MIA: (Dixon, Hultsch, \& Herzog, 1988; Ponds \& Jolles, 1996)). Participants were asked to rate 12 statements, reflecting feelings of anxiety and stress about one's memory function (e.g., "I get anxious when I am asked to remember something", "I find it harder to remember things when I am upset", on a scale from $1=$ disagree strongly to $5=$ agree strongly; $\alpha=.88$ ). 


\section{Memory self-efficacy}

The Metamemory in Adulthood Questionnaire (MIA) was also used to measure memory self-efficacy. Memory self-efficacy, which consists of the mean of the subscales Anxiety (feelings of stress and anxiety related to memory performance), Change (perceived change in memory function), and Capacity (beliefs about personal memory capacity), is thought to reflect beliefs about personal competence in various memory situations (Herzog, Hultsch, \& Dixon, 1989). Examples are "The older I get the harder it is to remember clearly", "My memory for phone numbers will decline as I get older" $(1=$ disagree strongly, 5 $=$ agree strongly; $\alpha=.94)$.

\section{Memory monitoring}

Memory monitoring was measured by the subscale Capacity of the MIA. Participants were asked to rate 10 statements, reflecting self-knowledge about one's capacity (e.g., "I am good at remembering birthdays", "I have no trouble remembering lyrics of songs", on a scale from $1=$ disagree strongly to $5=$ agree strongly; $\alpha=.91)$.

\section{Attitude}

The attitude towards one's memory was determined with two items (i.e., 'When I think about my memory, my first impression is...', The feeling I have about my memory is...', on a scale from $1=$ very negative to $5=$ very positive; $\alpha=$ .89)

\section{Social norm}

Four items measured the social norm regarding the use of one's memory (e.g., "Most people important to me think I should not avoid situations where I have to remember things", "Most people important to me think that I should perform more effort to remember things", ranging from $1=$ surely not to $5=$ surely yes; $\alpha=.76)$.

\section{Social support}

Four items measured the social support regarding the use of one's memory (e.g., "Most people important to me encouraged me to perform more effort in using my memory", "Most people important to me encouraged me to have conversations where I have to remember things", on a scale from $1=$ surely not to $5=$ surely yes; $\alpha=.73$ ). 


\section{Societal beliefs}

Societal belief was assessed by one item (i.e., 'Forgetfulness is accepted in our society' with the scale ranging from $1=$ disagree strongly to $5=$ agree strongly).

\section{Knowledge}

Knowledge about memory and aging was measured with six items (e.g., 'For older people, education, occupation, and verbal skill tend to have little influence on their memory'). Response options were 'yes', 'no' or 'don't know'. The 'don't know' option was added to reduce the likelihood of random guessing and make the questionnaire more sensitive (Cherry, Brigman, Hawley, \& Reese, 2003). Correct responses were scored 1 , all other responses scored 0 , providing a range of total scores between 0 and 6 . The variable knowledge was the total score of correct answers.

\section{Statistical analyses}

The data were analysed using the statistical software SPSS version 11 programme series for Apple Macintosh. Mean scores were calculated to describe each determinant. Pearson's correlations and Spearman's correlations were calculated to establish the correlations between the determinants at an ordinal level and between the ordinal determinants and dichotomous determinants, respectively. A backward logistic regression procedure was used to determine the contribution of each determinant to the prediction of forgetfulness. No previous hypothesis was present with respect to the order of importance of the determinants, so the determinants were entered in the model without specific sequence. Furthermore, respondents were categorised into younger and older adults based on a median split of the age distribution. Multivariate analysis of variance (MANOVA) was used to explore the differences between both age groups on the determinants. The significance level was set at $\alpha=.05$.

\section{Results}

\section{Relation between determinants and forgetfulness}

Approximately $48 \%$ of the participants consider themselves as forgetful. Table 1 presents the means, standard deviations and the correlations for all variables. In general, participants had little symptoms of depression, fear of dementia and scored low on the perceived social support and subjective norm. Forgetfulness was significantly correlated with 9 of the 15 determinants, namely attitude $(r=-$ $.552)$, memory self-efficacy $(r=-.548)$, memory monitoring $(r=-.483)$, memory-related anxiety $(r=.384)$, subjective norm $(r=.351)$, fear of dementia 


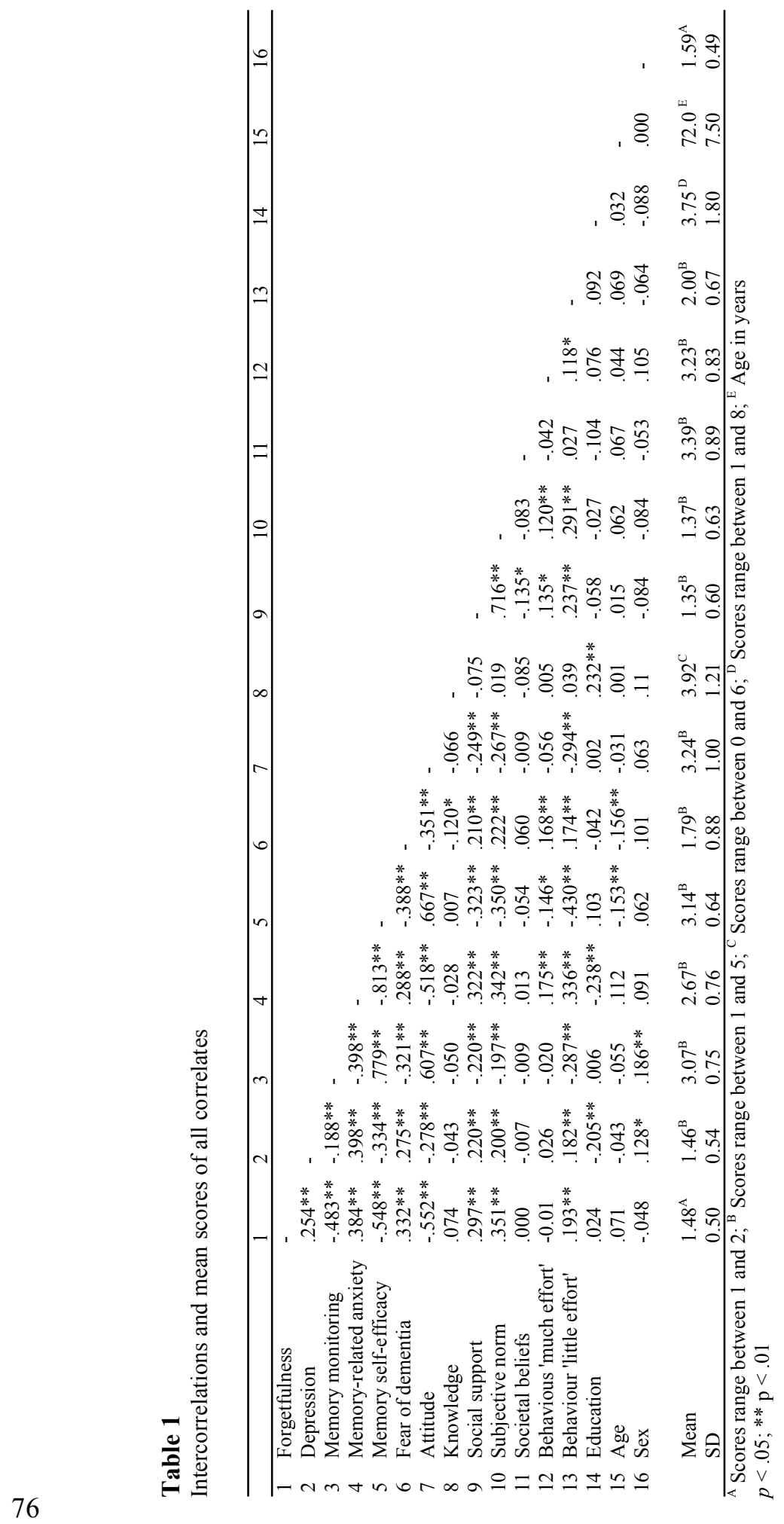




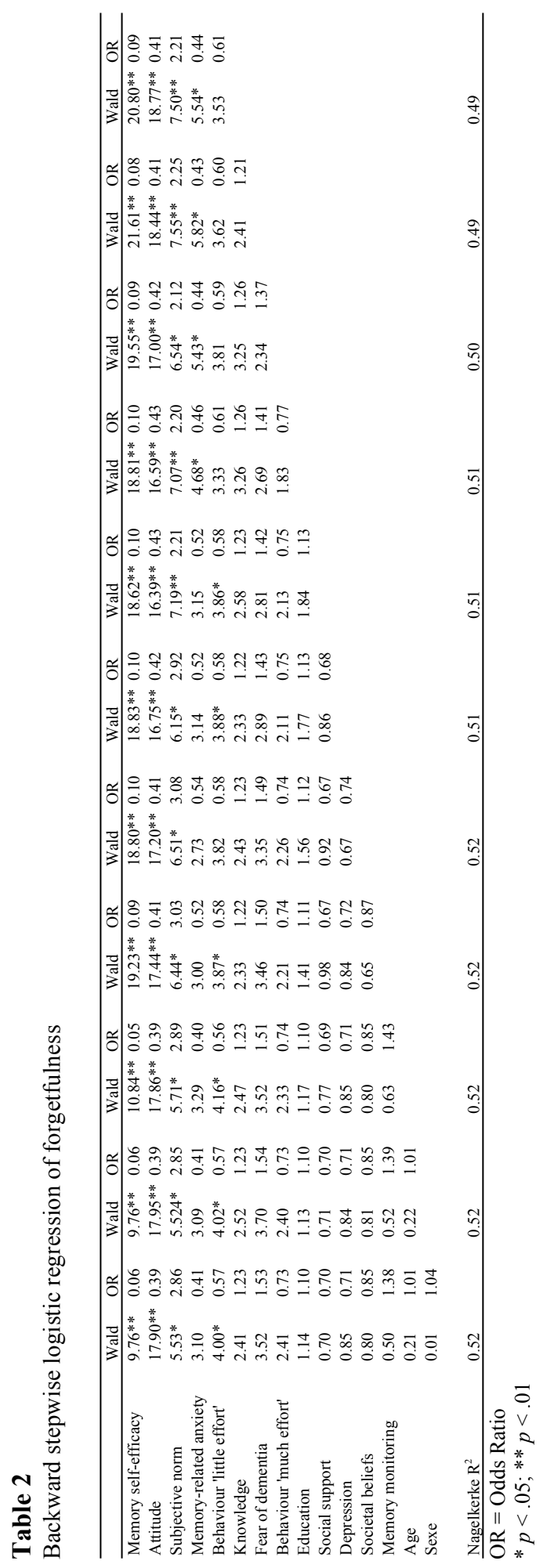


( $r=.332)$, social support $(r=297)$, symptoms of depression $(r=.254)$, and behaviour 'little effort' $(r=.193)$.

\section{Correlates of forgetfulness}

The logistic regression on forgetfulness is presented in Table 2. The significant predictors of forgetfulness were a low memory self-efficacy (i.e., beliefs about memory abilities and strength), negative attitude (i.e., evaluation of one's memory functioning), high memory-related anxiety (i.e., affective state, generated by memory demanding situations) and high social norm (i.e., anticipating negative evaluations by important others). The determinant 'performing little effort' is still present in the final model, but is not significant. A suppressor-effect (Darlington, 1968; Friedman \& Wall, 2005), was found between memory self-efficacy and anxiety. This is noticeable in the logistic regression, where anxiety has a negative beta weight (i.e. odds ratio below one) despite the fact that the correlation between anxiety and forgetfulness is positive. Because anxiety and memory self-efficacy are correlated, memory self-efficacy consumes a part of the explained variance of anxiety in the regression, resulting in a negative beta weight. When performing a logistic regression without memory self-efficacy, the beta weight of anxiety is in the expected direction. Therefore, the relation between anxiety and forgetfulness is interpreted as a positive relation.

Table 3

Differences between younger and older adults and corrected mean values

\begin{tabular}{llcc}
\hline & Younger adults $(n=153)$ & Older adults $(n=147)$ & $F$ value \\
\hline Forgetfulness $^{\mathrm{A}}$ & $1.45(0.04)$ & $1.52(0.04)$ & 1.31 \\
Depression $^{\mathrm{B}}$ & $1.44(0.04)$ & $1.49(0.04)$ & 0.67 \\
Memory monitoring $^{\mathrm{B}}$ & $3.08(0.06)$ & $3.06(0.06)$ & 0.07 \\
Memory-related anxiety $^{\mathrm{B}}$ & $2.60(0.06)$ & $2.75(0.06)$ & 3.15 \\
Memory self-efficacy $^{\mathrm{B}}$ & $3.22(0.05)$ & $3.06(0.05)$ & $4.55^{*}$ \\
Fear of dementia $^{\mathrm{B}}$ & $1.89(0.07)$ & $1.69(0.07)$ & $4.08^{*}$ \\
Attitude $^{\mathrm{B}}$ & $3.23(0.08)$ & $3.26(0.08)$ & 0.08 \\
Knowledge $^{\mathrm{C}}$ & $2.91(0.10)$ & $2.93(0.10)$ & 0.03 \\
Social support $^{\mathrm{B}}$ & $1.34(0.05)$ & $1.36(0.05)$ & 0.13 \\
Subjective norm $^{\mathrm{B}}$ & $1.33(0.05)$ & $1.41(0.05)$ & 1.17 \\
Societal beliefs $^{\mathrm{B}}$ & $3.31(0.07)$ & $3.47(0.07)$ & 2.48 \\
Previous behaviour 'much effort' $^{\mathrm{B}}$ & $3.18(0.07)$ & $3.29(0.07)$ & 1.20 \\
Previous behaviour 'little effort' $^{\mathrm{B}}$ & $1.96(0.05)$ & $2.05(0.06)$ & 1.35 \\
Education $^{\mathrm{D}}$ & $3.75(0.15)$ & $3.75(0.15)$ & 0.00 \\
Sexe $^{\mathrm{B}}$ & $1.59(0.04)$ & $1.59(0.04)$ & 0.00 \\
\hline
\end{tabular}

${ }^{\mathrm{A}}$ Scores range between 1 and $2 ;{ }^{\mathrm{B}}$ Scores range between 1 and $5 ;{ }^{\mathrm{C}}$ Scores range between 0 and $6 ;{ }^{\mathrm{D}}$ Scores range between 1 and 8

$p<.05 ; * * p<.01$ 


\section{Differences between younger and older individuals}

The sample was divided into two groups, to explore differences between younger (aged 53-72) and older (aged 73-94) individuals on forgetfulness and the selected determinants. The mean age of the younger group was 66.0 years $(\mathrm{SD}=4.5)$ and the mean age of the older group was 78.1 years $(\mathrm{SD}=4.4)$. The MANOVA conducted to determine differences between these groups in all previously described variables was significant (Wilks' $\lambda=0.904, F=2.02, p<$ $.05)$. Subsequent ANOVAs showed that younger individuals experienced higher levels of memory self-efficacy than older individuals. In addition, younger individuals were more afraid of becoming demented than older individuals. There was no significant difference between younger and older adults with regard to forgetfulness. Results on the differences and corrected mean values between younger and older adults on each determinant are reported in Table 3.

\section{Discussion}

To improve the effectiveness of interventions for individuals with subjective memory complaints, interventions should be targeted at determinants that predict forgetfulness. This study showed that low memory self-efficacy, high memory-related anxiety, negative attitude, and high social norm were correlates of forgetfulness.

An important correlate of forgetfulness is memory self-efficacy. Memory self-efficacy reflects the degree of confidence one has in the ability to mobilize skills for a task (Bandura, 1977, 1989; Hultsch et al., 1988). Poor memory selfefficacy reflects self-doubt and low self-esteem rather than lack of skills. Besides the influence of memory self-efficacy on subjective memory complaints, memory self-efficacy has also been an important predictor of diminished objective cognitive performance (Valentijn et al., 2006). So, memory self-efficacy is of great importance in predicting the use of one's memory.

Another significant correlate of forgetfulness is memory-related anxiety. Memory-related anxiety reflects experienced arousal when forgetting things and perceived tension when using one's memory. The relation between memory-related anxiety and subjective memory complaints was previously studied by Ponds and Jolles (1996), who found that young (age 24-51 years) as well as older (age 54-86 years) forgetful participants reported higher memoryrelated anxiety than non-forgetful participants. Several other studies investigated symptoms of anxiety in relation to memory complaints and found a correlation between severity of subjective memory complaints and anxious symptomatology (Derouesné et al., 1989; Jorm, Christensen, Korten, Jacomb, \& Henderson, 2001). The findings of the present study contribute to these studies by identifying memory-related anxiety as an important factor in forgetfulness. Furthermore, attitude towards one's memory was found to be 
significantly related to forgetfulness, while controlling for other variables. Attitude is defined as a positive or negative evaluation of entity, but can include more specific psychosocial constructs, such as beliefs, outcome expectations, assessment of advantages and disadvantages, self-evaluation and motivation to act (Eagly \& Chaiken, 1993). So, when people perceive themselves forgetful, negative beliefs and evaluations about their memory functioning come to mind. This might possibly be due to negative experiences in the past, for example repeatedly forgetting things, such as keys or names. To our knowledge, it is the first time that the importance of attitude is highlighted with regard to predicting forgetfulness.

Subjective norm is another important correlate of forgetfulness. The subjective norm reflects beliefs about how others will approve or disapprove of subjective memory complaints or perceived memory failures. Apparently, when someone thinks that others will disapprove of their memory failures, it will result in higher perceived expectations, which can lead to perceived failure, and thus to subjective memory complaints. For example, when you forget your keys, you think your friends will say that you are thoughtless and careless. The next time, you will be extra careful in taking your keys with you. But then you forget your wallet. You think that your friends will say you have failed again to take your belongings with you. When this happens several times, you might think your friends are right and you perceive yourself to be forgetful.

It is interesting to note that behaviour leading to forgetfulness, such as performing much effort and performing little effort were no important correlates of forgetfulness. The determinant 'performing little effort' was in the final model, but was not significant. This indicates that performing little effort might influence forgetfulness, but is not a very important correlate. Apparently, perceiving oneself forgetful differs from the behaviour that leads to forgetting things. According to Cromwell (1994) forgetfulness can be seen as a social label that is applied to oneself when acceptable standards for remembering are not met. In this view, labelling oneself forgetful is a personal response to the interaction between one's forgetting and one's social world (Cromwell, 1994). This notion is supported in the present study. Perceiving oneself forgetful was not solely determined by the behaviour leading to forgetfulness, it was also determined by the experienced subjective norm, which was an important correlate of forgetfulness. In the present study, the subjective norm was even a stronger factor than the behaviour leading to forgetfulness.

Additional analyses were performed to explore possible age-differences in the determinants related to forgetfulness. Because individuals tend to acquire more information when the intervention is adjusted to the needs of the individuals (Ruiter, Kessels, Jansma, \& Brug, 2006) we studied differences in younger (aged 53-72) and older individuals (aged 73-94). Older individuals perceived less memory self-efficacy and experienced less fear of dementia than younger individuals. Reason for this may be that older people believe that their forgetfulness is attributed to less manageable and to irreversible memory- 
intrinsic causes, such as 'aging' and 'always had a poor memory' (Commissaris et al., 1998; Ponds et al., 1997). Most likely, older individuals accept forgetfulness as being part of the aging process, resulting in less fear of dementia and less memory self-efficacy.

The findings in this study have several implications for future interventions. A focus of future interventions could be the experienced anxiety and the perceived tension when using one's memory. Furthermore, individuals with forgetfulness experience that their relatives disapprove of their memory complaints. By aiming the intervention at building skills to recognise and resist experienced social pressure (Bartholomew et al., 2006), individuals might cope better with the social influence from others. Also, individuals with subjective memory complaints have a negative attitude about their memory. One of the most widely used intervention method for attitude change is the presentation of arguments in a persuasive message (McGuire, 1985), for example by stating that memory complaints are very common and are experienced by more than $50 \%$ of the older population. Another focus of future interventions could be on memory self-efficacy. Poor memory self-efficacy rather reflects self-doubt and low self-esteem than lack of skills. By enlarging self-esteem in individuals with forgetfulness, better performance and less memory complaints might be accomplished. This might be achieved by positively reinforcing individuals after remembering and recalling things. In addition, it should be taken into account that especially older individuals (aged above 70) experience low memory self-efficacy. This implicates the need for interventions tailored to specific age groups. Interventions for individuals aged over 70 should be aimed at enlarging memory self-efficacy to improve perceived memory functioning. Interventions for individuals aged between 50 and 70 should be aimed at the differences between forgetfulness in old age and dementia, to diminish the fear of becoming demented. This is because adults aged between 53 and 72 experience more fear of dementia than older adults, aged above 73 years. Overall, it is preferred that all determinants are addressed in a comprehensive intervention programme, to achieve the best possible results (Bartholomew et al., 2006).

Our study has also some methodological considerations and implications for future research. Due to the cross-sectional design of the study, we were not able to determine a causal relation between the determinants and forgetfulness. Future research should aim at performing longitudinal or experimental studies to elaborate on the causal relations. Also, experimental evaluations targeting the determinants highlighted in the present study are required to establish whether our implications can be translated into effective interventions to decrease the subjective memory complaints. Furthermore, the present study did not confirm the relation between forgetfulness and behaviour that is observed in clinical settings. The items measuring the behaviour leading to forgetfulness were newly developed items. Possibly, the items were too abstract and did not match the perceptions of the participant's behaviour leading 
to forgetfulness. Future studies should re-evaluate the behaviour leading to forgetfulness and investigate whether aspects of the behaviour were missed or not determined correctly.

In conclusion, the findings of the current study, based on 300 participants aged between 53 and 94 years, indicate that the most important determinants of forgetfulness are memory self-efficacy, memory-related anxiety, attitude, and subjective norm. Focussing future interventions on these determinants might improve effectiveness of interventions for individuals with forgetfulness.

\section{Acknowledgements}

We thank KBO Limburg (Katholieke Bond voor Ouderen) for their cooperation, Dick Willems for his statistical advice and Ruben Wensing for his assistence in collecting and organising the data. 


\section{References}

Ajzen, I. (1991). The theory of planned behaviour. Organizational Behavior and Human Decision Processes, 50, 179-211.

Ajzen, I. (1998). Models of Human Social Behavior and their application to health psychology. Psychology and Health, 13, 735-739.

Arrindell, W. A., \& Ettema, J. H. M. (1986). SCL-90. Manual for a multidimensional indicator of psychopathology [Handleiding bij een multidimensionele psychopathologie-indicator]. Lisse, the Netherlands: Swets \& Zeitlinger B.V.

Ball, K., Berch, D. B., Helmers, K. F., Jobe, J. B., Leveck, M. D., \& Marsiske, M. (2002). Effects of cognitive training interventions with older adults. Journal of the American Medical Association, 288(18), 2271-2281.

Bandura, A. (1977). Self-efficacy: towards a unifying theory of behavioral change. Psychology Review, 84, 191-215.

Bandura, A. (1989). Regulation of cognitive processes through perceived self-efficacy. Developmental Psychology, 25, 729-735.

Bandura, A. (1998). Health promotion from the perspective of social cognitive theory. Psychology and Health, 13, 623-649.

Bartholomew, L. K., Parcel, G. S., Kok, G., \& Gottlieb, N. H. (2006). Planning health promotion programs. An intervention mapping approach. San Francisco, CA: Jossey-Bass.

Bassett, S. S., \& Folstein, M. F. (1993). Memory complaint, memory performance, and psychiatric diagnosis: a community study. Journal of Geriatric Psychiatry and Neurology, 6(2), 105-111.

Blazer, D. G., Hays, J. C., Fillenbaum, G. G., \& Gold, D. T. (1997). Memory complaint as a predictor of cognitive decline: a comparison of African American and White elders. Journal of Aging and Health, 9(2), 171-184.

Brug, J., \& De Vries, H. (Eds.). (1999). Computer-tailored education [special issue]. Patient Education and Counseling, 36(2).

Buchner, A., Faul, F., \& Erdfelder, E. (1992). GPOWER: a priori-, post hoc-, and compromise power analyses for the Macintosh (Version 2.1). Bonn, Germany: Bonn University.

Cherry, K. E., Brigman, S., Hawley, K. S., \& Reese, C. M. (2003). The knowledge of memory aging questionnaire: effects of adding a "don't know" response option. Educational Gerontology, 29, 427-446.

Cohen, J. (1988). Statistical power analyses for the behavioral sciences (2nd edition). Hillsdale, NJ: Erlbaum.

Comijs, H. C., Deeg, D. J. H., Dik, M. G., Twisk, J. W. R., \& Jonker, C. (2002). Memory complaints: the association with psycho-affective and health problems and the role of personality characteristics. A 6-year follow-up study. Journal of Affective Disorders, 72, 157-165.

Commissaris, C. J. A. M., Jolles, J., Verhey, F. R. J., Ponds, R. W. H. M., Damoiseaux, V., \& Kok, G. (1996). Forgetfulness or dementia? Who is worried and why? European Journal of Public Health, 6, 297-299.

Commissaris, C. J. A. M., Ponds, R. W. H. M., \& Jolles, J. (1998). Subjective forgetfulness in a normal Dutch population: possibilities for health education and other interventions. Patient Education and Counseling, 34, 25-32.

Cromwell, S. L. (1994). The subjective experience of forgetfulness among elders. Qualitative health research, 4(4), 444-462.

Darlington, R. B. (1968). Multiple regression in psychological research and practice. Psychological Bulletin, 69, 161-182.

De Bie, S. E. (1987). Standaardvragen 1987: voorstellen voor uniformering van vraagstellingen naar achtergrondkenmerken en interviews [Standard questions 1987: proposal for 
uniformisation of questions regarding background variables and interview]. (2nd ed.). Leiden, The Netherlands: Leiden University Press.

De Vries, H., Backbier, E., Kok, G., \& Dijkstra, M. (1995). The impact of social influences in the context of attitude, self-efficacy, intention, and previous behaviour as predictors of smoking onset. Journal of Applied Social Psychology, 25, 237-257.

Derogatis, L. R. (1977). SCL-90: administration, scoring and procedures manual-I for the R(evised) version. Baltimore: John Hopkins School of Medicine, Clinical Psychometrics Research unit.

Derouesné, C., Alperovitch, A., Arvay, N., Migeon, P., Moulin, F., Vollant, M., et al. (1989). Memory complaints in the elderly: a study of 367 community-dwelling individuals from 50 to 80 years old. Archives of Gerontology and Geriatrics. Supplement, 1, 151-163.

Dixon, R. A., Hultsch, D. F., \& Herzog, C. (1988). The Metamemory in Adulthood (MIA) Questionnaire. Psychopharmacology Bulletin, 24, 671-688.

Dreezens, E., Martijn, C., Tenbult, P., Kok, G., \& de Vries, N. K. (2005). Food and the relation between values and attitude characteristics. Appetite, 45(1), 40-46.

Eagly, A. H., \& Chaiken, S. (1993). The psychology of attitudes. Fox Worth, TX: Harcourt Brace Jovanovich.

Eysenck, M. W., \& Calvo, M. G. (1992). Anxiety and performance: the processing efficiency theory. Cognition and Emotion, 6(6), 409-434.

Floyd, M., \& Scogin, F. (1997). Effects of memory training on the subjective memory functioning and mental health of older adults: a meta-analysis. Psychology and Aging, 12, 150-161.

Friedman, L., \& Wall, M. (2005). Graphical views of suppression and multicollinearity in multiple linear regression. The American Statistician, 59(2), 127-136.

Green, L. W., \& Kreuter, M. W. (2005). Health program planning: an educational and ecological approach (4th ed.).

Herzog, C., Hultsch, D. F., \& Dixon, R. A. (1989). Evidence for the convergent validity of two self-report metamemory questionnaires. Developmental psychology, 25(5), 687-700.

Hultsch, D. F., Hertzog, C., Dixon, R. A., \& Davidson, H. (1988). Memory self-knowledge and self-efficacy in the aged. In N. L. Lowe \& C. J. Brainerd (Eds.), Cognitive development in adulthood: progress in cognitive developmental research (pp. 65-92). New York: Springer-Verlag.

Jonker, C., Geerlings, M. I., \& Schmand, B. (2000). Are memory complains predictive for dementia? A review of clinical and population-based studies. International Journal of Geriatric Psychiatry, 15, 983-991.

Jorm, A. F., Christensen, H., Korten, A. E., Henderson, A. S., Jacomb, P. A., \& Mackinnon, A. (1997). Do cognitive complaints either predict future cognitive decline or reflect past cognitive decline? A longitudinal study of an elderly community sample. Psychological Medicine, 27, 91-98.

Jorm, A. F., Christensen, H., Korten, A. E., Jacomb, P. A., \& Henderson, A. S. (2001). Memory complaints as a precursor of memory impairment in older people: a longitudinal analysis over 7-8 years. Psychological Medicine, 31(3), 441-449.

Lemmens, K. P., Abraham, C., Hoekstra, T., Ruiter, R. A., De Kort, W. L., Brug, J., et al. (2005). Why don't young people volunteer to give blood? An investigation of the correlates of donation intentions among young nondonors. Transfusion, 45(6), 945-955.

McGuire, W. J. (1985). Attitudes and attitude change. In G. Lindzey \& E. Aronson (Eds.), The handbook of social psychology (vol. 2) (pp. 233-346). New York: Random House.

Mol, M. E. M., Van Boxtel, M. P. J., Willems, D., \& Jolles, J. (2006). Do subjective memory complaints predict cognitive dysfunction over time? A 6-year follow-up of the Maastricht Aging Study. International Journal of Geriatric Psychiatry, 21(5), 432-441.

Norman, P., \& Conner, M. (2005). The theory of planned behavior and exercise: evidence for the mediating and moderating roles of planning on intention-behavior relationships. Journal of Sport and Exercise Psychology, 27(4). 
Ponds, R. W., Commissaris, K. J., \& Jolles, J. (1997). Prevalence and covariates of subjective forgetfulness in a normal population in The Netherlands. International Journal of Aging and Human Development, 45(3), 207-221.

Ponds, W. H. M., \& Jolles, J. (1996). The abridged Dutch metamemory in adulthood (MIA) questionnaire: structure and effect of age, sex and education. Psychology and Aging, 11(2), 324-332.

Rasmusson, X., Rebok, G. W., Bylsma, F. W., \& Brandt, J. (1999). Effects of three types of memory training in normal elderly. Aging Neuropsychology and Cognition, 6(1), 56-66.

Ruiter, R. A. C., Kessels, L., Jansma, B. M., \& Brug, J. (2006). Increased attention for computertailored health communications: an event-related potential study. Health Psychology, 25, 300-306.

Schmidt, I. W., Dijkstra, H. T., Berg, I. J., \& Deelman, B. G. (1999). Memory training for remembering names in older adults. Clinical Gerontologist, 20(2), 57-73.

Valentijn, S. A., Hill, R. D., Van Hooren, S. A., Bosma, H., Van Boxtel, M. P., Jolles, J., et al. (2006). Memory self-efficacy predicts memory performance: results from a 6-year follow-up study. Psychology and Aging, 21(1), 165-172. 


\section{Education about dementia: effectiveness of a public lecture}

Martine E.M. Mol, Martin P.J. van Boxtel \& Jelle Jolles 


\begin{abstract}
Memory and dementia are often the subject of educational activities, but there is only limited information about the effectiveness of this education. In this study the effectiveness of a lecture, as part of a series of lectures about dementia, has been evaluated. The results showed an improvement in knowledge and the participants were satisfied after the lecture. Finally, it showed that there is a need for this kind of education; for professionals and for people who were worried about their memory function or their partner's memory function.
\end{abstract}




\section{Introduction}

Memory complaints and worries about becoming demented are very common among older people. Such problems can diminish the quality of life (Commissaris, Ponds, \& Jolles, 1998). Although many educational activities about dementia are organized by health institutions and health organizations such as Alzheimer Centres and Memory Clinics, the effectiveness of these activities has been poorly investigated. According to a small amount of studies that have been performed in this field, the level of knowledge might increase after educational activities (Commissaris et al., 1998; Commissaris, Verhey, \& Jolles, 1996).

The information presented at an educational activity about dementia can contribute significantly to higher self-esteem and a higher locus of control (Chenoweth \& Spencer, 1986; Van den Borne \& Pruyn, 1984). Since subjective memory complaints are based on factors like low self-esteem and low feelings of control over one's own memory function, educational activities can be beneficial to people with these complaints (Commissaris, Verhey, Ponds, Jolles, \& Kok, 1994; Ponds, 1998). Individuals with mild cognitive impairment or dementia and their partners or carers can also benefit from educational activities (Van Woerkum, Kuiper, \& Bos, 1999). Attending educational activities might cause a better notion of the situation and a better way to handle the consequences of the dysfunctions. In addition to the target group of older people and their support system, professionals are also interested in information about this topic (Claxton, 1999). Professionals can benefit from expanding their knowledge about dementia and as a result cope better with issues concerning dementia. Other reasons for the interest of professionals can be that they want to be informed about the developments in their field of study and form consensus with other experts in terms of the theoretical basis and approach ("Consensus Conference on Dementia: Differential diagnosis of dementing diseases", 1987). After all, cognitive problems are present in several disciplines, such as neurology, psychiatry and health sciences. Further training and optimization of the latest development in these fields might be preferable (Moris, Evans, Hebert, \& Bienias, 1999).

The main aim of the present study is to demonstrate that professionals as well as laymen can improve their knowledge about dementia by attending a public lecture. Giving lectures is a well-known method for communicating information and knowledge (Bligh, 1972). The low costs, the ability to interact with the lecturer and easy access are positive sides of a lecture. But on the other hand, a lecturer cannot always connect to the level of knowledge of those in the audience. This is important for the storage of new information, which is most successful when the listener can relate new information to existing, already stored information (Damoiseaux, Van der Molen, \& Kok, 1993). Furthermore, the amount of knowledge transfer is also determined by the expressiveness of 
the lecturer and the motivation of the audience (Bligh, 1972; Ware \& Williams, 1975).

The public lecture evaluated in the present study was held on one evening and was part of a series of lectures around the topic of dementia, one of the activities of the Alzheimer Centre Limburg, which was founded in 2000. During the lecture, which was entitled 'Dementia and Depression', two experts in the field elaborated on the relation between dementia and depression. The lecture was advertised in regional papers and focused on a wide audience. The recruitment of the audience was deliberately aimed at both professionals and laymen.

It was expected that the public lecture would be effective in promoting information and knowledge. We therefore determined whether the information that was offered to different populations lead to an increase in the level of knowledge. In order to investigate this, the effect of knowledge transfer was measured by asking several knowledge questions before and after the lecture. This procedure was previously successfully used in a study by Commissaris (1994), who evaluated education about memory. Furthermore, it was expected that the audience would return home satisfied. In addition, the need for education about dementia was investigated because this is of importance to the development of new public education and the improvement of existing education. For a proper interpretation of the results, the study population was divided in two groups; a group of participants who were concerned about themselves, about a proxy or otherwise interested in dementia (referred to below as the non-professionals), and a group of participants who visited the lecture because of professional interest (referred to below as the professionals).

\section{Method}

\section{Demographic variables}

Before and after the lecture all attendees filled in a questionnaire. Data were analyzed for 39 of the 44 attendants. Five attendees did not complete their questionnaire and were therefore excluded from further analyses. The group consisted of 13 men and 26 women, with a mean age of 53, ranging from 26 to 83 years. The participants were divided into two groups. The first consisted of professionals $(n=19)$, who attended the lecture because of their present or future professional engagement with this topic. Among the professionals were nurses $(n=7,36 \%)$, psychologists $(n=3,16 \%)$, teachers $(n=2,11 \%)$, staff members of a care facility $(n=2,11 \%)$, students $(n=2,11 \%)$ or otherwise working in a care setting $(n=3,15 \%)$. The second group of participants, the non-professionals $(n=20)$, came to the lecture because of concerns about their own memory functioning or because of personal interest in the topic. 
Educational level was measured by a Dutch scoring system, which consists of an 8-point scale, ranging from primary education to university education (De Bie, 1987).

\section{Questionnaire}

The participants filled in five knowledge questions before and after the lecture as an objective measure to determine the increase in knowledge. The knowledge questions concerned general assumptions and were related to the core of the message of the lecture. The five questions were (with the correct answer): 'Pondering can lead to memory complaints' (correct), 'Demented persons often become depressed' (correct), 'Depression and dementia are easy to distinguish' (incorrect), 'Depression can be a precursor of dementia' (correct), 'When someone has a depression at an older age, signs of dementia can be present' (correct). Participants were asked whether the statements were correct or incorrect. The 'don't know'-option could be filled in when the participant did not know the answer. Every correct answer was scored one point, with a maximum of five points; an incorrect or no answer scored no points,

Furthermore, satisfaction was investigated by asking the participants if the lecture fulfilled their expectations. This was scored on a 5-point scale, ranging from 'very much' (score 1) to 'not at all' (score 5).

Also, a question about the need for this kind of education was asked on a 5-point scale ranging from 'very much' (score 1) to 'not at all' (score 5), and the need for other forms of education was asked.

\section{Statistics}

Differences between the professionals and the non-professionals were analyzed with a $t$-test. The analyses of the knowledge questions were performed with analyses for repeated measures (ANOVA), corrected for education. The significance level was set at $p<.05$.

\section{Results}

Level of education was significantly different between the two groups. The professionals were significantly higher educated than the non-professionals ( $\mathrm{M}$ $=5.6 \mathrm{vs} \mathrm{M}=4.2 ; p<.05)$.

The total score on the knowledge test for both groups is shown in Figure 1. This figure shows that the professionals had a higher score before the lecture than the non-professionals $(p<.01)$. After the lecture, the knowledge increased almost significantly $(p=.057)$. The average increase in knowledge was similar for both groups. 


\section{Figure 1}

Total score on five knowledge items before and after the lecture, divided into professionals and non-professionals

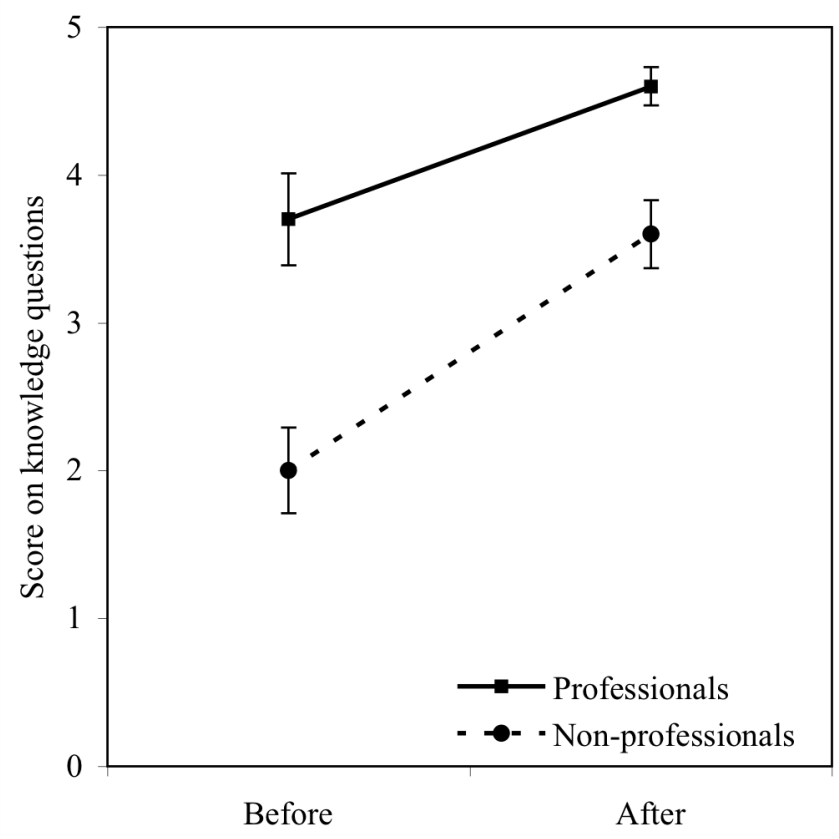

Results concerning satisfaction about the lecture showed that the lecture was satisfactory for both groups (professionals $\mathrm{M}=2.4$ vs non-professionals $\mathrm{M}$ $=2.3$ ).

The need for this type of education was higher among the nonprofessionals than the professionals; the difference was significant (nonprofessional $\mathrm{M}=2.0$ vs professionals $\mathrm{M}=3.1 ; p<.05$ ).

When participants were asked about their favourite type of education, both groups preferred a public lecture to another form of education. Furthermore, it appeared that professionals as well as non-professionals were not interested in a discussion group or education by means of a radio programme. Participants could also fill in another form of education but the participants did not use this option. Results of this last question are listed in Table 1. 


\section{Table 1}

Reactions from respondents when asked about their favourite type of education

\begin{tabular}{lll}
\hline & Professionals $(n=14)$ & Non-Professionals $(n=16)$ \\
\hline $\begin{array}{l}\text { Which form of education do you appreciate } \\
\text { most? }\end{array}$ & \\
A public lecture & $44 \%$ & $70 \%$ \\
An information brochure & $31 \%$ & $18 \%$ \\
An information video & $25 \%$ & $12 \%$ \\
Information through a radio programme & $0 \%$ & $0 \%$ \\
A discussion group & $0 \%$ & $0 \%$ \\
\hline
\end{tabular}

Note: nine participants did not answer this question

\section{Discussion}

The results showed a significant difference in knowledge between professionals and non-professionals before as well as after the lecture. This can be explained by the difference in level of knowledge beforehand about the topic of the lecture. An important finding is that professionals as well as non-professionals answered more knowledge questions correctly after the lecture. Furthermore, the lecture fulfilled the expectations of both groups, because the participants reviewed the lecture positively. The importance of this finding is that a relatively low-profile lecture, characterized by low expenses and easy access for a large number of individuals, can be effective in knowledge transfer and is positively evaluated.

The professionals may show a ceiling effect on the total score of the knowledge questions (Figure 1). For further research it is important to use an instrument that consists of more items, with a larger distribution in the level of difficulty than the knowledge items that were used in the present study. Furthermore, the results have to be interpreted cautiously because of the small number of participants and because of the possibility of selection bias, because the participants visited the lecture of their own volition (Bouter \& Dongen van, 2000). In addition, the knowledge questions before and after the lecture used in the present study were deliberately similar in advantage of the comparability. In a future study with a larger amount of participants, two parallel knowledge questionnaires could be used.

It can be concluded in regard to this lecture that the information offered was suitable for both groups of participants. However, the non-professionals in particular indicated their need for this kind of information. This shows that the needs of the non-professionals are different from those of the professionals. This is also shown when the preferences for the form of education are considered. It emerged that non-professionals prefer a public lecture more than professionals do.

In conclusion, the results showed that it is useful to give information through a public lecture. This is an important finding, because a public lecture is 
an efficient and inexpensive method. More research is necessary to determine the needs and the preferences of the target group with memory complaints. Further investigation is also needed to construct an integrated strategy of different forms of education. A lecture as evaluated in this study could be part of that strategy. For future research it is important to take the characteristics and the level of knowledge of the participants into consideration. This is of importance to the development of future education, so the information can be provided as specifically as possible (De Haes, 1985).

\section{Acknowledgements}

We thank the Alzheimer Centre Limburg (Alzheimer Centrum Limburg) for its cooperation, Kees Commissaris and Margot Krook for sharing their expertise, and Geert Leenders and Renate de Groot for their advice and support. 


\section{References}

Bligh, D. A. (1972). What's the use of lectures? Harmondsworth: Penguin.

Bouter, L. M., \& Dongen van, M. C. J. M. (2000). Epidemiologisch onderzoek: opzet en interpretatie [epidemiologic research: planning and interpretation]. Houten: Bohn Stafleu Van Loghum.

Chenoweth, B., \& Spencer, B. (1986). Dementia: the experience of family caregivers. The Gerontologist, 26, 267-272.

Claxton, G. (1999). Wise up. The challenge of lifelong learning. New York: Bloomsbury Publishing.

Commissaris, C. J. A. M., Ponds, R. W. H. M., \& Jolles, J. (1998). Subjective forgetfulness in a normal Dutch population: possibilities for health education and other interventions. Patient Education and Counseling, 34, 25-32.

Commissaris, C. J. A. M., Verhey, F. R. J., Ponds, R. W. H. M., Jolles, J., \& Kok, G. (1994). Patient education about normal forgetfulness and dementia: importance and effects. Patient Education and Counseling, 25, 163-167.

Commissaris, K., Verhey, F. R., \& Jolles, J. (1996). A controlled study into the effects of psychoeducation for patients with cognitive disturbances. The Journal of Neuropsychiatry and Clinical Neurosciences, 8(4), 429-435.

Consensus Conference on Dementia: differential diagnosis of dementing diseases. (1987). Journal American Medical Association, 258, 3411-3416.

Damoiseaux, V., Van der Molen, H. T., \& Kok, G. J. (1993). Gezondheidsvoorlichting en gedragsverandering [Health promotion and behaviour change]. Assen: van Gorcum.

De Bie, S. E. (1987). Standaardvragen 1987: voorstellen voor uniformering van vraagstellingen naar achtergrondkenmerken en interviews [Standard questions 1987: proposal for uniformisation of questions regarding background variables and interview]. (2nd ed.). Leiden, The Netherlands: Leiden University Press.

De Haes, W. F. M. (1985). Voorlichting en onderzoek [Health education and research]. Nederlands Tijdschrift voor de Psychologie, 40, 77-86.

Moris, M. C., Evans, D. A., Hebert, L. E., \& Bienias, J. L. (1999). Methodological issues in the study of cognitive decline. American Journal of Epidemiology, 149(9), 789-793.

Ponds, R. W. H. M. (1998). Forgetfulness and cognitive aging. Prevalence, characteristics and determinants. Unpublished $\mathrm{PhD}$ Thesis, Maastricht University, Maastricht.

Van den Borne, H. W., \& Pruyn, J. F. A. (1984). Informatiebehoefte en lotgenotencontact bij kankerpatienten [Need for information and contact with cancer patients]. Gezondheid en Samenleving, 5, 180-187.

Van Woerkum, C., Kuiper, D., \& Bos, E. (1999). Informatieve communicatie: informatiedienstverlening [Informative communication: information services]. In C. Woerkum van, D. Kuiper \& E. Bos (Eds.), Communicatie en innovatie, een inleiding [Communication and innovation, an introduction]. Alphen aan de Rijn: Samson.

Ware, J. E., \& Williams, R. G. (1975). The dr. Fox effect: a study of lecturer effectiveness and ratings of instructions. Journal of Medical Education, 50(2), 149-156. 
7

\section{Public education about memory and aging:} objective findings and subjective insights

Martine E.M. Mol, Renate H.M. de Groot, Dick Willems \& Jelle Jolles Published in Educational Gerontology, 2006; 30: 843-858 


\section{Abstract}

Public education about memory was evaluated with a controlled intervention trial. Participants in group $1(n=273)$ attended a symposium covering memoryrelated topics and received a magazine with identical information. Group $2(n=$ 141) only received the magazine. Participants were non-professionals and professionals aged between 29 and 88. Outcome measures were knowledge about memory and subjective experience. For non-professionals, knowledge increment was higher in group 1 than in group 2, indicating that an objective increment in knowledge is present in non-professionals after attending the symposium. No knowledge change occurred in professionals. Furthermore, participants were very satisfied after both interventions, even when knowledge transfer was limited. 


\section{Introduction}

Subjective memory complaints are very prevalent in the general population, with percentages ranging from approximately $39 \%$ in a population with an age range from 24 to 86 (Ponds, Commissaris, \& Jolles, 1997) to over 50\% in a population aged 65 and older (Blazer, Hays, Fillenbaum, \& Gold, 1997). Many people are afraid that their forgetfulness is a sign of senile dementia (Comijs, Deeg, Dik, Twisk, \& Jonker, 2002). The fear of severe memory impairment can have a negative impact on someone's life (Commissaris, Verhey, Ponds, Jolles, \& Kok, 1994; Verhaeghen, Geraerts, \& Marcoen, 2000). People can become insecure, avoid contact with others and turn to medical aid facilities (Commissaris et al., 1994). However, subjective memory complaints are not always driven by actual memory problems. They can also be determined by other variables, such as personality traits, memory self-efficacy, psychological wellbeing and subjective health (Comijs et al., 2002; McDougall, 2004; Niederehe, 1998; Pearman \& Storandt, 2004).

A possible way to reduce the anxiety about memory complaints is to inform people by means of public education about the differences between forgetfulness in old age and pathological memory failures. An approach which is frequently followed is the organization of a one-day symposium for the general public where knowledge about memory is communicated (Commissaris, Jolles, \& Kok, 1993; Commissaris et al., 1996). These educational activities have some advantages. They are usually attended by a large number of people, which gives a good cost-effectiveness ratio with regard to organizational costs versus yield in terms of knowledge among the general public. These meetings are characterized by low expenses, easy accessibility, the ability to interact with the lecturer, and the transfer of knowledge and experiences about different aspects of memory. An important point is that it is implicitly assumed that the attendees return home with understandable and useful information that influences their attitudes and/or behaviour. However, a lecturer cannot always connect to the level of knowledge of the attendee, which is important for the storage of new information (Damoiseaux, Van der Molen, \& Kok, 1993). Furthermore, the amount of knowledge transfer is also determined by the expressiveness of the lecturer and the motivation of the audience (Bligh, 1972; Ware \& Williams, 1975). Because of the implicit assumption about the effectiveness of lectures and symposiums, it is important to know whether these one-day activities are more effective than a more 'traditional' form of education, where information brochures or written information is given.

The effectiveness of symposiums and public education about memory and aging has been little investigated. In a previous study we reported that attending a lecture of two hours about dementia improved knowledge about this topic in non-professionals $(n=20)$ as well as in professionals $(n=19)(\mathrm{Mol}$, Van Boxtel, \& Jolles, 2004). However, these results are based on a small group 
of participants. Troyer (2001) administered a memory education programme to 36 older adults and compared the increase in knowledge with 24 participants in a control group who received no information. General knowledge regarding memory and aging increased by $26 \%$ between pre-test and post-test according to a specially designed general measure of factual knowledge. As far as we know, until now no information concerning the effectiveness of education about memory in terms of a change in knowledge is available for a large sample. Therefore, we report here the results of a large-scale study involving 414 participants investigating the objective and subjective effectiveness of education about memory.

The objective effectiveness of a symposium can be measured by the change in knowledge. Knowledge about the difference between forgetfulness and dementia is important, because it is a prerequisite for the correct interpretation of warning signs, and is associated with appropriate help-seeking behaviour (Mor, Masterson-Allen, Goldberg, Guadagnoli, \& Wool, 1990; Sheikh \& Ogden, 1998; Werner, 2003), and with a decrease of concerns when no disease symptoms are present (Commissaris, Ponds, \& Jolles, 1998). Therefore, the first aim of the present study is to investigate whether a one-day symposium about memory is effective in changing knowledge, as measured using the Knowledge of Memory and Aging Questionnaire (Cherry, Brigman, Hawley, \& Reese, 2003).

The subjective effectiveness of a lecture is important in order to get an impression of the satisfaction experienced by the volunteers. The satisfaction experienced might promote better learning (Saroyan \& Snell, 1997). The second aim was therefore to study the subjective experience of the participants who take part in education about memory and aging.

Furthermore, many participants attend public education about memory because of their forgetfulness. However, subjective forgetfulness is not always related to decreased objective functioning (Blazer et al., 1997; Jorm et al., 1997). It is therefore assumed that forgetful participants learn as much from public education as the non-forgetful participants do. To examine this, the third aim of the study is to investigate whether being forgetful influences the change in knowledge.

To measure these aims properly, a design with a pre- and postmeasurement of a one-day symposium with vivid and lively presentations was used and compared with a control condition whereby participants received comparable information in the form of a magazine. It is expected that more knowledge is transferred during a symposium than when participants receive information as a magazine because the participants are more actively involved and have the possibility to interact with other participants at the symposium (Foley \& Smilansky, 1980; Frederick, 1986; Saroyan \& Snell, 1997).

In summary, public education about memory and aging is limited and the effect of this education is has been little investigated. Therefore, this study investigated whether participants who attended a one-day symposium obtained 
added value in terms of changed knowledge compared with participants who received the same information in a magazine and whether the participants were satisfied afterwards. Furthermore, this study investigated whether being forgetful influenced the change in knowledge after both interventions. We hope to use all the information obtained in order to make future interventions about memory and aging more effective and efficient.

\section{Methods}

\section{Participants and Procedure}

The study was a controlled trial with a pre- and post-measurement. All participants completed a questionnaire twice, one week before and two weeks after the intervention.

Two groups of participants were recruited through the Dutch Alzheimer Society. Participants in group 1 (intervention group) attended a one-day symposium and received the same magazine as group 2. Participants of group 1 were recruited though the general media, the Internet site of the Dutch Alzheimer Society, and through invitations to volunteers and donors of the Alzheimer Society. It was not necessary to be a member to register for this day. The symposium was held at a central location in the Netherlands and the entrance fee was EUR 25. Everyone who registered for the symposium $(N=$ 600) was invited to participate in this study. Respondents could indicate their willingness to participate in the study by completing the first questionnaire. Of the 366 participants who were willing to participate, 305 participants also returned the second questionnaires for the post-measurement (response rate $51 \%$ ). Only questionnaires with complete data were included, leaving a total of 273 participants in the study assessing the effect of the symposium in combination with the magazine.

Group 2, the control group, consisted of individuals who received only the magazine. Volunteers, donors and people who are interested in Alzheimer's disease and related topics subscribe to a magazine, which is edited and published by the Dutch Alzheimer Society about 6 times per year. A random sample of 700 out of the 1,100 people who subscribe to the magazine were invited to participate in the study. Respondents could indicate their willingness to participate in the study by completing the first questionnaire. Two hundred and thirty-three participants were willing to participate in the study. One hundred and eighty-one participants returned the questionnaires from the postmeasurement as well (response rate 26\%). Only questionnaires with complete data were included, leaving a total of 141 participants in the study assessing the effect of the magazine.

We expected two groups of individuals to attend the symposium and read the magazine, namely individuals who are concerned about their memory and are interested in the functioning of the memory, referred to below as non- 
professionals, and professionals who work in the field, referred to below as professionals.

\section{Intervention}

The intervention consisted of a one-day symposium, organized by the Dutch Alzheimer Society, to inform the general public about memory. Eight speakers, all experts in the field, were invited to talk about memory and memory-related topics, including 'Memory in elderly people', 'Memory and imaging techniques', 'Subjective memory problems', 'Memory tests', 'Causes of memory problems', 'Memory and dietary intake', 'Dementia among famous and other people', and 'The impact of the diagnosis of dementia'. At the end of the symposium participants received a magazine, which was also given to group 2 (see below).

Participants in the control group (group 2) only received the magazine, which was a special issue with articles about memory written by the speakers at the symposium and covering the same topics as discussed at the symposium.

\section{Measures}

\section{Independent measures}

Sample characteristics, such as age, sex and level of education were obtained in the first questionnaire. Educational level was measured using a Dutch scoring system, which consists of an 8-point scale, ranging from primary to university education (De Bie, 1987). The main reason for attending the symposium or subscribing to the magazine was also asked in the questionnaire. The outcome was split between professionals and non-professionals. In addition, participants were asked before and after the intervention if they considered themselves forgetful, with the question: 'Do you consider yourself to be forgetful?' (yes/no). Subjective memory complaints were measured with a single question, because this has appeared to be sufficient to demonstrate a correlation between memory complaints and test performance in several large-scale studies (Bassett \& Folstein, 1993; Geerlings, Jonker, Bouter, Ader, \& Schmand, 1999; Schofield et al., 1997).

\section{Dependent measures}

The primary outcome measure was knowledge about memory, measured using the Knowledge of Memory and Aging Questionnaire (KMAQ) (Cherry, West, Reese, \& Yassuda, 2000), which was translated into Dutch. A coefficient alpha was calculated in order to determine the internal consistency and reliability of the Dutch version of the Knowledge of Memory and Aging Questionnaire. The alpha determined on the basis of all the volunteers in this study $(N=599)$ participating in the baseline measurement was 0.75 , indicating that the internal consistency is only slightly below the recommended value of 0.80 (Nunnally \& 
Bernstein, 1994). Furthermore, proportion correct scores of the baseline measurement in this study are comparable with the results reported by Cherry (2003), who measured the proportion correct scores of 41 community dwelling older adults, with a mean age of 78.9. These findings suggest that the translation of the KMAQ was performed successfully.

The questionnaire consists of 28 items, half the items address knowledge about normal memory changes that occur in later life as a result of maturational processes. The following are examples: 'For older people, education, occupation, and verbal skills tend to have little influence on their memory' (false) and 'Memory for how to do well-learned things, such as reading a map or riding a bike, does not change very much, if at all, in later adulthood' (true). The other half of the items addresses knowledge of pathological memory changes that may affect memory functioning in older adults. The following are examples 'Frequent complaints about memory problems is an early sign of Alzheimer's disease' (false) and 'Confusion and memory lapses in older people can sometimes be due to physical conditions that doctors can treat so that these symptoms go away over time' (true). Response options were 'yes', 'no' or 'don't know'. The 'don't know' option was added to reduce the likelihood of random guessing and to make the questionnaire more sensitive (Cherry et al., 2003). Correct responses were scored 1, all other responses scored 0 , providing a range of total scores between 0 and 28. The dependent measure was the total score of correct answers. All participants filled in the KMAQ before and after the intervention. To avoid a sequence effect, the order of the items of the KMAQ was randomized over the study population. Half of the participants received the items in the first questionnaire in order A and the items in the second questionnaire in order B. The other half of the participants received the items in the first questionnaire in order B and the items in the second questionnaire in order A.

Furthermore, in order to determine the perceived effectiveness of the intervention, participants answered 4 questions on a 5-point Likert scale with regard to their subjective experience of the intervention. The questions are described in Table 1. The dependent measure was the sum of the percentages of scores 4 ('agree') and 5 ('strongly agree') on the 5-point Likert scale.

\section{Analysis}

Unpaired $t$-tests were performed in respect of age and education in order to examine differences in participants' characteristics between group 1 and group 2. In addition, a Chi-square test was employed to analyze the variables sex, forgetfulness before and after the intervention, and whether the magazine was read or not. ANOVA repeated measures, adjusted for education, age, sex, and subjective forgetfulness before the intervention, were used to test whether knowledge improvement differed between group 1 and group 2. A MannWhitney test was used to determine differences between groups regarding 
questions on the 5-point Likert scale concerning subjective experience about the intervention. To test the influence of forgetfulness on the effect of both interventions, a 3-way interaction of time*group*forgetfulness was determined with ANOVA repeated measures, corrected for age, sex and education. All analyses were performed separately in non-professionals and professionals. The alpha level for significance testing was set at $p<.05$.

\section{Table 1}

Subjective experience (\% score 'agree' and 'strongly agree') of non-professional and professional participants at the second measurement divided into group 1 (symposium and magazine) and group 2 (magazine)

\begin{tabular}{lllll}
\hline & \multicolumn{3}{l}{ Non-professionals } & Professionals \\
\cline { 2 - 5 } & Group 1 & Group 2 & Group 1 & Group 2 \\
\hline $\begin{array}{l}\text { My overall impression of the } \\
\text { symposium/magazine was very good }\end{array}$ & $93 \%$ & $89 \%$ & $97 \%$ & $89 \%$ \\
$\begin{array}{l}\text { Because of the symposium/magazine, I know } \\
\text { how my memory works }\end{array}$ & $38 \%$ & $35 \%$ & $37 \%$ & $36 \%$ \\
$\begin{array}{l}\text { I considered the presentations/the text in the } \\
\text { magazine to be very difficult }\end{array}$ & $11 \% * *$ & $45 \%$ & $6 \%$ & $21 \%$ \\
$\begin{array}{l}\text { After attending the symposium/reading the } \\
\text { magazine, I would like to have a group meeting } \\
\text { to discuss the use of my memory }\end{array}$ & $23 \%$ & $22 \%$ & $24 \%$ & $26 \%$ \\
$* *$ Significantly different between groups at $p<.01$ & & & \\
\hline
\end{tabular}

\section{Results}

\section{Participants' characteristics}

Participants' characteristics are shown in Table 2. Among the non-professionals it was found that significantly more attendees in group 1 considered themselves forgetful than participants of group $2\left(56 \%\right.$ vs $40 \% ; \chi^{2}(1, n=267)=6.2, p=$ $0.014)$. Among the professionals, more women participated in group $1(88 \% \mathrm{vs}$ $\left.64 \% ; \chi^{2}(1, n=147)=11.3, p<.01\right)$ and participants in group 1 were significantly less well educated than participants in group $2(5.3$ vs $6.2 ; t(145)=$ $-3.18, p<.01)$.

No differences were found among non-professionals or professionals between volunteers participating in the second measurement and the volunteers who did not participate in the follow-up after the first measurement. 


\section{Table 2}

Demographic variables of non-professional and professional participants divided into group 1 (symposium and magazine) and group 2 (magazine)

\begin{tabular}{lllll}
\hline & \multicolumn{2}{l}{ Non-professionals } & \multicolumn{2}{l}{ Professionals } \\
\cline { 2 - 5 } & Group 1 & Group 2 & Group 1 & Group 2 \\
\hline$n$ & 176 & 91 & 97 & 50 \\
Age (range 29-88 years) & $67.5( \pm 8.7)$ & $66.4( \pm 11.8)$ & $55.3( \pm 13.5)$ & $53.6( \pm 15.3)$ \\
Education (8-point scale) & $5.5( \pm 1.9)$ & $5.3( \pm 2.0)$ & $5.3( \pm 1.7)^{*}$ & $6.2( \pm 1.9)$ \\
Sex (male/female ratio) & $41 / 59$ & $39 / 61$ & $12 / 88^{*}$ & $36 / 64$ \\
Magazine read (y/partial/n ratio) & $36 / 55 / 9$ & $50 / 41 / 9$ & $49 / 43 / 8$ & $44 / 50 / 6$ \\
Forgetfulness before (y/n ratio) & $56 / 44^{* *}$ & $40 / 60$ & $30 / 70$ & $18 / 82$ \\
Forgetfulness after (y/n ratio) & $46 / 54$ & $41 / 59$ & $26 / 74$ & $16 / 84$ \\
\hline
\end{tabular}

$\mathrm{y}=\mathrm{yes} ; \mathrm{n}=$ no

* Significantly different between groups at $p<.05$

** Significantly different between groups at $p<.01$

\section{Change in knowledge}

Among the non-professionals $(n=267)$, a significant group*time effect ( $p<$ $.01, \eta^{2}=0.026$ ) was found, indicating that the knowledge increment was higher for non-professional participants in group 1 than for non-professional participants in group 2 (9\% vs 4\%, Figure 1).

Professionals participating in group 1 increased their level of knowledge by $2 \%(17.4 \pm 0.4$ vs $18.2 \pm 0.4)$ and participants in group 2 increased only $0.5 \%(18.0 \pm 0.5$ vs $18.1 \pm 0.5)$. No interaction effect of group*time was found after performing analyses of professionals, indicating that professionals in group 1 did not increase their knowledge more than professionals in group 2.

\section{Subjective experience of the intervention}

Results from the questions about subjective experience are presented in Table 1 . When non-professional participants were asked how satisfied they felt after the intervention it appeared that 164 of the 176 non-professional participants in group $1(93 \%)$ and 76 of the 91 non-professional participants in group $2(89 \%)$ were satisfied with the intervention (no significant difference between groups). Sixty-seven of the 176 non-professional participants in group $1(38 \%)$ and 30 of the 91 of the non-professional participants in group $2(35 \%)$ agreed with the statement 'because of the intervention I know how my memory works' (no significant difference between groups). Also, 40 of the 176 non-professional participants in group $1(23 \%)$ and 18 of the 91 non-professional participant in group $2(22 \%)$ were interested in a group meeting to discuss the use of their memory (no significant difference between groups). When asked how difficult the presentations and the text were, it appeared that non-professional participants in group 2 considered the text in the magazine to be more difficult than non-professional participants in group $1(n=37(45 \%)$ vs $n=19(11 \%), U$ 
$=4171.5, p<.01)$.

Results for professional participants were similar, except for the question about the difficulty of the text and the presentations no differences were found between the professionals in group 1 and group 2. In addition, the non-professionals consider the texts and the presentations to be more difficult than the professionals $(U=14766.0, p<.01)$.

\section{Figure 1}

Adjusted scores on the KMAQ for non-professional in group 1 (symposium and magazine) and in group 2 (magazine) $(n=267)$.

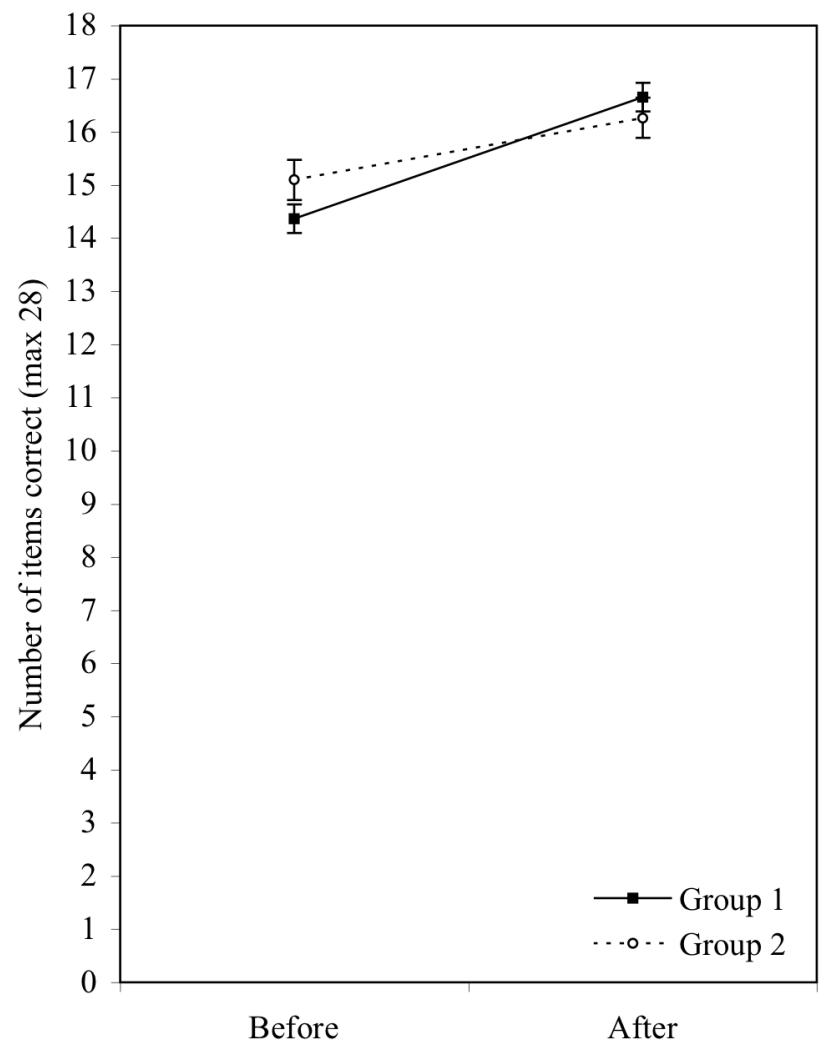

\section{Knowledge change in forgetful participants}

In the non-professional group, $56 \%$ of the participants in group 1 and $40 \%$ of the participants in group 2, considered themselves forgetful. No significant 3way interaction of time*group*forgetful was found, indicating that forgetfulness did not affect the intervention effect in the non-professionals. Furthermore, among the non-professionals data about subjective satisfaction 
show a high percentage of satisfied forgetful participants in group $1(91.8 \%)$ and group $2(90.9 \%)$ and a high percentage of non-forgetful participants in group $1(96.1 \%)$ and group $2(88.4 \%)$. No significant differences between forgetful and non-forgetful non-professional participants were found after performing a Mann-Whitney test.

Among the professionals, $30 \%$ of the participants in group 1 and $18 \%$ of the participants in group 2 considered themselves forgetful. No significant 3way interaction of time*group*forgetful was found, which indicates that forgetfulness did not affect the intervention effect in the professionals. Furthermore, as regards the professionals, data about subjective satisfaction show a high percentage of satisfied forgetful participants in group $1(100 \%)$ and group $2(77.8 \%)$, and a high percentage of satisfied non-forgetful participants in group $1(95.6 \%)$ and group $2(92.1 \%)$. After performing a Mann-Whitney test, no significant difference between forgetful and non-forgetful professional participants was found.

\section{Discussion}

The aim of this controlled intervention study was to investigate the change in knowledge and the subjective experience of, on the one hand, participants who attended a one-day symposium about memory and read a magazine and, on the other hand, participants who only read a magazine with comparable information. Two types of individuals participated in the study: nonprofessionals and professionals. Non-professional participants attending the symposium and reading the magazine had a higher increase in knowledge than participants who only read the magazine. However, the increment in knowledge was very small ( $9 \%$ vs $4 \%$, respectively). The professional participants did not differ in the change in knowledge after the interventions. Furthermore, the subjective experience of all participants was very positive. Almost all participants were satisfied after the intervention.

There was a small significant knowledge increment in nonprofessionals who attended the symposium and read the magazine compared with participants who only read the magazine. The ability to interact with the lecturer and the expressiveness of the lecturer are important factors that positively influence the transfer of knowledge during a symposium (Bligh, 1972; Ware \& Williams, 1975). Also, the fact that the audience is actively involved for a whole day and can benefit from the comforting and motivating effect of sharing their concerns about memory with other attendees (Verhaeghen, Marcoen, \& Goossens, 1992) stimulates the learning process. The presence of these factors could have led to a higher level of knowledge change when individuals attended the symposium. Furthermore, an important negative factor of only reading the magazine is the high reading level of the information in the magazine. Written materials are often written by skilled readers and are not appropriate for most adults with limited literacy skills (Davis, Crouch, 
Wills, Miller, \& Abdehou, 1990). Even when adults have attained a high educational level, this cannot be used to predict their actual reading skills (Guralnik, Land, Blazer, Fillenbaum, \& Branch, 1993; Murphy, Chesson, Walker, Arnold, \& Chesson, 2000). In the present study, readers of the magazine considered the text in the magazine to be more difficult compared with the participants in the symposium group, who did not consider the presentations at the symposium to be very difficult. Most likely the reading level of the text in the magazine was too high for the readers, which could have resulted in little knowledge transfer.

On the other hand, among professional participants, no significant effect of knowledge change after attending the symposium and reading the magazine was found. This could be due to the fact that a lecturer cannot always connect to the level of knowledge of the attendee. This is essential for the storage of new information because the greatest success is achieved when the listener can relate new information to existing, already stored information (Damoiseaux et al., 1993). Individuals also tend to acquire more information when the message is adjusted to considerations that are relevant to them. Public education should therefore be tailored to the needs of the individuals (Brug, Schaalma, Kok, Meertens, \& van der Molen, 2000). Apparently, the information provided at the symposium was adjusted more to the needs of the non-professionals than those of the professionals. So, future symposiums have to be dedicated to a specified target group with information adjusted to their level of knowledge. Furthermore, objective increment of knowledge might improve when education is designed according to conventional health promotion planning processes, including a refined needs assessment process, the creation of multilevel interventions, the acknowledgement of the importance of understanding the determinants, and the assurance of adequate programme implementation (Bartholomew, Parcel, Kok, \& Gottlieb, 2001). Hence, an integrated strategy of different forms of public education should be designed to improve knowledge change. A symposium as was evaluated in the present study could be part of that strategy.

The subjective experience of public education appeared to be very positive in non-professionals as well as in professionals. But when participants were asked after the intervention whether they knew how their memory worked, only about one third of all participants knew. About $25 \%$ of all participants would still like to have a group meeting to discuss the use of their memory. These results suggest that according to the subjective satisfaction of the participants, the activity is successful although only little knowledge transfer was experienced. It seems plausible that the amount of objectively learned information is not the most important factor in the subjective experience of satisfaction. Coming to a symposium and being with individuals who are interested in the same information can be just as important. The readers of the magazine also experienced a high level of satisfaction, so the fact that the topic of forgetfulness and the difference with respect to pathological memory failures is addressed can be of major importance. The success of public education about 
memory and aging is therefore not determined by the transfer of knowledge, but mainly by the amount of satisfaction experienced by the attendees. The satisfaction might be caused by a feeling of comfort and coping that has been experienced during public education. Further research is needed to study the constructs of the satisfaction experienced in more detail.

Being forgetful did not influence the change in knowledge after the intervention, indicating that non-forgetful as well as forgetful participants acquire information during the intervention. Also, the subjective experience of forgetful and non-forgetful participants was very positive. These findings show that among forgetful as well as non-forgetful participants, the objective increment in knowledge is similar, and the level of subjective satisfaction is very high.

The small change in knowledge as a result of the symposium and magazine was inconsistent with our previous study reporting that attending a low-profile lecture about dementia improved knowledge about this topic among non-professionals as well as in professionals (Mol et al., 2004). Our previous study was performed with only 39 participants, used a smaller questionnaire to measure knowledge transfer and had no control group. Mahony, Tarlow, Jones and Sandaire (2002) evaluated the effect of a CD-ROM-based multimedia programme as a tool to increase knowledge about the differences between normal forgetfulness and more serious memory loss associated with Alzheimer's disease. They found that the 56 participants in the intervention group had a significantly higher level of knowledge after the intervention, compared with 57 participants in the control group. These results are based on a post-measurement only. Overall, previous studies have results that are different from our study. But, these studies are methodologically less accurate because of the lower number of participants, lack of a control group and no pre-post design. In the present study we accounted for these methodological drawbacks. The results in the present study were obtained from a controlled intervention trail with a pre- and post-measurement of 414 participants.

A limitation of the current study involves the participants' selection. Participants of the symposium were self-referrals, while participants of the magazine group were approached in regard to participation. This means that the two groups are not randomly selected from the same source population. This might have biased the results. However, both groups are connected to the Dutch Alzheimer Society and involved in the topic of dementia, which might suggest that the participants have the same interests. Furthermore, the question concerning the overall impression about the intervention scored very high, which could have resulted from a possible social desirability bias. However, the other subjective questions, with the same chance in respect of social desirability, were answered with normal, lower scores, which makes the chance of a social desirability bias less likely.

In conclusion, we showed that knowledge improvement is more effective when non-professionals attended a symposium combined with reading 
a magazine than when non-professionals only read a magazine. However, the objective increment in knowledge was only present for a select group, the nonprofessional participants. This indicates that a symposium can be effective as long as the information provided is tailored to the needs of the participants. Furthermore, almost all participants were satisfied after the intervention, but only one third of the participants knew how their memory works and one fourth of them still want a group meeting. Thus, even when the participants observe little transfer of knowledge, the subjective experience of both forms of education was very positive. The success of public education about memory and aging is therefore not only determined by the observed transfer of knowledge, but mainly determined by the amount of satisfaction experienced by the attendees. This implies that public education about memory is useful for satisfying and comforting the participants.

\section{Acknowledgements}

We thank the Dutch Alzheimer Society (Alzheimer Nederland) for their cooperation, with special thanks to Edmar Weitenberg and Ron Wiebolt for their contribution to the project, and Renate Smeets for her help with the data entry. 


\section{References}

Bartholomew, L. K., Parcel, G. S., Kok, G., \& Gottlieb, N. H. (2001). Intervention Mapping. Designing theory-and evidence-based Health Promotion. New York: McGraw-Hill.

Bassett, S. S., \& Folstein, M. F. (1993). Memory complaint, memory performance, and psychiatric diagnosis: a community study. Journal of Geriatric Psychiatry and Neurology, 6(2), 105-111.

Blazer, D. G., Hays, J. C., Fillenbaum, G. G., \& Gold, D. T. (1997). Memory complaint as a predictor of cognitive decline: a comparison of African American and White elders. Journal of Aging and Health, 9(2), 171-184.

Bligh, D. A. (1972). What's the use of lectures? Harmondsworth: Penguin.

Brug, J., Schaalma, H., Kok, G., Meertens, R. M., \& van der Molen, H. T. (2000). Gezondheidsvoorlichting en Gedragsverandering [Health Promotion and Behaviour Change]. Assen: Van Gorcum.

Cherry, K. E., Brigman, S., Hawley, K. S., \& Reese, C. M. (2003). The knowledge of memory aging questionnaire: effects of adding a "don't know" response option. Educational Gerontology, 29, 427-446.

Cherry, K. E., West, R. L., Reese, C. M., \& Yassuda, M. (2000). The knowledge of memory aging questionnaire. Educational Gerontology, 26(3), 195-219.

Comijs, H. C., Deeg, D. J. H., Dik, M. G., Twisk, J. W. R., \& Jonker, C. (2002). Memory complaints: the association with psycho-affective and health problems and the role of personality characteristics. A 6-year follow-up study. Journal of Affective Disorders, $72,157-165$.

Commissaris, C. J. A. M., Jolles, J., \& Kok, G. (1993). Dementie en geheugenproblemen in Nederland. Inventarisatie van voorlichtingsactiviteiten. [Dementia and memory problems in the Netherlands. An inventory of education]. Medisch Contact, 48, 143144.

Commissaris, C. J. A. M., Jolles, J., Verhey, F. R. J., Ponds, R. W. H. M., Damoiseaux, V., \& Kok, G. (1996). Forgetfulness or dementia? Who is worried and why? European Journal of Public Health, 6, 297-299.

Commissaris, C. J. A. M., Ponds, R. W. H. M., \& Jolles, J. (1998). Subjective forgetfulness in a normal Dutch population: possibilities for health education and other interventions. Patient Education and Counseling, 34, 25-32.

Commissaris, C. J. A. M., Verhey, F. R. J., Ponds, R. W. H. M., Jolles, J., \& Kok, G. (1994). Patient education about normal forgetfulness and dementia: importance and effects. Patient Education and Counseling, 25, 163-167.

Damoiseaux, V., Van der Molen, H. T., \& Kok, G. J. (1993). Gezondheidsvoorlichting en Gedragsverandering [Health Promotion and Behaviour Change]. Assen: van Gorcum.

Davis, T. C., Crouch, M. A., Wills, G., Miller, S., \& Abdehou, D. M. (1990). The gap between patient reading comprehension and the readability of patient education materials. The Journal of Family Practice, 31(5), 533-538.

De Bie, S. E. (1987). Standaardvragen 1987: voorstellen voor uniformering van vraagstellingen naar achtergrondkenmerken en interviews [Standard questions 1987: proposal for uniformisation of questions regarding background variables and interview]. (2nd ed.). Leiden, The Netherlands: Leiden University Press.

Foley, R., \& Smilansky, J. (1980). Teaching Techniques. New York: McGraw Hill.

Frederick, P. (1986). The lively lecture- 8 variations. College Teaching, 34, 43-50.

Geerlings, M. I., Jonker, C., Bouter, L. M., Ader, H. J., \& Schmand, B. (1999). Association between memory complaints and incident Alzheimer's disease in elderly people with normal baseline cognition. The American Journal of Psychiatry, 156(4), 531-537. 
Guralnik, J. M., Land, K. C., Blazer, D., Fillenbaum, G. G., \& Branch, L. G. (1993). Educational status and active life expectancy among older blacks and whites. The New England Journal of Medicine, 329(2), 110-116.

Jorm, A. F., Christensen, H., Korten, A. E., Henderson, A. S., Jacomb, P. A., \& Mackinnon, A. (1997). Do cognitive complaints either predict future cognitive decline or reflect past cognitive decline? A longitudinal study of an elderly community sample. Psychological Medicine, 27, 91-98.

Mahony, D. F., Tarlow, B. J., Jones, R. N., \& Sandaire, J. (2002). Effects of a multimedia projects on users' knowledge about normal forgetting and serious memory loss. Journal of the American Medical Association, 9(4), 383-394.

McDougall, G. J. (2004). Memory self-efficacy and memory performance among black and white elders. Nursing Research, 53(5), 323-331.

Mol, M. E., Van Boxtel, M. P., \& Jolles, J. (2004). Voorlichting over Dementie: effectiviteit van een voorlichtingsavond [Education about dementia: Effectiveness of a public lecture]. Tijdschrift voor Gerontologie en Geriatrie, 35(2), 72-75.

Mor, V., Masterson-Allen, S., Goldberg, R., Guadagnoli, E., \& Wool, M. S. (1990). Prediagnostic symptom recognition and help seeking among cancer patients. Journal of Community Health, 15(4), 253-266.

Murphy, P. W., Chesson, A. L., Walker, L., Arnold, C. L., \& Chesson, L. M. (2000). Comparing the effectiveness of video and written material for improving knowledge among sleep disorders clinic patients with limited literacy skills. The Southern Medical Journal, 93(3), 297-304.

Niederehe, G. (1998). The significance of memory complaints in later life: methodological and theoretical considerations. In J. Lomranz (Ed.), Handbook of aging and mental health: an integrative approach (pp. 417-434). New York: Plenum Press.

Nunnally, J. C., \& Bernstein, I. H. (1994). Psychometric theory (3rd ed.). New York: McGrawHill.

Pearman, A., \& Storandt, M. (2004). Predictors of subjective memory in older adults. Journals of Gerontology Series B: Psychological Sciences and Social Sciences, 59B(1), p4-6.

Ponds, R. W., Commissaris, K. J., \& Jolles, J. (1997). Prevalence and covariates of subjective forgetfulness in a normal population in The Netherlands. International Journal of Aging and Human Development, 45(3), 207-221.

Saroyan, A., \& Snell, L. S. (1997). Variations in lecturing styles. Journal of Higher Education, 33, 85-104.

Schofield, P. W., Marder, K., Dooneief, G., Jacobs, D. M., Sano, M., \& Stern, Y. (1997). Association of subjective memory complaints with subsequent cognitive decline in community-dwelling elderly individuals with baseline cognitive impairment. The American Journal of Psychiatry, 154(5), 609-615.

Sheikh, I., \& Ogden, J. (1998). The role of knowledge and beliefs in help seeking behaviour for cancer: a quantitative and qualitative approach. Patient Education and Counseling, $35(1), 35-42$.

Troyer, A. (2001). Improving memory knowledge, satisfaction and functioning via an education and intervention program for older adults. Aging, Neuropsychology and Cognition, 8(4), 256-268.

Verhaeghen, P., Geraerts, N., \& Marcoen, A. (2000). Memory complaints, coping, and well-being in old age: a systemic approach. Gerontologist, 40(5), 540-548.

Verhaeghen, P., Marcoen, A., \& Goossens, L. (1992). Improving memory performance in the aged through mnemonic training: A meta-analytic study. Psychology and Aging, 12, $150-161$.

Ware, J. E., \& Williams, R. G. (1975). The dr. Fox effect: a study of lecturer effectiveness and ratings of instructions. Journal of Medical Education, 50(2), 149-156.

Werner, P. (2003). Knowledge about symptoms of Alzheimer's disease: correlates and relationship to help-seeking behavior. International Journal of Geriatric Psychiatry, 18(11), 1029-1036. 
8

\section{An evaluation of the use of a website and telephonic information service as public education about forgetfulness}

Martine E.M. Mol, Renate H.M. de Groot, Esther M. Hoogenhout, Aukje Aben, Frans R.J. Verhey \& Jelle Jolles

In press in Telemedicine and e-health 


\section{Abstract}

\section{Objectives}

There is increasing interest in telehealth as a potential new approach for health care delivery. To investigate whether telehealth is suitable to inform the older population about forgetfulness, we designed and compared two types of telehealth, i.e. the Memory Website and the Memory Phone. The aim of this study was to analyze characteristics of the individuals who are interested in the Memory Phone and the Memory Website, to investigate the nature of the information in which the users were interested, and to evaluate the usefulness of the services.

\section{Materials and Methods}

Participants were asked to answer several questions before and after visiting the main information menu of the telehealth facilities.

\section{Results}

Characteristics are given for all participants who used the facilities. In the evaluation period of three months, more individuals used the Memory Website $(n=2,631)$ than the Memory Phone $(n=228)$. The two services were used by different populations. Phone users were significantly older, more often female, and perceived themselves more often as forgetful. In the specific group of non-professional older individuals, general information about memory was more requested by Phone users compared with Website users (67\% vs $41 \%)$. Website users requested more often strategies and tips than Phone users $(66 \%$ vs 34\%). The Phone and the Website were both considered useful.

\section{Conclusions}

Overall, the Memory Website and the Memory Phone are two different types of evidence-based telehealth interventions, which are relevant for different populations, and are considered useful in informing the older population about forgetfulness and aging. 


\section{Introduction}

In recent years, there is increasing interest in e-health and telehealth as an approach for health care delivery (Mair \& Whitten, 2000). Telehealth refers to public health services and health prevention delivered via electronic communications. Especially people who are not necessarily unhealthy, but who wish to remain well and independent might benefit from telehealth (Craig \& Patterson, 2005). It can be expected that the use of telehealth will form an integral part of everyday lives in the future, especially of older people, because many older people wish to remain healthy and independent in their own homes for as long as possible. There are several advantages in using telehealth. Individuals do not have to travel to public health services to get information, saving travel time and appointment delay. In addition, telehealth can give immediate access to extensive information resources. The information is always available, and can be retrieved as often as needed (Bashshur, 2002; Bos, Visser, Tempert, \& Schaalma, 2004). For the health providers it reduces costs of, for instance, printing and distribution of brochures. With these advantages, it might be a suitable approach to supply general and health information to the large group of older people in the general population.

A common health problem in the general older population is forgetfulness. The percentage of individuals with subjective memory complaints was more than $50 \%$ in a population aged 65 years and older (Blazer, Hays, Fillenbaum, \& Gold, 1997). Although complaints of forgetfulness are not necessarily associated with an actual decline in objective memory functioning (Bolla, Lindgren, Bonaccorsy, \& Bleecker, 1991; Jorm et al., 1997), much hindrance and worries may be experienced as a result of this forgetfulness in daily life. In a study by Commissaris, Ponds and Jolles (1998) approximately $60 \%$ of all forgetful individuals perceived much hindrance and feel hampered by their forgetfulness in daily life, and approximately $70 \%$ of these individuals were very worried about their forgetfulness. Furthermore, several studies found that subjective memory complaints were related to a lower quality of life (Bazargan \& Bazargan, 1997; Derouesné, Lacomblez, Thibault, \& LePoncin, 1999; Mol et al., in press; Verhaeghen, Geraerts, \& Marcoen, 2000). So, forgetfulness seems to be an issue for many individuals. For that reason, it is important to inform the general population about forgetfulness and aging by easily accessible, always available, low cost information services.

There is a limited amount of earlier studies on the use of telehealth, showing that telehealth could be useful to inform individuals about dementia. Mundt, Kaplan, and Greist, (2001) investigated the need for an interactive voice response telephone system providing information about dementia. During one month, 193 people called, with an average call length of 9 minutes. Most people rated the information as very helpful (Mundt et al., 2001). In a study by Mahoney, Tarlow, and Jones (2003), the effect of an automated 
telecommunication system designed for caregivers of patients with Alzheimer's disease was investigated. Results of the 100 caregivers showed positive effects for a specific group; wives who exhibited low mastery and high anxiety benefited most from the intervention.

A proportion of people with forgetfulness is interested to receive an intervention (e.g. memory training or other educational activities) to decrease their worries and increase memory functioning (Commissaris et al., 1998). With the advantages of telehealth, it should be possible to reach large groups of older individuals with subjective memory complaints. However, no previous research has been done to evaluate whether telehealth is suitable to inform the older population about forgetfulness. It is therefore important to describe characteristics of individuals who use telehealth interventions that are aimed at older individuals. In addition, it is imperative to investigate what kind of information they request, and to evaluate their satisfaction with telehealth. In order to accomplish this, we designed two types of information services using telehealth and performed a systematic evaluation in this study. One type of information service was developed to give information through the Internet: the Memory Website. Access to the Internet is growing rapidly also for the older population, and many individuals are able to use this information service (Slegers, Van Boxtel, \& Jolles, in press). In addition, the internet has become an increasingly important source of health information for many individuals (Hesse et al., 2005; Jadad et al., 2001). The second type of information service was by telephone: the Memory Phone. Many older persons use their telephones comfortably and effectively and do not have access to, or are not able to navigate the Internet (Magnusson, Hanson, \& Borg, 2004; Mundt et al., 2001).

The Memory Website and the Memory Phone were constructed according to the same design and procedure and contain the same information. They provide information about five topics related to memory and aging. The Memory Phone and the Memory Website are newly developed information services and offer structured information about memory and aging, are easily accessible, available 24 hours per day, anonymous, and have low costs. Both information services were specifically aimed at older individuals (above 50 years), who were non-professionally interested in information about memory and forgetfulness. The evaluation of the information services presented in this study might be a lead for future interventions.

In sum, the present study had three aims. Since telehealth is accessible for individuals of all ages, the first aim of the study was to describe the characteristics of all individuals who were interested in the Memory Phone and the Memory Website and compare differences between the two information services. The second aim was to investigate in older (above 50 years) nonprofessional individuals whether Memory Website users and Memory Phone users requested different topics when using the services. The last aim was to determine and compare experiences after visiting the Memory Phone and the Memory Website in non-professional older (above 50 years) individuals. 


\section{Materials and Methods}

\section{Participants}

The Memory Phone and the Memory Website were launched in the Netherlands in March 2006 by press messages in newspapers, journals, radio programmes and by brochures that were distributed to the 38 memory clinics in the Netherlands and to other public health services. At all times the Memory Phone and the Memory Website were presented as equivalents of each other. Participants were individuals who called the Memory Phone and/or visited the Memory Website. The participants were informed that the Memory Phone and Memory Website would be scientifically evaluated. Access to the Memory Website was free of costs and the Memory Phone was 1 Euro-cent per minute. The Ethical Committee Psychology (Faculty of Psychology, Maastricht University) approved the study.

\section{Procedure}

We composed the Memory Phone and the Memory Website with information obtained from scientific and medical literature (e.g. Commissaris, Verhey, \& Jolles, 1996; Valentijn et al., 2005). Figure 1 illustrates the framework of the structure of the two information services. Both information services had the same menu structure and they presented identical information. The Memory Phone was an automated telephone system, where individuals could listen to spoken information. The Memory Website was an Internet site on the World Wide Web, where the information could be read.

As an introduction to the Memory Phone and the Memory Website, the participants received brief instructions about how to use the information services, and about the scientific evaluation that was coupled to the services. Participants who indicated that they would like to receive more information, could obtain instructions and/or information about the research. Subsequently, all individuals were asked to answer several questions (e.g. sex, age, the reason for visiting), which were of importance for the scientific evaluation of the facility. The questions are described in detail below.

After answering the questions, participants entered the main menu. From the main menu individuals could choose one of the 5 submenus with information. The first was (a) 'functioning of the memory', where information was given about the different kinds of memory, such as long term and short term memory, and conditions for a good functioning of the memory. The second submenu was (b) 'factors that influence memory', where information could be obtained about physical, psychological and social factors and about how selfconfidence can influence memory functioning. In the third submenu (c) 'differences between normal forgetfulness and dementia', information is provided about normal forgetfulness that is caused by aging and the differences 
with dementia. In this submenu it is also stated that a general practitioner should be consulted when individuals think that dementia is causing the forgetfulness. The fourth submenu is (d) 'tips to keep the memory fit', where tips and strategies are given to improve the use of one's memory. The last submenu was (e) 'where to find more information', providing addresses, phone numbers, and websites of institutes where more information could be obtained about forgetfulness and dementia. These topics are thought to give adequate background information about forgetfulness and aging, and provide strategies to cope with forgetfulness and give leads for further information. At any time, participants could return to the main menu and subsequently visit another submenu.

Participants were asked to leave the Memory Phone and Memory Website via the exit procedure. The option to go to the exit procedure was available in every menu. In the exit procedure, participants were asked several final questions (e.g. about the usefulness of the information) which are described below. Participants could also leave a message with any information such as missed information or other suggestions. Responding to questions in the exit procedure was not obligatory.

Due to the expected burden for the participants, and consequently probable drop-out, we restricted the number of the questions before entering the main menu. Several questions, such as level of education, were therefore asked during the exit procedure. Furthermore, to avoid convenient answers on the questions, the answer options ranging from positive to negative were in different order for each question.

\section{Figure 1}

Overview of the structure of the Memory Phone and the Memory Website

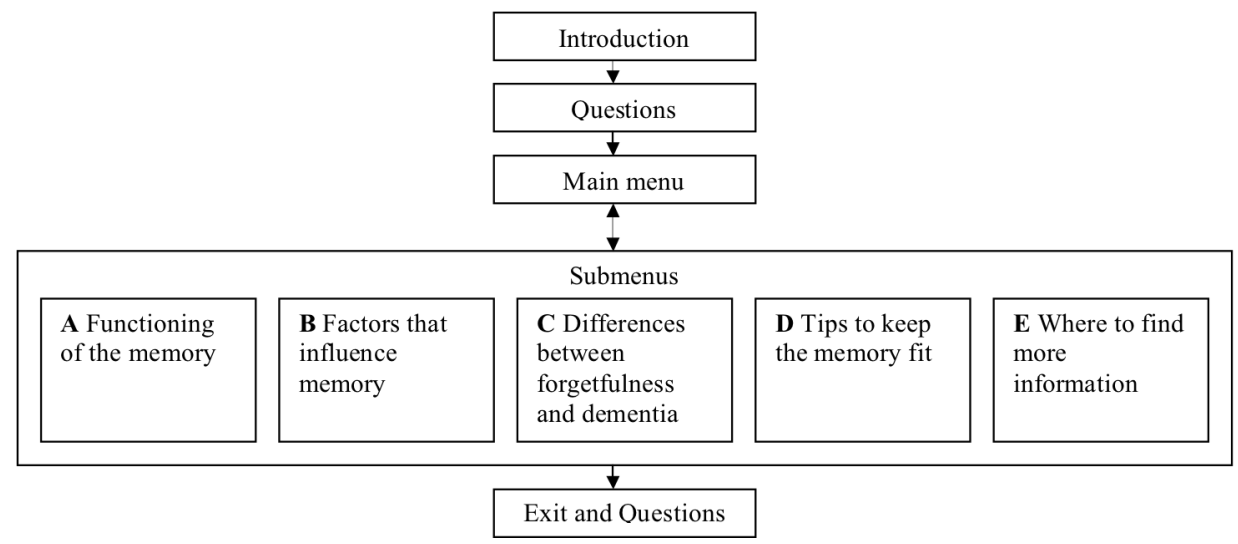




\section{Measures}

Six characteristics were asked of participants before entering the main menu: sex, age, the main reason for calling (the answer options are stated in Table 2), and whether individuals perceived themselves forgetful (answer options: yes/no). Only those participants who indicated to be forgetful were additionally asked whether they perceived hindrance from their forgetfulness in daily life (answer options: yes/no). The last question was 'Is this the first time you used the Memory Phone/Memory Website?' (answer options: yes/no).

In the exit procedure, participants were asked to answer four more questions: 'How useful did you find the Memory Phone/Memory Website?', 'Did your worries about your forgetfulness decrease after listening/reading the information?', 'Are you planning to search for additional information after using the Memory Phone/Memory Website?'. Answers to the questions in the exit procedure are stated in Table 2. The highest education was also asked. This was scored on an 8-point scale, ranging from (1) primary education to (8) university education (De Bie, 1987).

The variables sex, age, reason for visit, forgetfulness (and hindrance), first time visiting and education were used as independent variables to describe the study population. The variables usefulness, decrease in worries and where to find more information were used as independent variables to describe the outcome features of the two information services.

The computer system logged the responses to the questions. Participants of the Memory Website typed all their answers on the computer. Participants of the Memory Phone could give all but one of their answers with a button press on their phone; only the question about highest education was voice recorded. Participants left their answer on the machine. The computer system recorded this answer and we manually scored the answers to the 8-point education scale. The computer system also logged the time and date of each visit to a question or to a submenu for every individual using the Memory Phone and the Memory Website. This made it possible to determine the time spent on each of the information services as well as which submenus with information the participants visited. Whether or not a participant visited a certain submenu was used as a dependent measure, when analysing the differences in requested information between participants from the Memory Website and Memory Phone.

\section{Statistical analyses}

To determine differences in age between participants from the Memory Phone and the Memory Website, unpaired $t$-tests were performed. To analyze differences between Memory Phone and Memory Website in nominal variables, such as sex, perceived forgetfulness and reason for visiting the information service, Chi-square tests were used. Mann-Whitney tests were performed to determine group differences in the level of education. 
Furthermore, logistic regression analysis was used to test whether there were differences in the requested information between participants from the Memory Phone and the Memory Website. Visiting a certain submenu was used as the dependent variable; being a participant of the Memory Phone or the Memory Website was the independent variable. Analyses were adjusted for two variables, namely age and sex, because users of the Memory Phone and the Memory Website differed on these two demographic variables. Five multiple logistic regression analyses are performed to analyse the five submenus. To correct for possible type I errors, a Bonferroni correction was applied resulting in an alfa level of $p<.01$. For all other analyses the alpha level for significance testing was set at $p<.05$.

\section{Results}

\section{Findings in all participants}

\section{Participants' characteristics}

In the first three months that the information services were accessible (March 2006 till June 2006), the Memory Website was visited by 3,872 individuals and the Memory Phone by 371 individuals. Of these, 1,241 Website users (32\%) and 143 Phone users $(39 \%)$ did not enter the main menu with the information and left, leaving 2,631 Website participants and 228 Phone participants that were used for analysis. Of 194 of the 1,384 individuals who dropped out before entering the main menu, data regarding age, sex, perceived forgetfulness and reason for visiting were available. The only significant difference between dropouts and participants was sex; less female participants dropped out $(49 \%$ vs $\left.57 \% ; \aleph^{2}(1, n=3,041)=4.4, p<.05\right)$.

The characteristics of all participants who entered the main menu with information are shown in Table 1. Due to an error in the log system, some values of participants of information services were missing (max. 5\%). Therefore, the number of participants is given with each variable. Some important differences were found between Memory Phone and Memory Website users. Individuals who used the Memory Phone were significantly older $(t(300)=12.17, p<.01)$, more often woman $\left(\aleph^{2}(1, n=2,847)=21.71, p\right.$ $<.01)$, and they perceived themselves more often as forgetful $\left(\aleph^{2}(1, n=2,829)\right.$ $=33.59, p<.01)$. Also, the reason for using the Memory Phone was mainly someone's forgetfulness, while many users of the Memory Website also visited because of general interest in the topic $\left(\aleph^{2}(3, n=2,838)=78.08, p<.01\right)$. 


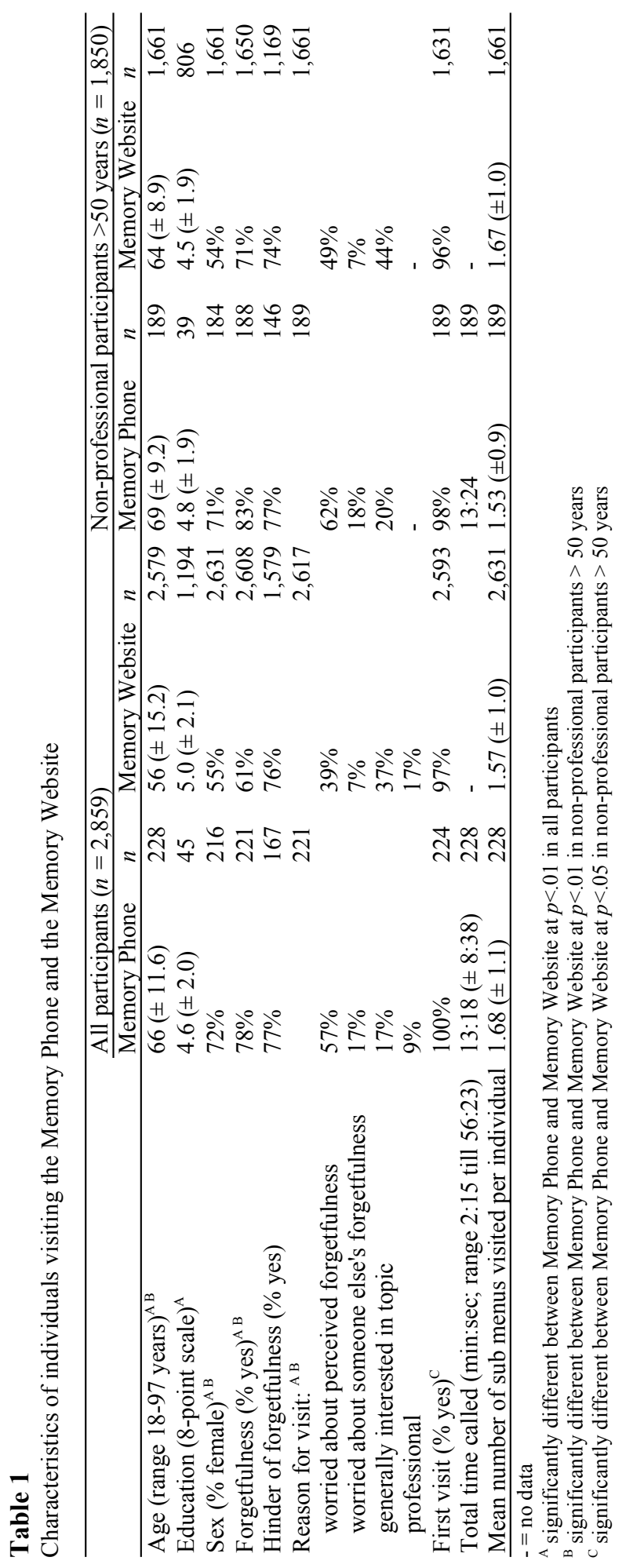




\section{Findings in non-professional participants above 50 years}

\section{Participants' characteristics}

$83 \%$ of the individuals who used the Memory Phone and $64 \%$ of the Memory Website users consisted of non-professional individuals, aged above 50 years. In this population, we also determined differences between Memory Website and Memory Phone users. Characteristics of these individuals are also shown in Table 1 . Individuals who used the Memory Phone were significantly older $(t(1,848)=6.51, p<.01)$, more often woman $\left(\aleph^{2}(1, n=1,845)=25.14, p\right.$ $<.01)$ and perceived themselves more often as forgetful $\left(\aleph^{2}(1, n=1,838)=\right.$ $211.38, p<.01)$. The reason for using the Memory Phone and the Memory Website was also different $\left(\aleph^{2}(2, n=1,850)=57.49, p<.01\right)$. More participants of the Memory Phone called because of their worries about their own or someone else's forgetfulness, compared with Memory Website users. Memory Website users visited more often because of their general interest than Memory Phone users.

\section{Figure 2}

Percentage visits of non-professional Memory Phone $(n=189)$ and Memory Website $(n=1,661)$ users above 50 years

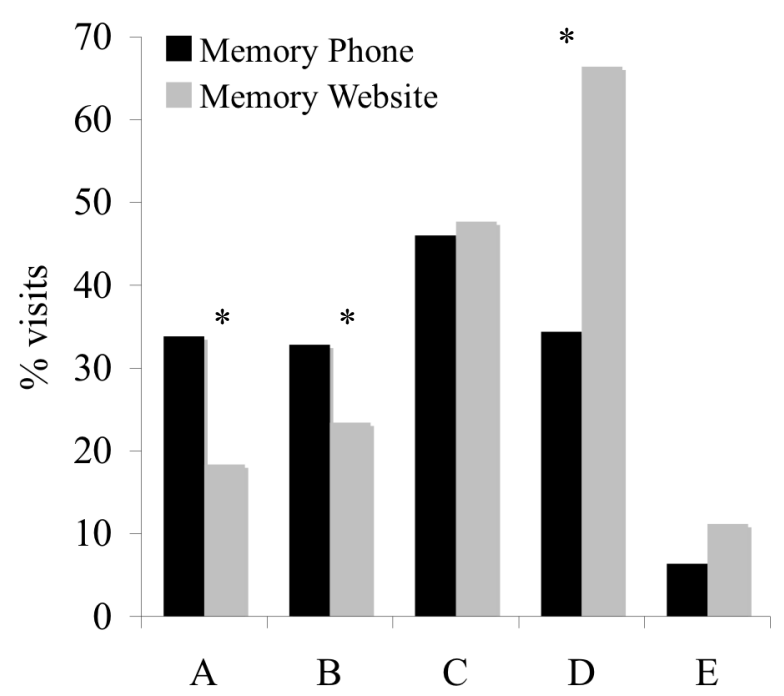

$\mathrm{A}=$ Functioning of the memory; $\mathrm{B}=$ Factors that influence memory; $\mathrm{C}=$ Differences between forgetfulness and dementia; $\mathrm{D}=$ Tips to keep the memory fit; $\mathrm{E}=$ Where to find more information $* p<0.01$ 


\section{Requested information}

In the non-professional participants aged above 50 years, users of the Memory Website visited an equal number of submenus compared with users of the Memory Phone (see Figure 2, where raw data are presented). After performing logistic regression (corrected for sex and age), it appeared that two submenus were significantly more visited by participants of the Memory Phone compared with participants of the Memory Website. (i.e. 'functioning of the memory' (OR $=0.3 ; \mathrm{W}=29.34, p<.01)$ and 'factors that influence the memory' $(\mathrm{OR}=0.5$; $\mathrm{W}=9.19, p<.01)$. On the other hand, Memory Website users visited the submenu 'tips to keep the memory fit' more $(\mathrm{OR}=3.4 ; \mathrm{W}=43.33, p<.01)$ than Memory Phone Users. The submenus 'Differences between forgetfulness and dementia' and 'Where to find more information' were equally visited by participants of the Memory Website and by participants of the Memory Phone. No information is available of the time spent in the submenus.

\section{Outcome information}

In the specific group of non-professional participants above 50 years, 32\% of the Memory Phone users and $49 \%$ of the Memory Website users visited the exit procedure. Individuals who did not enter the exit procedure were significantly older $(\mathrm{M}=65$ vs $\mathrm{M}=64 ; t(1848)=2.28, p<.05)$ perceived themselves more often as forgetful $\left(74 \%\right.$ vs $\left.70 \% ; \aleph^{2}(1, n=1,838)=4,0, p<.05\right)$ and visited more often because of worries about forgetfulness $\left(\aleph^{2}(2, n=1,850)=9,0, p<\right.$ $.05)$.

In the non-professional participants above 50 years, results showed that a large part of the users of the Memory Phone and of the Memory Website considered the service to be very useful or a little useful (no significant difference between Website and Phone users, see Table 2).

When asked if the worries about someone's own or someone else's forgetfulness had decreased, $63 \%$ of the participants of the Memory Phone indicated that their worries had decreased, compared with $36 \%$ of the users of the Memory Website $\left(\aleph^{2}(3, n=877)=18.16, p<.01\right)$. The percentage of individuals who indicated that they perceived no worries or did not know whether their memory complaints had reduced yet was higher among Website users than among Phone users. Additional analyses with logistic regression showed that the difference between decrease in worries (yes/no) was still significantly different between Memory Phone and Memory Website users, after correcting for sex and age $(\mathrm{OR}=0.35 ; \mathrm{W}=5.27, p<.05)$.

When participants were asked whether they were planning to search for more information, significant differences between users of the Memory Website and users of the Memory Phone were also found $\left(\aleph^{2}(4, n=870)=48.45, p<\right.$ $.01)$. 


\section{Table 2}

Outcome information of non-professional individuals above 50 years, visiting the Memory Phone and the Memory Website

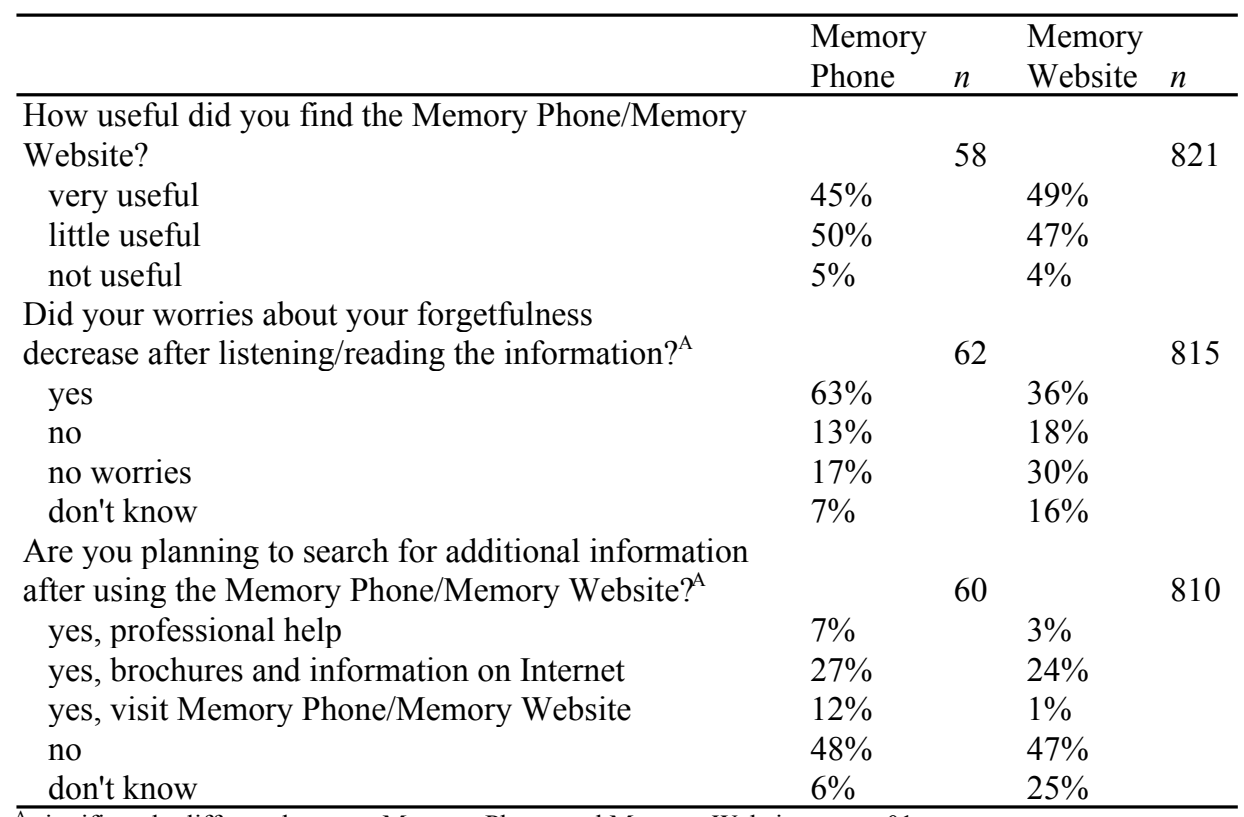

${ }^{\mathrm{A}}$ significantly different between Memory Phone and Memory Website at $p<.01$

\section{Discussion}

The present study aimed to evaluate and compare two newly developed information services about forgetfulness and aging, the Memory Phone and the Memory Website. A large group of individuals used the information services. The Memory Website was used by far more individuals than the Memory Phone. Yet, it is interesting to note that the two services were used by different populations. Individuals who used the Memory Phone were significantly older, more often female, and perceived themselves more often as forgetful. On the other hand, more users of the Memory Website visited because of general interest in the topic of memory and aging compared with Memory Phone users. Specific differences were also found in the requested information between Memory Phone users and Memory Website users. Our focus was on the population consisting of non-professional participants above 50 years. In this group of participants, general information about memory was more often requested by Memory Phone users compared with Memory Website users (67\% vs $41 \%$, respectively). Memory Website users, on the other hand, requested strategies and tips more often than Memory Phone users (66\% vs 34\%, respectively). After obtaining the information, the Memory Phone and the Memory Website were considered equally useful. 
In the present study, more individuals used the Memory Website than the Memory Phone $(n=2,631$ vs $n=228)$. Several previous studies have also found that the telephone as information service is used less frequently than a website facility. In a study by Larner (2003), the use of internet websites and a telephone helpline as sources of medical information were investigated in patients and their caregivers attending a specialized health care facility for cognitive dysfunction. Of the 104 patients and carers evaluated in that study, 28 patients/carers searched for medical websites and only 10 had used the telephone service. Basch, Thaler, Shi, Yakren, and Schrag (2004) investigated in a survey among 223 cancer patients and 220 companions that telephone resources were used substantially less often as information resources about cancer than the Internet. So, telephone resources were not commonly accessed. We can only speculate about possible reason for the finding that the telephone is not used as often as the Internet. Possibly, calling a telephone service requires more effort and is experienced as less easy than visiting a website. However, with the advent of new mobile technologies such as wireless web browsing, short messaging systems, or interactive telephone programmes, there may be an opportunity for increased use of telephone based health care application in the future (Basch et al., 2004). Furthermore, even though the telephone is not used as often as the Internet, it is still an information service that can be used by the older population. This is also found in the current study, in which the average age of users of the Memory Phone was higher than that of the Memory Website. Only few older people own a computer or have access to it (Irizarry, Downing, \& West, 2002; Magnusson et al., 2004) and many older persons use their telephones comfortably and effectively (Magnusson et al., 2004; Mundt et al., 2001). Therefore, it is underscored that different types of information services should be used to offer information about memory and aging to reach a broad range of people.

In non-professionals above 50 years it appeared that participants of the Memory Phone were more interested in general information about the memory than Website users, who were more interested in tips and strategies to cope with forgetfulness. Previous studies have also found specific differences in requested information between information services. However, these studies give contradictory results, with regard to the information requested for the Internet and for the telephone. Basch, et al. (2004) investigated the information resources by patients with cancer and their companions. Comparable to our study, it was found that most Internet users sought information on treatment and coping. Another study, by Hardyman, Hardy, Brody and Stephens (2005), found opposite results, when investigating two comparable sources of cancer information, a website and a telephone helpline. Results showed that Internet users search for facts to fulfil their basic information needs, while users of the telephone helpline wish to discuss issues such as treatments and coping with the disease. Finally, Mundt (2001) investigated an interactive voice response (IVR) dementia information system. Of the 178 callers reaching the main menu, most 
individuals requested general information about dementia and information about treatment, while a minority requested information about the prevalence and risk factors and the information about where to find more information. So, populations interested in other topics use different information services to obtain the information they need. In the present study, both information services were used to request specific information. This underscores the need for both services, so everybody can obtain the information needed.

After using the information services we hope to enable individuals to evaluate their cognitive functioning and subsequently decrease the worries about developing dementia, or encourage them to visit the general practitioner when memory complaints have a more serious character. In the target group, worries were reduced more often after using the Memory Phone than after using the Memory Website. A possible explanation for this might be the different information that is obtained while using the two services. Apparently, after obtaining general information regarding the memory, worries will decrease more, than when tips are obtained. Another possible explanation could be that the phone, as a medium, decreases more worries than the Internet. Although the analyses to determine the differences between Memory Phone and Memory Website were corrected for age and sex, it is also possible that other participant's characteristics (e.g. the amount of experienced fear of dementia, level of education) are causing the difference in decrease in worries. Note, however, that the results have to be interpreted with caution, because the decrease in worries was asked with a single question, without specifying the amount of worries experienced beforehand and afterwards. More research is needed to elaborate on these results and explanations.

Other than traditional care and health prevention, the users of telehealth are non-professionals as well as professionals. The non-professionals are consumers, such as 'worried well' and health conscious individuals and the professionals are health providers, such as the traditional physicians, nurses and other health professionals (Heinzelmann, Lugn, \& Kvedar, 2005). These professionals are interested to learn and want to be informed about the latest information available (Claxton, 1999). The professionals in the present study had a distinct preference for the Memory Website over the Memory Phone (17\% vs $9 \%$, respectively).

A strong point of the present study is the large number of participants who used the information services. Also, older individuals who were not professionally interested were reached by the mediums; $83 \%$ of the Phone users and $64 \%$ of the Website users belonged to this population. Besides these strong aspects, the results of this study have to be interpreted with caution. Differences found between Memory Website and Memory Phone users might not only be caused by the intervention, other factors, such as level of education, previous obtained knowledge about forgetfulness, experienced memory-related anxiety, access to and experiences with computer use and the fact that the use of the Memory Website was free but the use of the Memory Phone was 1 cent per 
minute might have also influenced the differences found between Memory Phone and Memory Website users. In the present study, we took possible influences of sex and age on the findings into account, by correcting the analyses for these two variables. In the future, more characteristics of individuals can be obtained, to correct for possible other factors influencing the differences between the two information services.

In conclusion, different populations used the Memory Phone and the Memory Website. Individuals who used the Memory Phone were significantly older, more often female, and perceived themselves more often as forgetful. On the other hand, users of the Memory Website visited more often because of general interest in the topic of memory and aging than Memory Phone users. In the specific group of non-professionals above 50 years, general information about the memory was more requested by Phone users compared with Website users. Memory Website users requested more often strategies and tips than Memory Phone users. Furthermore, the Memory Phone and the Memory Website were both considered useful. Overall, the Memory Website and the Memory Phone are two different types of evidence-based telehealth interventions, reaching different populations, and are considered useful by older individuals.

\section{Acknowledgements}

We thank Jim Mundt for sharing his expertise, Nico Rozendaal for his technical support with the information services, Martin van Boxtel for his assistance in the construction of the Memory Phone, Kelly Schaekens for her assistance in collecting and organizing the data and all others who contributed to this project: Floor van Bergen, Kees Commissaris, Hans Hasker, Geert Leenders, Ron Mengelers, Elsa Misdom, Emilio Perez, Caroline Roulaux, Marjolein de Vugt and Eric Vuurman. 


\section{References}

Basch, E. M., Thaler, H. T., Shi, W., Yakren, S., \& Schrag, D. (2004). Use of information resources by patients with cancer and their companions. Cancer, 100(11), 2476-2483.

Bashshur, R. L. (2002). Telemedicine/telehealth: an international perspective. Telemedicine and health care. Telemedicine Journal and e-Health, 8(1), 5-12.

Bazargan, M., \& Bazargan, S. (1997). Self-reported memory function and psychological wellbeing among elderly African American persons. Journal of Black Psychology, 23(2), 103-119.

Blazer, D. G., Hays, J. C., Fillenbaum, G. G., \& Gold, D. T. (1997). Memory complaint as a predictor of cognitive decline: a comparison of African American and White elders. Journal of Aging and Health, 9(2), 171-184.

Bolla, K. I., Lindgren, K. N., Bonaccorsy, C., \& Bleecker, M. L. (1991). Memory complaints in older adults. Fact or fiction? Archives of Neurology, 48(1), 61-64.

Bos, A. E., Visser, G. C., Tempert, B. F., \& Schaalma, H. P. (2004). Evaluation of the Dutch AIDS information helpline: an investigation of information needs and satisfaction of callers. Patient Education and Counseling, 54(2), 201-206.

Claxton, G. (1999). Wise Up. The Challenge of Lifelong Learning. New York: Bloomsbury Publishing.

Commissaris, C. J. A. M., Ponds, R. W. H. M., \& Jolles, J. (1998). Subjective forgetfulness in a normal Dutch population: possibilities for health education and other interventions. Patient Education and Counseling, 34, 25-32.

Commissaris, K., Verhey, F. R., \& Jolles, J. (1996). A controlled study into the effects of psychoeducation for patients with cognitive disturbances. The Journal of Neuropsychiatry and Clinical Neurosciences, 8(4), 429-435.

Craig, J., \& Patterson, V. (2005). Introduction to the practice of telemedicine. Journal of Telemedicine and Telecare, 11(1), 3-9.

De Bie, S. E. (1987). Standaardvragen 1987: voorstellen voor uniformering van vraagstellingen naar achtergrondkenmerken en interviews [Standard questions 1987: proposal for uniformisation of questions regarding background variables and interview]. (2nd ed.). Leiden, The Netherlands: Leiden University Press.

Derouesné, C., Lacomblez, L., Thibault, S., \& LePoncin, M. (1999). Memory complaints in young and elderly subjects. International Journal of Geriatric Psychiatry, 14(4), 291301.

Hardyman, R., Hardy, P., Brodie, J., \& Stephens, R. (2005). It's good to talk: comparison of a telephone helpline and website for cancer information. Patient Education and Counseling, 57(3), 315-320.

Heinzelmann, P. J., Lugn, N. E., \& Kvedar, J. C. (2005). Telemedicine in the future. Journal of Telemedicine and Telecare, 11(8), 384-390.

Hesse, B. W., Nelson, D. E., Kreps, G. L., Croyle, R. T., Arora, N. K., Rimer, B. K., et al. (2005). Trust and sources of health information: the impact of the Internet and its implications for health care providers: findings from the first Health Information National Trends Survey. Archives of Internal Medicine, 165(22), 2618-2624.

Irizarry, C., Downing, A., \& West, D. (2002). Promoting modern technology and Internet access for under-represented older populations. Journal of Technology in Human Services, 19(4), 13-30.

Jadad, A. R., Sigouin, C., Cocking, L., Booker, L., Whelan, T., \& Browman, G. (2001). Internet use among physicians, nurses, and their patients. Journal of the American Medical Association, 286(12), 1451-1452.

Jorm, A. F., Christensen, H., Korten, A. E., Henderson, A. S., Jacomb, P. A., \& Mackinnon, A. (1997). Do cognitive complaints either predict future cognitive decline or reflect past 
cognitive decline? A longitudinal study of an elderly community sample. Psychological Medicine, 27, 91-98.

Larner, A. J. (2003). Use of the internet and of the NHS direct telephone helpline for medical information by a cognitive function clinic population. International Journal of Geriatric Psychiatry, 18(2), 118-122.

Magnusson, L., Hanson, E., \& Borg, M. (2004). A literature review study of Information and Communication Technology as a support for frail older people living at home and their family carers. Technology and Disability, 16, 223-235.

Mahoney, D. F., Tarlow, B. J., \& Jones, R. N. (2003). Effects of an automated telephone support system on caregiver burden and anxiety: findings from the REACH for TLC intervention study. Gerontologist, 43(4), 556-567.

Mair, F., \& Whitten, P. (2000). Systematic review of studies of patient satisfaction with telemedicine. British Medical Journal, 320(7248), 1517-1520.

Mol, M. E. M., Carpay, M., Ramakers, I., Rozendaal, N., Verhey, F. R. J., \& Jolles, J. (in press). The effect of perceived forgetfulness on quality of life in older adults: a qualitative review. International Journal of Geriatric Psychiatry.

Mundt, J. C., Kaplan, D. A., \& Greist, J. H. (2001). Meeting the need for public education about dementia. Alzheimer Disease and Associated Disorders, 15(1), 26-30.

Slegers, K., Van Boxtel, M. P. J., \& Jolles, J. (in press). The effects of computer training and Internet usage on autonomy, wellbeing and social network of older adults: A randomized controlled study. Journal of Gerontology: Psychological Sciences.

Valentijn, S. A., van Hooren, S. A., Bosma, H., Touw, D. M., Jolles, J., Van Boxtel, M. P., et al. (2005). The effect of two types of memory training on subjective and objective memory performance in healthy individuals aged 55 years and older: a randomized controlled trial. Patient Education and Counseling, 57(1), 106-114.

Verhaeghen, P., Geraerts, N., \& Marcoen, A. (2000). Memory complaints, coping, and well-being in old age: a systemic approach. Gerontologist, 40(5), 540-548. 


\section{9}

\section{Concluding remarks}


The main objective of this thesis was to gain more insight into the possibilities of educational interventions for healthy older adults with forgetfulness. In order to achieve this, the present thesis had two aims. The first aim was to increase knowledge of forgetfulness by studying determinants of those individuals who regard themselves as forgetful. The second aim was to evaluate specific educational interventions and to investigate whether these interventions were suitable for providing information on forgetfulness to the older population.

Regarding the first aim, several determinants, i.e. factors that may be related to forgetfulness, were studied. One of the determinants of interest was cognitive performance. When studying the relation between objective cognitive performance and subjective memory complaints, results showed that forgetfulness might be accompanied by poor cognitive functioning. However, complaints of forgetfulness do not precede cognitive decline over a period of several years. Another determinant of interest was quality of life. A significant negative association was observed between forgetfulness on the one hand and quality of life on the other. Furthermore, several psychosocial, psychiatric and behavioural determinants of forgetfulness were identified as possible factors as a target for future interventions. With regard to the second aim, two educational interventions (a lecture and a symposium) were investigated in order to determine whether they were suitable for providing information to the older population. Findings showed that an educational intervention might improve knowledge on forgetfulness when the information was tailored to the needs of the participants. In addition, two types of newly developed information services using telehealth (i.e, the Memory Website and the Memory Phone) were compared and evaluated, providing interesting insights into the benefits of telehealth services for older individuals who perceive themselves as forgetful.

The present chapter is dedicated to a discussion of issues that have emerged from the empirical findings reported in the current thesis. More specifically, characteristics of forgetfulness and the impact on daily life are discussed, and implications for future research are given. Subsequently, possibilities for interventions for older adults are addressed. This chapter ends with an elaboration on some practical implications for interventions on forgetfulness.

\section{Forgetfulness in daily life}

There is ample evidence that advancing age is associated with decrements in a wide range of cognitive functions, such as information recall and information processing speed (e.g. Birren \& Schaie, 2006; Kausler, 1994). Thus a small decrease in cognitive functioning when growing older is a common phenomenon and is a symptom of normal aging. Results in this thesis showed that forgetfulness was an indicator of slower general information processing and a decreased delayed recall at baseline; however, forgetfulness did not predict a change in cognitive decline over a period of six years (Chapter 2). Thus, 
forgetfulness might co-occur with poor cognitive function but does not precede cognitive decline over a longer period.

It is important to establish the potential causes of memory complaints, but it is of equal importance to acknowledge that forgetfulness has a negative impact on someone's quality of life. In the current thesis a negative relation was observed between forgetfulness and quality of life (Chapters 3 and 4). Determining the relationship between forgetfulness and quality of life has some important implications. For instance, forgetfulness is stressed as a serious health issue in the daily life of older individuals. Furthermore, this particular health issue (i.e. forgetfulness) has proven to be serious enough to invest in and to create interventions for. Acknowledgement of the health issue is an important step in designing interventions, according to systematic health promotion planning models such as Intervention Mapping (Bartholomew, Parcel, Kok, \& Gottlieb, 2006) and the PRECEDE-PROCEED planning model (Green \& Kreuter, 2005).

The need for interventions for individuals who perceive themselves as forgetful is stressed here, especially for individuals in the age range between 54 and 70 years. Results in the present thesis showed that forgetfulness and decreased satisfaction with life were apparent in individuals aged between 54 and 69 years, but not in individuals aged between 70 and 91 years (Chapter 4). A possible explanation for the observation that forgetfulness is appreciated differently by individuals of different ages is that older individuals may accept forgetfulness as being part of the aging process, as opposed to younger individuals who might perceive forgetfulness mainly as a burden, as it interferes with everyday life. That is, younger individuals, contrary to older individuals, are likely to be active in professional activities and experience workload. They may therefore encounter more direct hindrance from their forgetfulness throughout the day. However, more research is needed to unravel the mechanisms proposed in this line of reasoning and more research can be done to investigate specific age differences in individuals who perceive themselves as forgetful.

In future research the relationship between subjective memory complaints and quality of life should be studied in more detail. Determining the extent to which depressive symptoms mediate the negative association between quality of life and forgetfulness might be relevant in this respect, because it is known that depression is associated with both quality of life (Diener \& Suh, 1998; Felce \& Perry, 1995) and forgetfulness (Comijs, Deeg, Dik, Twisk, \& Jonker, 2002; Ponds, Commissaris, \& Jolles, 1997). Furthermore, the influence of objective memory performance on quality of life could be investigated in order to establish potential differences in the extent to which subjective and objective memory complaints can affect quality of life. In the present thesis quality of life was assessed using scales relating to general aspects of quality of life, such as wellbeing and satisfaction with life. In the future, a dedicated scale of quality of life should be developed in order to assess quality of life related to 
cognitive functions, such as memory and information processing speed. This could provide detailed insight into how cognitive functions might influence quality of life.

\section{Interventions for older adults}

According to the concept of 'lifelong learning' that has been promoted in recent years, learning from the lifelong perspective spans the period from before the start of school into old age (OECD, 2002). It is important to enable individuals to continue learning throughout their lives so they can function independently and healthily into old age. Interventions on forgetfulness are an important aspect of lifelong learning in older adults. Up till now interventions on forgetfulness were mainly based on the principles of psycho-education. Although this particular kind of intervention can be effective (e.g. Valentijn et al., 2005; Van Hooren et al., in press), it is often time consuming and only suitable for implementation in small groups. Since a rather large part of the older population perceives itself as forgetful, it is crucial to address large groups of individuals. The present thesis used health promotion approaches and general educational activities for the purpose of educating older individuals about forgetfulness.

Findings in Chapters 6 and 7 show that currently available easily accessible educational interventions on forgetfulness can be successful, provided that the content of the educational information is tailored to the needs and the level of knowledge of the participant. Tailoring the information content to the needs of the individuals was previously found to be a promising strategy for health education (Brug \& De Vries, 1999; Kreuter, Strecher, \& Glassman, 1999; Ruiter, Kessels, Jansma, \& Brug, 2006). It is reasonable to assume that this approach also applies to educational interventions focusing on forgetfulness. Furthermore, telehealth (i.e. public health services and health promotion through electronic means of communications) appeared to be useful for informing the older population about forgetfulness. As described in Chapter 8, the Memory Website and the Memory Phone, two newly developed information services, are different with respect to visitors' characteristics, information requested and were both considered useful. In conclusion, not only psycho-education, but also educational interventions and health promotion approaches are suitable for informing the extensive proportion of older adults in our population about forgetfulness.

The educational interventions in the present thesis were specifically not investigated as a randomized controlled trial, but were evaluated in their original setting with their natural users. In this way the functioning of educational interventions in their original form could be assessed. In the future new studies should be performed to assess other effects of educational interventions, such as decreases in worrying about becoming demented and changes in quality of life and wellbeing. 


\section{Implications for future interventions on forgetfulness}

Findings in the present thesis have some implications for future interventions for older individuals with subjective memory complaints. Firstly, characteristics of individuals with subjective memory complaints have to be taken into account when designing new interventions. It has been observed that forgetfulness is associated with the presence of symptoms of depression and anxiety (Chapters 2, 4 and 5). These should therefore be the focus of future interventions. Symptoms of anxiety can, for instance, be diminished by reducing the level of arousal experienced and the tension that arises when someone forgets things.

Memory self-efficacy has also been identified as an important determinant of forgetfulness in older individuals (Chapter 5). Memory selfefficacy refers to the degree of belief one has in the ability to mobilize skills for a task (Bandura, 1977, 1989; Hultsch, Hertzog, Dixon, \& Davidson, 1988). Poor memory self-efficacy reflects self-doubt and low self-esteem rather than lack of skills. It might therefore be favourable to increase self-esteem in individuals with forgetfulness in order to achieve better performance and fewer memory complaints. This might be achieved by positively reinforcing individuals after remembering and recalling things.

Furthermore, it appeared that forgetfulness is appreciated differently by individuals of different ages. For example, individuals with subjective memory complaints aged between 50 and 70 experience low satisfaction with life, while this negative association is not apparent in older individuals (Chapter 4). In addition, adults aged between 53 and 72 experience more fear of dementia, while adults above 70 have a lower memory self-efficacy (Chapter 5). These observations emphasize the need for age-specific interventions on forgetfulness. Interventions for individuals aged between 50 and 70 years, might focus more on the differences between forgetfulness in old age and dementia, and reducing the fear of dementia. This might subsequently lead to an increased level of quality of life. Interventions for individuals above 70 might be aimed at improving memory self-efficacy in order to improve perceived memory function.

It is known that the social environment within which individuals live is very important, because the nature of one's social relationships can affects one's health (House, Umberson, \& Landis, 1988). Thus, besides aiming the intervention at characteristics of individuals it is also important to involve the social environment in the intervention. In the present thesis it was found that individuals with forgetfulness experience a high level of disapproval of their memory complaints by significant others (Chapter 5). Future interventions should focus at building skills to recognize and resist experienced social pressure (Bartholomew et al., 2006). This might lead to better coping with the social influence from significant others and possibly lead to lower perceived forgetfulness. 
Evaluation of currently available interventions on forgetfulness also gives insight into ways to improve existing interventions and design new ones. A relatively low-profile lecture, characterized by low expenses and easy accessibility for a large number of individuals, might be effective in knowledge transfer (Chapter 6). Furthermore, attending a symposium and reading a magazine induced a small significant knowledge increment in a group of nonprofessional participants (Chapter 7). When an integrated strategy of different forms of public education is being designed, a lecture, symposium and magazine could be used to improve knowledge change.

It is recommended that future interventions on forgetfulness should be dedicated to relevant subgroups, covering information that is adjusted to the level of knowledge of the participants involved. This is because the content of the information desired is not the same for different groups of individuals, such as non-professionals and professionals (Chapter 6) and the amount of information transfer is also different for professionals and non-professionals (Chapter 7).

Finally, telehealth (e.g. telephone and Internet) as a means for informing the older population about memory and aging is effective in addressing populations of different age groups (Chapter 8). When offering information about memory and aging to a broad range of older individuals, telehealth can be used.

\section{Conclusion}

The present thesis has increased our insight into some psychosocial aspects of forgetfulness. An important finding is the impact of forgetfulness on someone's wellbeing. In view of the large number of older individuals who perceive themselves as forgetful, it is important to acknowledge the need for large-scale interventions on forgetfulness. Besides the currently available psychoeducation, this thesis proposed the use of educational interventions as a useful option when addressing older adults and possibly changing knowledge. The empirical studies in the present thesis provide various implications for interventions, based on characteristics of older individuals with forgetfulness, their social environment and existing and newly developed interventions. 


\section{References}

Bandura, A. (1977). Self-efficacy: towards a unifying theory of behavioral change. Psychology Review, 84, 191-215.

Bandura, A. (1989). Regulation of cognitive processes through perceived self-efficacy. Developmental Psychology, 25, 729-735.

Bartholomew, L. K., Parcel, G. S., Kok, G., \& Gottlieb, N. H. (2006). Planning Health Promotion Programs. An Intervention Mapping Approach. San Francisco, CA: Jossey-Bass.

Birren, J. E., \& Schaie, K. W. (2006). Handbook of the psychology of aging (6th ed.). San Diego, CA: Elsevier Academic Press.

Brug, J., \& De Vries, H. (1999). Computer-tailored education. Patient Education and Counseling, $36(2)$.

Comijs, H. C., Deeg, D. J. H., Dik, M. G., Twisk, J. W. R., \& Jonker, C. (2002). Memory complaints: the association with psycho-affective and health problems and the role of personality characteristics. A 6-year follow-up study. Journal of Affective Disorders, 72, 157-165.

Diener, E., \& Suh, E. M. (1998). Subjective well-being and age: an international analysis. Annual Review of Gerontology and Geriatrics, 17, 304-324.

Felce, D., \& Perry, J. (1995). Quality of life: its definition and measurement. Research in Developmental Disabilities, 16(1), 51-74.

Green, L. W., \& Kreuter, M. W. (2005). Health program planning: an educational and ecological approach (4th ed.).

House, J. S., Umberson, D., \& Landis, K. R. (1988). Structures and processes of social support. Annual Review of Sociology, 14, 293-318.

Hultsch, D. F., Hertzog, C., Dixon, R. A., \& Davidson, H. (1988). Memory self-knowledge and self-efficacy in the aged. In N. L. Lowe \& C. J. Brainerd (Eds.), Cognitive development in adulthood: progress in cognitive developmental research (pp. 65-92). New York: Springer-Verlag.

Kausler, D. H. (1994). Learning and Memory in Normal Aging (1st ed). San Diego, : Academic Press.

Kreuter, M. W., Strecher, V. J., \& Glassman, B. (1999). One size does not fit all: the case for tailoring print materials. Annals of Behavioral Medicine, 21(4), 276-283.

OECD. (2002). Understanding the brain. Towards a new learning science. Paris: OECD publications.

Ponds, R. W., Commissaris, K. J., \& Jolles, J. (1997). Prevalence and covariates of subjective forgetfulness in a normal population in The Netherlands. International Journal of Aging and Human Development, 45(3), 207-221.

Ruiter, R. A. C., Kessels, L., Jansma, B. M., \& Brug, J. (2006). Increased attention for computertailored health communications: an event-related potential study. Health Psychology, 25, 300-306.

Valentijn, S. A., van Hooren, S. A., Bosma, H., Touw, D. M., Jolles, J., Van Boxtel, M. P., et al. (2005). The effect of two types of memory training on subjective and objective memory performance in healthy individuals aged 55 years and older: a randomized controlled trial. Patient Education and Counseling, 57(1), 106-114.

Van Hooren, S., Valentijn, S. A. M., Bosma, H., Ponds, R. W. H. M., Van Boxtel, M., Robertson, B., et al. (in press). Effect of a structured course involving goal management training in older adults: a randomised controlled trial. Patient Education and Counseling. 


\section{0}

\section{Summary}


The central theme of this thesis was to gain insight into the characteristics of healthy individuals who perceive themselves as forgetful. With the information we hope to give recommendations for interventions for forgetful older people. First of all, possible determinants, i.e. factors that may be related to forgetfulness, were investigated. Objective cognitive performance, quality of life and a variety of psychosocial factors were determinants of interest. Next, specific intervention methods were evaluated to investigate whether they could contribute to providing information on forgetfulness to the older population. In Chapter 1, a general introduction was given on the central theme, the aims and the approach of this thesis.

The objective of Chapter 2 was to investigate the relation between subjective memory complaints and actual objective performance on cognitive tasks. Furthermore, trying to keep mentally active, as a possible way to improve objective cognitive performance, was investigated in participants with subjective memory complaints. Data from baseline and 6-year follow-up measurements were obtained from the longitudinal Maastricht Aging Study, involving 557 participants aged from 55 to 85 years. At baseline, subjective memory complaints were associated with a lower speed of general information processing and a poorer performance on delayed recall. At the 6-year follow-up, however, subjective memory complaints were not associated with a significant change in cognitive performance. Taking steps to remain cognitively active was not a predictor of better performance on cognitive tasks at baseline or at the 6year follow-up. In conclusion, being forgetful might be an indicator of slower general information processing speed and poorer delayed recall at baseline, but does not predict cognitive change over 6 years in older adults. However, the observed effects are relatively small and therefore cannot directly be generalized to applications in clinical settings. Other factors, such as depression and anxiety, might also underlie the occurrence of subjective memory complaints.

Chapter 3 presented a systematic review of previous research on the relation between perceived forgetfulness and quality of life in older individuals. Scientific papers investigating this relation were searched. This search resulted in 682 relevant publications, of which five met the inclusion criteria. Two independent raters scored these publications in terms of the methodology. The methodological quality was taken into account when conclusions were drawn. The methodologically adequate studies showed a relation between memory complaints and diminished quality of life in older individuals, even though the five studies differed in their methodology. The negative impact that subjective memory complaints can have on quality of life makes it important to acknowledge forgetfulness as a serious issue in the everyday life of older individuals. However, a more thorough exploration of the observed relationship between subjective memory complaints and quality of life is needed, especially with regard to the potential influence of depression and objective memory performance on this relationship. 
The relation between subjective memory complaints and quality of life was also investigated in Chapter 4. A large group of healthy older adults $(N=$ $412,>54$ years) participating in the Maastricht Aging Study was studied in order to determine whether forgetfulness was related to quality of life and whether forgetfulness can be regarded as a predictor of changes in quality of life over time. Data obtained at baseline and at 3, 6, and 9 year follow-up were analyzed using Linear Mixed Models. Results showed that forgetfulness was negatively associated with an overall reduced quality of life. In addition, anxiety symptoms in forgetful individuals were shown to increase by the year, while these symptoms remained stable over the years in individuals who did not report subjective memory complaints. Furthermore, the relation between forgetfulness and low satisfaction with life was significant in younger participants (aged from 54 to 69 years), but not in older participants (70 to 91 years). Again, these findings emphasize the negative impact of perceived forgetfulness on a person's life.

Many healthy individuals perceive themselves to be forgetful and are interested in educational interventions that might be helpful in decreasing worries and reducing forgetfulness. Educational interventions might be more effective when determinants, that are known to predict forgetfulness, are targeted. In Chapter 5, a broad range of relevant determinants was selected from the literature and from experiences in clinical settings. Subsequently, the most important determinants among the selected ones were identified. The study was cross-sectional in nature: a large sample of 300 healthy participants over the age of 54 years filled in a self-report questionnaire. The results of the logistic regression showed that low memory self-efficacy, high memory-related anxiety, negative attitude and high subjective norm (e.g. anticipating negative evaluations by important others) were the most important determinants of forgetfulness. Focussing future interventions on these particular determinants might improve the effectiveness of interventions for individuals with forgetfulness. In this chapter several implications for future interventions for individuals with forgetfulness were presented.

Chapters 6 and 7 evaluated the effectiveness of several educational interventions on forgetfulness and aging. In Chapter 6, the effectiveness of a lecture that was part of a series of lectures about dementia was evaluated. Before and after the lecture the participants filled in a questionnaire with knowledge questions and some additional questions regarding subjective experiences of the lecture. The results showed an improvement in knowledge after the lecture and satisfaction of the participants afterwards. Furthermore, it appeared that this kind of educational intervention is especially useful for professionals as well as for individuals who were worried about their memory function or their partner's memory function.

In Chapter 7, a one-day symposium covering memory-related topics and a magazine with similar information, were evaluated. A controlled intervention trial with a parallel group design and a pre- and post-measurement 
was used. Participants in group $1(n=273)$ attended the one-day symposium and received the magazine. Group $2(n=141)$ only received the magazine. Participants were both non-professionals and professionals. As regards nonprofessionals, General Linear Models showed that the knowledge increment was higher in group $1(9 \%)$ than in group $2(4 \%)$. In professionals, no change in knowledge was observed. All participants positively evaluated the specific intervention they had participated in. The findings indicate that educational activities on forgetfulness and aging can contribute to high participant satisfaction, even when knowledge transfer was limited.

With the increasing interest in the use of telehealth as a method of health care delivery, telehealth was investigated as a possible suitable method to inform the general public about forgetfulness. In Chapter 8, two newly developed telehealth-based interventions, i.e. the Memory Website and the Memory Phone, were evaluated and compared. The aims of this study were to describe and compare the characteristics of individuals who are interested in the Memory Phone and the Memory Website, to investigate the content of information the users are interested in, and to investigate their appreciation of the intervention afterwards. Participants were individuals who voluntarily called the Memory Phone or visited the Memory Website. They were asked to respond to a number of questions before and after using the information service. Results showed that more individuals used the Memory Website $(n=2,631)$ than the Memory Phone $(n=228)$, however, both services were used by different populations. That is, users of the Memory Phone were significantly older, more often female and perceived themselves more often as forgetful, compared with the users of the Memory Website. When the specific group of non-professional participants above the age of 50 years was investigated it appeared that more users of the Memory Phone requested general information on memory, compared with Memory Website users. Users of the Memory Website requested strategies and tips more than Memory Phone users. Furthermore, both the Memory Phone and the Memory Website were evaluated as being useful. Summarizing, the Memory Phone and the Memory Website seem to be two information services for different populations and both are considered to be useful by the older population.

Finally, in Chapter 9 the findings and main conclusions presented in this thesis were discussed. Overall, the findings of the present thesis increased insight into subjective forgetfulness. The impact of forgetfulness on someone's wellbeing is highlighted, indicating the importance of interventions on this issue. In the current thesis the application of educational interventions is proposed as a useful intervention method for addressing older adults and possibly change knowledge. The outcome of the empirical studies in this thesis provided various implications and suggestions for future interventions based on determinants of subjective forgetfulness, existing and newly developed interventions. 


\section{1}

\section{Samenvatting}


Het doel van het voorliggende proefschrift was om meer inzicht te verwerven in de kenmerken van gezonde mensen die zichzelf vergeetachtig vinden. Met de bevindingen die zijn voortgekomen uit de studies zouden vervolgens aanbevelingen kunnen worden gedaan voor interventies gericht op vergeetachtigheid bij gezonde oudere mensen. Verschillende determinanten, of factoren, die mogelijk gerelateerd zijn aan vergeetachtigheid werden onderzocht, zoals cognitieve prestatie, kwaliteit van leven en diverse psychosociale factoren. Daarnaast werden enkele interventiemethoden geëvalueerd op hun geschiktheid om oudere mensen te informeren over vergeetachtigheid. In Hoofdstuk 1 werd een algemene introductie gegeven inzake de achtergrond en de vraagstellingen van het onderzoek en werd een overzicht gegeven van de opbouw van dit proefschrift.

In Hoofdstuk 2 werd een onderzoek beschreven naar de mogelijke relatie tussen subjectieve geheugenklachten en objectieve cognitieve prestatie, zoals gemeten met behulp van diverse neuropsychologische tests. Aanvullend werd onderzocht of het ondernemen van activiteiten gericht op het 'mentaal actief' blijven de cognitieve prestatie bij mensen die zichzelf vergeetachtig vinden kon verbeteren. Om deze vraagstellingen te kunnen beantwoorden werden de gegevens gebruikt op baseline en na zes jaar. Het ging om 557 deelnemers (55-85 jaar) van de longitudinale Maastricht Aging Study (MAAS). Op baseline werd vergeetachtigheid geassocieerd met een verminderde snelheid van informatieverwerking en een verminderde uitgestelde herinnering. Echter, vergeetachtigheid op baseline was niet geassocieerd met een verandering in cognitieve prestatie na zes jaar. Tenslotte was het ondernemen van activiteiten gericht op het 'mentaal actief' blijven niet geassocieerd met betere cognitieve prestaties op baseline of na 6 jaar. Kortom, subjectieve vergeetachtigheid kan een indicator zijn van een verminderd cognitief functioneren op baseline, maar voorspelt geen cognitieve verandering na 6 jaar. Echter, de geobserveerde effecten zijn relatief klein en kunnen daarom niet direct worden gegeneraliseerd naar een klinische setting. In aanmerking dient te worden genomen dat andere factoren, zoals symptomen van angst en depressie, ook ten grondslag kunnen liggen aan vergeetachtigheid.

Hoofdstuk 3 gaf een systematisch overzicht van eerder onderzoek naar de relatie tussen vergeetachtigheid en kwaliteit van leven in de oudere populatie. Wetenschappelijke artikelen werden verzameld die deze relatie onderzochten. In totaal werden 682 relevante wetenschappelijke artikelen gevonden, waarvan er 5 voldeden aan de inclusiecriteria. Twee onafhankelijke beoordelaars scoorden de publicaties op methodologische kwaliteit. Bij het trekken van de conclusies werd met de methodologische kwaliteit rekening gehouden. De methodologisch adequate studies rapporteerden alle een relatie tussen subjectieve geheugenklachten en een verminderde kwaliteit van leven, ondanks dat de 5 studies verschillende methoden gebruikten. Deze negatieve associatie tussen subjectieve geheugenklachten en kwaliteit van leven benadrukt hoe belangrijk het is om vergeetachtigheid bij gezonde oudere mensen als een 
serieus probleem te beschouwen. Verder onderzoek is echter nodig om vast te stellen hoe factoren zoals depressie en objectieve geheugenprestatie aangrijpen op de relatie tussen subjectieve geheugenklachten en kwaliteit van leven.

De relatie tussen geheugenklachten en kwaliteit van leven werd ook bestudeerd in Hoofdstuk 4. Bij gezonde ouderen werd bepaald of vergeetachtigheid gerelateerd was aan een verminderde kwaliteit van leven en of de vergeetachtigheid een verandering in kwaliteit van leven kon voorspellen in de loop van de tijd. Een grote groep deelnemers, ouder dan 54 jaar $(N=412)$, aan de longitudinale Maastricht Aging Study (MAAS) werd ondervraagd op baseline en na 3, 6, en 9 jaar. De uitkomstmaten waren vier aspecten van kwaliteit van leven, namelijk tevredenheid met het leven, mentaal welbevinden, en symptomen van angst en depressie. Statistische analyses werden uitgevoerd met Linear Mixed Models. De resultaten lieten allereerst zien dat vergeetachtigheid negatief geassocieerd was met alle gebruikte uitkomstmaten van kwaliteit van leven. Echter, de relatie tussen vergeetachtigheid en verminderde tevredenheid met het leven was uitsluitend significant in de groep jongere deelnemers (54-69 jaar) en niet in de groep oudere deelnemers (71-91 jaar). Tot slot nam in de loop van de tijd de symptomen van angst significant meer toe bij mensen die zichzelf vergeetachtig vonden, dan bij mensen die zichzelf niet vergeetachtig vonden. De bevindingen van deze studie benadrukken wederom de impact van subjectieve vergeetachtigheid op het dagelijkse leven van de individu. Bovendien is gebleken dat de negatieve invloed van vergeetachtigheid op kwaliteit van leven verschillend is voor verschillende leeftijdsgroepen. Verder onderzoek zal moeten uitwijzen of interventies gericht op het reduceren van subjectieve geheugenklachten voor specifieke leeftijdsgroepen een verbetering in iemands kwaliteit van leven zou kunnen opleveren.

Veel gezonde ouderen vinden zichzelf vergeetachtig en zijn geïnteresseerd in mogelijke interventies gericht op het reduceren van deze vergeetachtigheid. Het zou de effectiviteit van dergelijke interventies wellicht ten goede komen als in deze interventies wordt ingespeeld op die determinanten die mogelijk bepalend zijn voor het ervaren van vergeetachtigheid. In Hoofdstuk 5 werd een overzicht gepresenteerd van een groot aantal van die determinanten, geselecteerd op basis van reeds beschikbare literatuur, aangevuld met ervaringen in de kliniek. Het onderzoek was cross-sectioneel van opzet; 300 gezonde deelnemers van 54 jaar en ouder vulden een vragenlijst in. De belangrijkste determinanten werden vervolgens bepaald met behulp van logistische regressie analyses. De resultaten van deze analyses lieten zien dat een lage eigen-effectiviteit ('self-efficacy'), een hoge mate van angst, een negatieve attitude ten opzichte van de eigen geheugenfuncties en een hoge subjectieve norm (i.e., anticiperen van negatieve evaluaties over het geheugen door mensen uit de directe omgeving) de belangrijkste determinanten van vergeetachtigheid waren. In dit hoofdstuk worden enkele suggesties gegeven voor interventies voor mensen met geheugenklachten. 
In de Hoofdstukken 6 en 7 werden verschillende interventies, gericht op ouderdomsvergeetachtigheid, geëvalueerd. In Hoofdstuk 6 werd de effectiviteit van een lezing uit een lezingencyclus over dementie geëvalueerd in termen van toegenomen kennis van het publiek. De deelnemers vulden voor en na de lezing een vragenlijst in met kennisvragen en vragen over de ervaren tevredenheid. Uit de resultaten bleek dat de kennis over het onderwerp na afloop van de lezing was toegenomen, en dat het publiek tevreden was over de aangeboden lezing. Bovendien kwam duidelijk naar voren dat er een grote behoefte was aan deze vorm van voorlichting, zowel voor de bezoekers die naar de lezing kwamen vanuit professionele overwegingen, als voor de mensen die de lezing bezochten omdat ze zich zorgen maakten over hun eigen geheugen of dat van iemand uit hun directe omgeving.

In Hoofdstuk 7 werd een symposium en een tijdschrift over geheugengerelateerde onderwerpen geëvalueerd. Het onderzoek werd uitgevoerd door middel van een gecontroleerde interventiestudie met een vooren een nameting. Deelnemers in groep $1(n=273)$ woonden het symposium bij en ontvingen het tijdschrift. Groep $2(n=141)$ ontving alleen het tijdschrift. Deelnemers waren zowel professionals als niet-professionals. Bij de nietprofessionals werd een significant grotere stijging in kennis geobserveerd in groep $1(9 \%)$ dan in groep $2(4 \%)$. Bij de professionals werd geen stijging in kennis geobserveerd. Alle deelnemers hebben de interventie waaraan ze deelnamen als positief ervaren. De bevindingen in dit hoofdstuk geven aan dat interventies gericht op het reduceren van vergeetachtigheid positief worden gewaardeerd door de deelnemers, zelfs als de kennisoverdracht beperkt is.

Met de toenemende interesse in het gebruik van telehealth als methode om gezondheidszorg aan te bieden via moderne media, werd in Hoofdstuk 8 onderzocht of telehealth een geschikte methode is om de oudere populatie te informeren over vergeetachtigheid. Twee nieuw ontwikkelde interventies, gebaseerd op telehealth, werden afzonderlijk geëvalueerd en met elkaar vergeleken, namelijk de Geheugentelefoon en de Geheugenwebsite. De doelen van deze studie waren het beschrijven en het vergelijken van de kenmerken van de deelnemers die gebruik maakten van de voorzieningen, het in kaart brengen welke informatie werd opgevraagd en het bepalen of men tevreden was na het gebruik van de Geheugentelefoon en Geheugenwebsite. Iedereen die de Geheugentelefoon of de Geheugenwebsite bezocht werd verzocht om een aantal vragen te beantwoorden voorafgaand aan en na gebruik van de specifieke voorziening. Resultaten lieten zien dat aanzienlijk meer mensen gebruik maakten van de Geheugenwebsite $(n=2631)$ dan van de Geheugentelefoon $(n=$ 228). Echter, er waren enkele kenmerkende verschillen tussen de gebruikers van de beide voorzieningen. De gebruikers van de Geheugentelefoon waren ouder, vaker van het vrouwelijke geslacht, en vonden zichzelf vaker vergeetachtig, vergeleken met de gebruikers van de Geheugenwebsite. In de specifieke groep van non-professionals boven de 50 jaar bleek dat algemene informatie over het geheugen meer werd opgevraagd door gebruikers van de Geheugentelefoon 
vergeleken met gebruikers van de Geheugenwebsite. Gebruikers van de Geheugenwebsite daarentegen waren meer geïnteresseerd in strategieën en tips om het geheugen optimaal te gebruiken dan gebruikers van de Geheugentelefoon. Daarnaast werden zowel de Geheugentelefoon als de Geheugenwebsite als bruikbaar ervaren. Kortom, de Geheugentelefoon en de Geheugenwebsite zijn blijkbaar twee informatie voorzieningen die elk een eigen publiek aanspreken, en die beide positief werden gewaardeerd.

Tot slot werden in Hoofdstuk 9 de belangrijkste bevindingen en conclusies uit dit proefschrift bediscussieerd. De bevindingen lieten herhaaldelijk zien dat vergeetachtigheid een negatieve invloed kan hebben op de kwaliteit van leven van de individu. Het is daarom van groot belang om de ernst en impact van dit probleem onder gezonde ouderen te erkennen. In dit proefschrift werd aangetoond dat voorlichtingsactiviteiten, zoals symposia en activiteiten gebaseerd op telehealth, bruikbare methoden waren om oudere mensen te benaderen en mogelijk kennis te vergroten over vergeetachtigheid. De bevindingen uit de wetenschappelijke studies in dit proefschrift leidden tot verschillende implicaties en suggesties voor toekomstige interventies, gebaseerd op determinanten van vergeetachtigheid en op bevindingen uit bestaande en nieuw ontwikkelde interventies. 


\section{Dankwoord}


Graag wil ik een aantal mensen bedanken voor hun bijdrage aan dit proefschrift. In de verschillende fasen van de totstandkoming van dit proefschrift, heb ik ieders hulp erg gewaardeerd!

Jelle Jolles, hartelijk dank voor je begeleiding en voor de mogelijkheid die je me gegeven hebt om me als wetenschapper te ontwikkelen.

Alle proefpersonen,

hartelijk dank voor jullie medewerking.

Aukje Aben, Martin van Boxtel, Margot Carpay, Jeanette Dijkstra, Renate de Groot, Esther Hoogenhout, Inez Ramakers, Nico Rozendaal, Rob Ruiter en Frans Verhey,

hartelijk dank voor jullie co-auteursschap en de inhoudelijke bijdrage aan de totstandkoming van de artikelen.

Floor van Bergen, Kees Commissaris, Dymphie Scholtissen, Kelly Schaekens, Desiree op het Veld, Marjolein de Vugt en Ruben Wensing,

hartelijk dank voor jullie inhoudelijke suggesties en jullie bijdrage aan het onderzoek en het proefschrift.

Ellen Dreezens, Ron Keulen, Bart Scholtissen, hartelijk dank voor jullie bijdrage aan de laatste fase van het proefschrift.

Netty Buijs, Marco van Hertrooy, Ankie Hochstenbach, Els Ketelslegers, Laurent Louwies, Ron Mengelers, Elsa Misdom, Desiree Morales, Astrid Quist, Renate Smeets,

hartelijk dank voor jullie altijd vriendelijke administratieve en praktische ondersteuning.

Dick Willems,

hartelijk dank voor je statistische adviezen, die je op elk moment bereid was te geven.

Karin Slegers, Sharon Bouwens, hartelijk dank voor jullie bereidheid om te overleggen en te brainstormen over mijn onderzoek en over allerlei andere zaken die besproken moesten worden. 
Lia Baars, Saartje Burgmans, Jeroen van Deursen, Pauline Dibbets, Koene van Dijk, Wim van der Elst, Lisbeth Evers, Ellen Gerrits, Pascal van Gerven, Susan van Hooren, Sebastiaan Köhler, Geert Leenders, Ellis Magnee, Natalie Marchetta, Celeste Meijs, Floortje Smeets, Leonore Stollwerk, Dori Touw, Susanne Valentijn, Renske Wassenberg, Karin Weirauch,

hartelijk dank voor de nodige afleiding en ontspanning tijdens het vervaardigen van mijn proefschrift en ook voor het geregeld meedenken met mijn onderzoek.

Luc en Angela Mol, Suzanne Mol en Laurens Schrijnemakers, de familie Verstraelen, de familie Bertram en alle andere vrienden en vriendinnen, hartelijk dank voor jullie enthousiaste interesse in mijn onderzoek.

Margot Krook en Willemien Meijer,

hartelijk dank voor jullie bereidheid om mijn paranimf te willen zijn, voor jullie onvermoeibare inzet om altijd even te helpen en te overleggen en voor jullie gezelligheid.

Renske Nelissen,

hartelijk dank voor je mailtjes en je vriendschap.

Emiel Verstraelen,

hartelijk dank voor je onvoorwaardelijk vertrouwen in mij, je suggesties waar nodig, maar vooral voor je eeuwig positieve instelling die de dag zoveel leuker maakt!

Hartelijk dank allemaal! 
Curriculum Vitae 
Martine Mol werd geboren op 9 maart 1978 te Tegelen. In 1996 behaalde zij haar VWO diploma aan het Collegium Marianum in Venlo. Hierna begon zij met de studie Gezondheidswetenschappen aan de Universiteit Maastricht, waar zij de afstudeerrichtingen Biologische Gezondheidskunde en Gezondheidsvoorlichting volgde. Voor de afstudeerrichting Biologische Gezondheidskunde deed zij onderzoeksstages aan de Gadjah Mada Universiteit van Yogjakarta, Indonesië en aan de Universiteit Maastricht bij de afdeling Humane Biologie. Voor de afstudeerrichting Gezondheidsvoorlichting schreef zij een literatuurscriptie bij de vakgroep Gezondheidsvoorlichting aan de Universiteit Maastricht. In 2002 behaalde zij haar diploma. Van 2002 tot en met 2006 werkte zij als Promovendus bij de vakgroep Psychiatrie en Neuropsychologie aan de Universiteit Maastricht. Het onderzoek dat zij hier deed staat beschreven in dit proefschrift. 